\title{
Modeling and control of a wind turbine as a distributed resource in an electric power system
}

\author{
Bongani Malinga \\ West Virginia University
}

Follow this and additional works at: https://researchrepository.wvu.edu/etd

\section{Recommended Citation}

Malinga, Bongani, "Modeling and control of a wind turbine as a distributed resource in an electric power system" (2001). Graduate Theses, Dissertations, and Problem Reports. 1201.

https://researchrepository.wvu.edu/etd/1201

This Thesis is protected by copyright and/or related rights. It has been brought to you by the The Research Repository @ WVU with permission from the rights-holder(s). You are free to use this Thesis in any way that is permitted by the copyright and related rights legislation that applies to your use. For other uses you must obtain permission from the rights-holder(s) directly, unless additional rights are indicated by a Creative Commons license in the record and/ or on the work itself. This Thesis has been accepted for inclusion in WVU Graduate Theses, Dissertations, and Problem Reports collection by an authorized administrator of The Research Repository @ WVU. For more information, please contact researchrepository@mail.wvu.edu. 


\title{
Modeling and Control of a Wind Turbine as a Distributed Resource in an Electric Power System
}

\author{
Bongani Malinga \\ Thesis submitted to the \\ College of Engineering and Mineral Resources \\ at West Virginia University \\ in partial fulfillment of the requirements \\ for the degree of \\ Masters of Science in Mechanical Engineering
}

Dr. Ali Feliachi, Ph.D.

Dr. John Loth, Ph.D.

Dr. Gary Morris, Ph.D.

Dr. John E. Sneckenberger, Ph.D.

Department of Mechanical and Aerospace Engineering

Morgantown, West Virginia

2001

Keywords: Wind Turbine, Modeling, Controls, Distributed Resources, Power 


\begin{abstract}
Modeling and Control of a Wind Turbine as a Distributed Resource in an Electric Power System
\end{abstract}

\title{
Bongani Malinga
}

Deregulation of electric utilities has led to consideration of new distributed resources (DRs) such as wind turbines. The DR dynamics have to be studied carefully to avoid unpredictable outputs and unknown interferences as well as to make sure that consistent and efficient power is supplied according to the load requirements.

The objective of this thesis is to make a contribution to the ongoing wind turbine research in the areas of modeling, control and implementation of wind turbines as DRs in deregulated electric power systems. A model of complete open-loop wind turbine system consisting of a rotor, a gearbox and a three-phase ac generator was developed, and it was used as a basis for the design of a controller for the wind turbine. The wind turbine (rotor and gearbox) transfer function was derived and its performance was studied using the MATLAB Program. The electric generator was modeled using the synchronous generator model in the MATLAB Power System Blockset.

This thesis provided a different approach to wind turbine modeling and control design methodology. All the results were in close agreement with results from other studies. The main strategy of the controller was to regulate the rotor angular speed and the power demand to match the required profiles. This thesis focused on controller design to maintain a constant shaft angular speed and constant power production for a variablepitch, constant-speed horizontal-axis wind turbine. A simple wind turbine model was 
linearized about an operating point and it was used to systematically perform trade-off studies between minimization parameters. The robust nature of the PID controller was illustrated and optimal operating conditions were determined.

Wind turbine economics was also studied in order to evaluate the economic feasibility of using wind turbines as DRs. Continued research illustrates that the optimum wind turbine has not yet been build and most of the remaining work lies in how the wind turbine is controlled. Additional design and control strategy improvements can be expected as experience is gained with wind turbine operations. 
Dedicated to my sister and dearest friend Siphiwe Malinga 


\section{ACKNOWLEDGMENTS}

I would first like to express my gratitude to my advisor and academic committee chairman, Dr. John Ed. Sneckenberger, for his support, guidance and encouragement throughout this research. I would also like to express my appreciation to my advisory committee Dr. Ali Feliachi, Dr. Gary Morris and Dr. John Loth, who was also my undergraduate advisor who introduced me to Aerospace Engineering.

I would especially like to thank my fiancée Noxxie for all the love and support she has given me. Her sacrifice and support have made it possible for me to concentrate on my work and to finally complete this thesis. No words can express my thanks to my parents. They taught me how important education is. They also taught me to be a man who never gives up. Their spiritual support and expectation are always my great propulsion to success. I give special regards to my family; MaDu, Mthoko, Du, Xolani, Nhlanhla, Buhle and Bambi for withstanding the rigors of my absence from home. Their constant support and encouragement helped make a tough endeavor easier.

I wish to thank my colleagues and friends, Sewelo 'S.K.' Keleagetse and Claudius Mundoma, with whom I had many enriching discussions and received a lot of support and encouragement. To my office mates; Padha, Asif and Ranjit, thank you for the support. Lastly, I would like to thank all the friends that I met in Morgantown during my studies at WVU; you are all a part of my achievements. To all those I did not mention, your contributions really made a difference. Thank you. 


\section{TABLE OF CONTENTS}

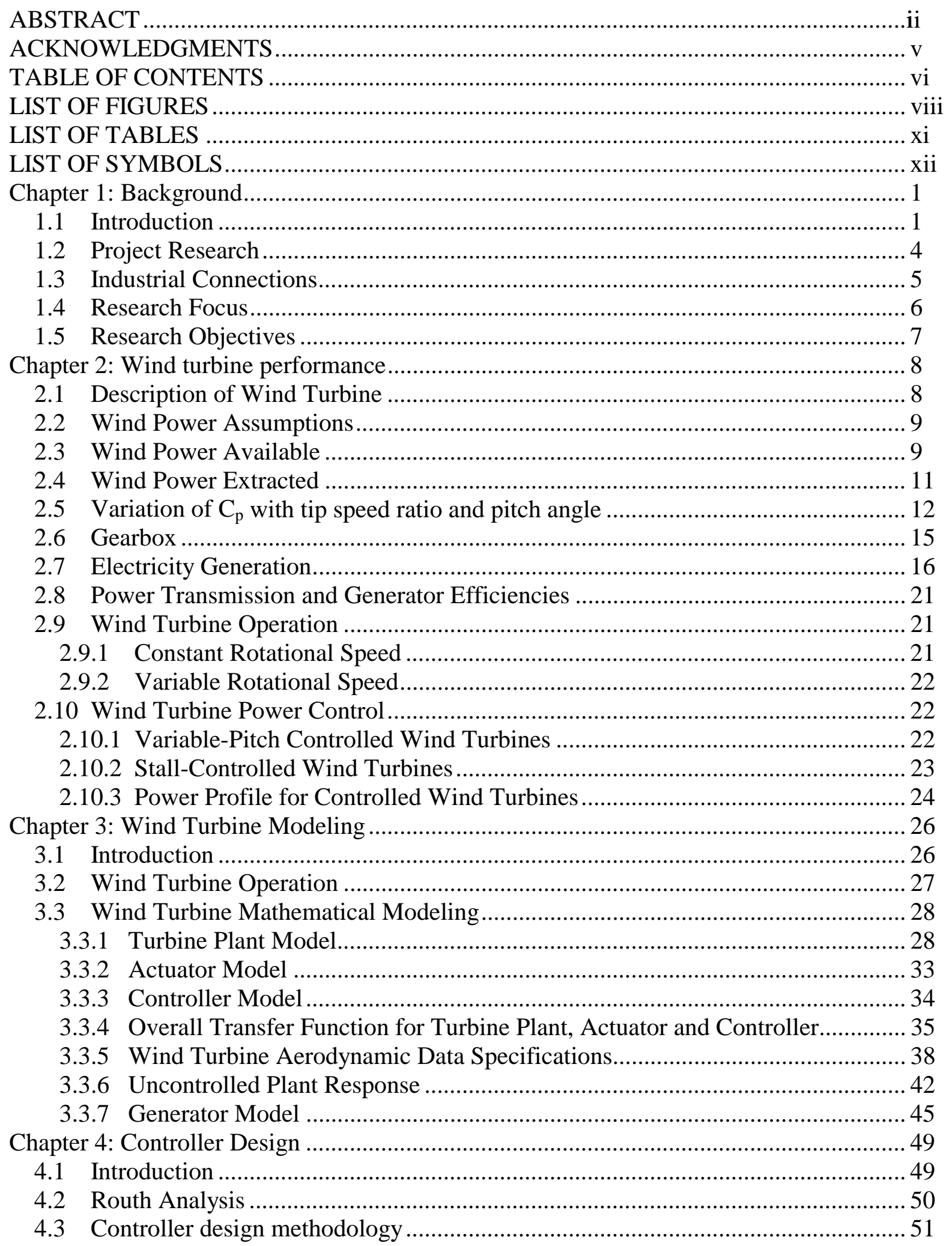




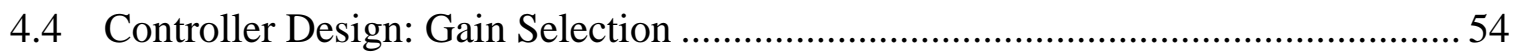

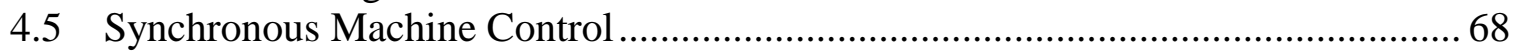

Chapter 5: Wind Turbine Economics........................................................................... 74

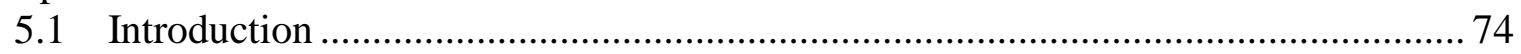

5.2 Wind Turbine System Hardware ..................................................................... 75

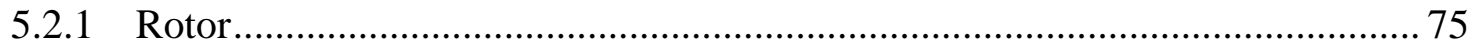

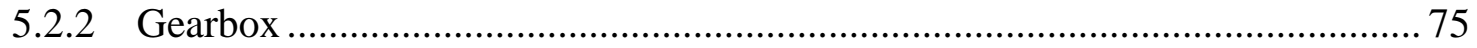

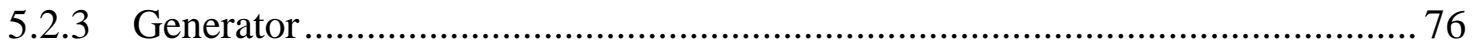

5.3 Wind Turbine Economic Performance.............................................................. 78

5.3.1 Installed Capital Cost ................................................................................ 78

5.3.2 Specific Capital Cost................................................................................... 79

5.3.3 Operating and Maintenance Costs............................................................... 79

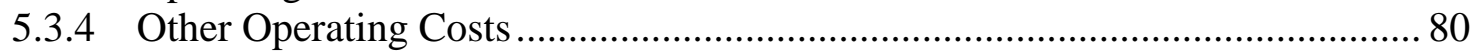

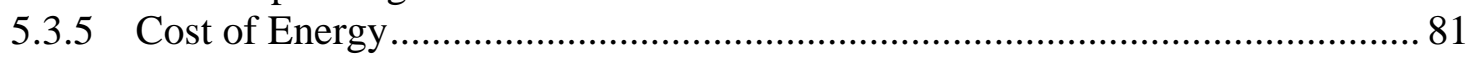

5.4 Economics of Grid Connected Wind Turbines ................................................... 81

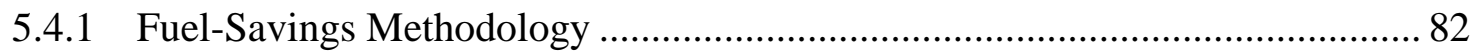

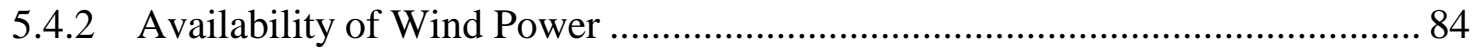

5.4.3 Reliability and Dispatchability of Wind Power................................................ 84

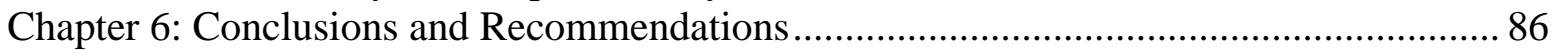

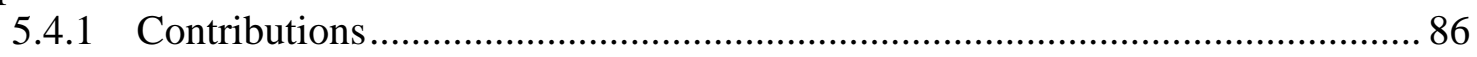

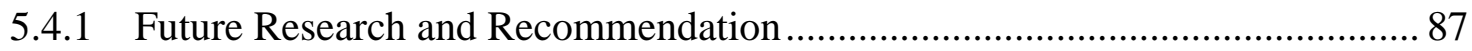

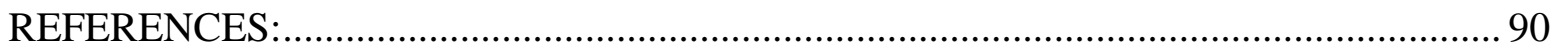

APPENDIX A: Wind Turbine Aerodynamics and Parameters ............................................ 93

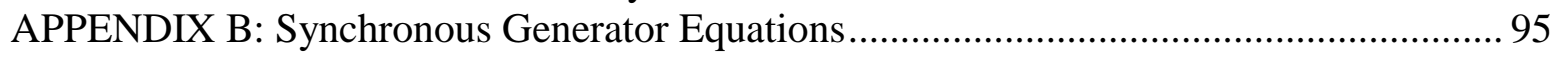

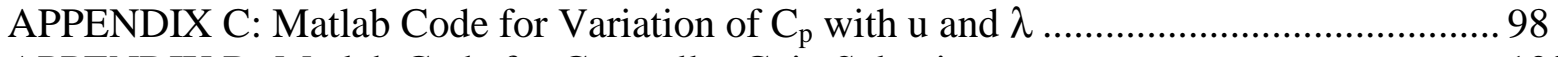

APPENDIX D: Matlab Code for Controller Gain Selection................................................. 100

APPENDIX E: Matlab Code for Wind Turbine Response Simulation................................... 102

APPENDIX F: Simulink Block Diagram for Wind Turbine Simulation................................ 105

APPENDIX G: Simulink Block Diagram for Electric Generator Simulation ....................... 106 


\section{LIST OF FIGURES}

Figure 2.1 Wind Turbine Plant .......................................................................... 8

Figure 2.2 Circular Tube of Air Flowing Through a Wind Turbine .................................. 10

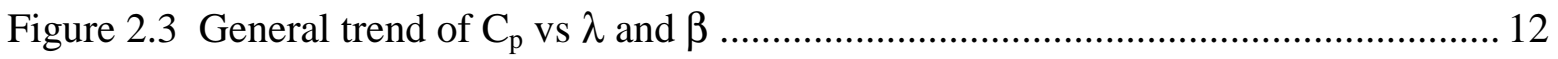

Figure 2.4 Typical generator and its dc exciter with brush and slip ring ........................... 17

Figure 2.5 Typical generator and its brushless de exciter ............................................... 17

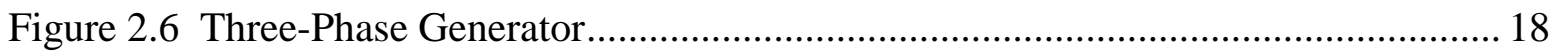

Figure 2.7 Voltages and Impedances in a three-phase generator and its connected load..... 19

Figure 2.8 Equivalent circuit of a three-phase generator showing only one phase .............. 19

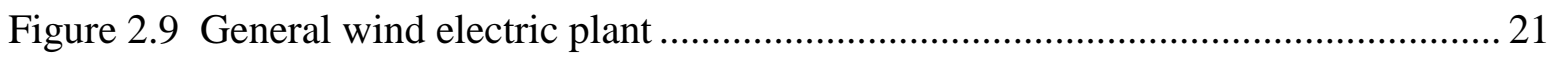

Figure 2.10 Basic block diagram for pitch-controlled wind turbines.................................. 23

Figure 2.11 Basic block diagram for stall-controlled wind turbines .................................... 24

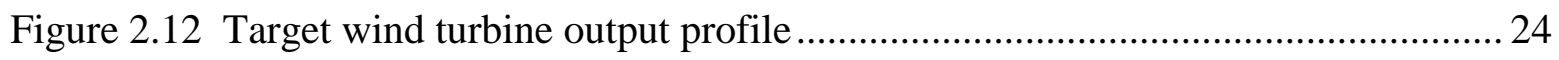

Figure 2.13 Basic block diagram with control strategies ..............................................2 25

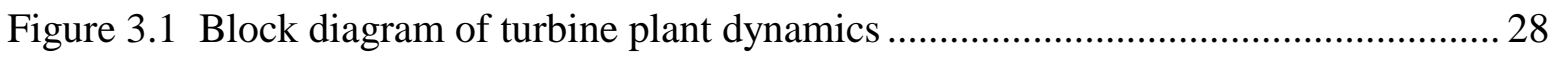

Figure 3.2 Block diagram of the linear turbine plant model ………................................... 31

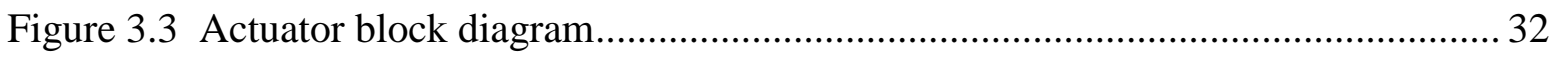

Figure 3.4 Block diagram of Proportional-Integral-Derivative (PID) controller .................. 34

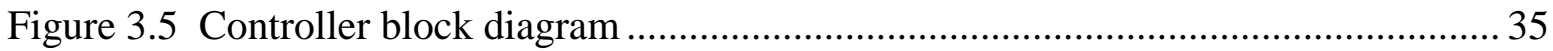

Figure 3.6a Block Diagram for the Turbine Plant with Actuator and Controller.................. 35

Figure 3.6b Wind turbine plant block diagram with power output shown........................... 36

Figure 3.6c Power output loop for wind turbine plant .......................................................... 36 
Figure 3.7 $\mathrm{Cp}$ vs $\mathrm{u}$ at fixed pitch angle $\beta$ of $9^{\circ}$ for the Grumman Windstream-33 ............ 39

Figure $3.8 \mathrm{Cp}$ vs $\lambda$ at fixed pitch angle $\beta$ of $9^{\circ}$ for the Grumman Windstream-33 ............ 40

Figure $3.9 \mathrm{P}_{\mathrm{m}}$ vs $\mathrm{u}$ at pitch angle $\beta$ of $9^{\circ}$ for the Grumman Windstream-33 wind turbine .. 40

Figure $3.10 \mathrm{Cp}$ vs $\beta$ at fixed tip speed ratio $\lambda$ of 7 for Grumman Windstream-33 ............ 41

Figure 3.11a Change in angular speed for a unit step in wind speed input ....................... 44

Figure 3.11b Change in angular speed for a unit step in pitch angle input ....................... 44

Figure 3.12 Block diagram of electric generator ................................................. 45

Figure 3.13 Block Diagram of the Synchronous generator ......................................... 47

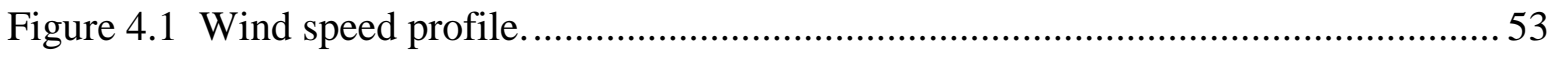

Figure 4.2a Graph of $\mathrm{k}_{\mathrm{D}}, \mathrm{k}_{\mathrm{P}}$ versus RMS of angular speed error for $\mathrm{k}_{\mathrm{I}}=1 \ldots \ldots \ldots \ldots \ldots \ldots \ldots . .55$

Figure 4.2b Graph of $\mathrm{k}_{\mathrm{D}}$, $\mathrm{k}_{\mathrm{P}}$ versus RMS of angular speed error for $\mathrm{k}_{\mathrm{I}}=1 \ldots \ldots \ldots \ldots \ldots \ldots \ldots . . .56$

Figure 4.3a Graph of $k_{D}, k_{P}$ versus RMS of angular speed error for $k_{I}=5 \ldots \ldots \ldots \ldots \ldots \ldots \ldots . .56$

Figure 4.3b Graph of $\mathrm{k}_{\mathrm{D}}$, $\mathrm{k}_{\mathrm{P}}$ versus RMS of angular speed error for $\mathrm{k}_{\mathrm{I}}=5 \ldots \ldots \ldots \ldots \ldots \ldots \ldots .57$

Figure 4.4a Graph of $k_{D}$, $k_{P}$ versus RMS of angular speed error for $k_{I}=10 \ldots \ldots \ldots \ldots \ldots \ldots . .57$

Figure $4.4 b$ Graph of $k_{D}$, $k_{P}$ versus RMS of angular speed error for $\mathrm{k}_{\mathrm{I}}=10 \ldots \ldots \ldots \ldots \ldots \ldots . .58$

Figure 4.5a Graph of $\mathrm{k}_{\mathrm{D}}, \mathrm{k}_{\mathrm{P}}$ versus RMS of angular speed error for $\mathrm{k}_{\mathrm{I}}=12 \ldots \ldots \ldots \ldots \ldots \ldots \ldots . .58$

Figure 4.5b Graph of $k_{D}$, $k_{P}$ versus RMS of angular speed error for $k_{I}=12 \ldots \ldots \ldots \ldots \ldots \ldots .59$

Figure 4.6a Angular speed for three gain combinations............................................. 61

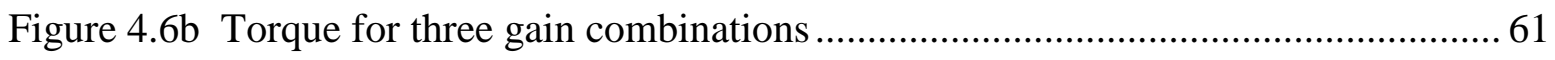

Figure 4.6c Mechanical Power for three gain combinations .......................................... 62

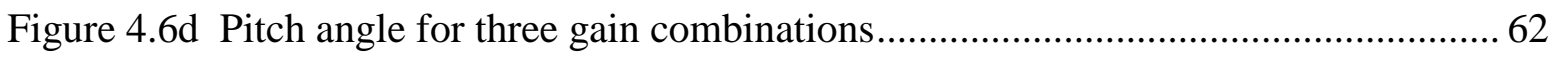

Figure 4.7a Angular speed response to unit step in wind speed for controlled turbine ...... 64

Figure 4.7b Torque response to unit step in wind speed for controlled turbine................. 65 
Figure 4.7c Mechanical power response to unit step in wind speed for controlled turbine. 65

Figure 4.7d Pitch Angle response to unit step in wind speed for controlled turbine 66

Figure 4.8 Angular speed profile for varying reference angular speed ........................... 67

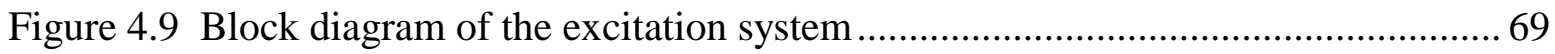

Figure 4.10 Wind Turbine Mechanical Power versus time............................................ 70

Figure 4.11 Electric Power versus Time …........................................................... 71

Figure 4.12 Excitation voltage versus time ........................................................ 71

Figure 4.13 RMS of the output voltage versus time.............................................. 72

Figure F.1 Simulink Block Diagram for Wind Turbine Simulation ............................... 104

Figure G.1 Simulink Block Diagram for Electric Generator Simulation .......................... 105 


\section{LIST OF TABLES}

Table 3.1 Grumman Windstream-33 parameters .................................................... 28

Table 3.2 Aerodynamic parameters for the Grumman Windstream-33 wind turbine......... 38

Table 3.3 Wind turbine linearization constants......................................................... 42

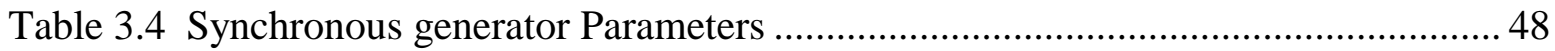

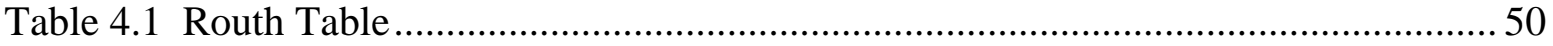

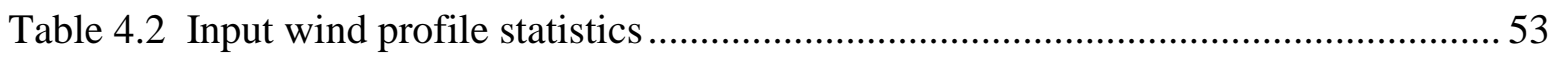

Table 5.1 Eight systems of generating synchronous electrical power............................ 76 


\section{LIST OF SYMBOLS}

\begin{tabular}{|c|c|}
\hline A & Rotor Swept Area \\
\hline $\mathrm{C}_{\mathrm{q}}$ & Torque Coefficient \\
\hline $\mathrm{C}_{\mathrm{p}}$ & Power Coefficient \\
\hline $\mathrm{C}_{\mathrm{pm}}$ & Maximum $\mathrm{C}_{\mathrm{p}}$ \\
\hline $\mathrm{C}_{\mathrm{pR}}$ & Rated $\mathrm{C}_{\mathrm{p}}$ \\
\hline DR & Distributed Resource \\
\hline $\mathrm{f}$ & Frequency \\
\hline $\mathrm{F}$ & Wind Turbine Performance Constant \\
\hline G & Wind Turbine Performance Constant \\
\hline I & Current \\
\hline $\left.\mathbf{J}_{(}\right)$ & Mass Moment of Inertia of Defined Component \\
\hline $\mathrm{L}$ & Inductance \\
\hline $\mathrm{N}$ & Gear Ratio \\
\hline $\mathrm{p}$ & Number of Magnetic Poles \\
\hline $\mathrm{P}$ & Power \\
\hline$P_{()}$ & Power at defined point \\
\hline $\mathrm{R}$ & Resistance \\
\hline $\mathrm{R}$ & Rotor Tip Radius \\
\hline $\mathrm{T}$ & Torque \\
\hline $\mathrm{u}$ & Wind Speed \\
\hline $\mathrm{u}_{()}$ & Wind speed at Defined point \\
\hline
\end{tabular}


V

$\begin{array}{ll}\alpha_{()} & \text {Aerodynamic Constant at Operating Conditions } \\ \beta & \text { Pitch Angle } \\ \delta_{()} & \text {Aerodynamic Constant at Operating Conditions } \\ \Delta & \text { Change } \\ \gamma_{()} & \text {Aerodynamic Constant at Operating Conditions } \\ \lambda & \text { Rotor Tip Speed to Wind Speed Ratio } \\ \eta_{()} & \text {Efficiency of component in subscript } \\ \rho & \text { Density of Air } \\ \lambda_{\mathrm{m}} & \text { Rotor Tip Speed to Wind Speed Ratio at } \mathrm{C}_{\mathrm{pm}} \\ \eta_{()} & \text {Efficiency of Specified Component } \\ \phi & \text { Ragnetic Flux } \\ \omega_{(} & \text {Rotor Angular Speed Angular Speed at Defined Point } \\ & \text { Rotor }\end{array}$

Voltage

\section{Greek Symbols}

\section{Subscripts}

c

emf

F

G

m

Cut-in

Electromotive Force

Furling

Generator

Maximum 


$\begin{array}{ll}\mathrm{m} & \text { Mechanical } \\ \mathrm{p} & \text { Performance } \\ \mathrm{q} & \text { Torque } \\ \mathrm{R} & \text { Rated } \\ \mathrm{T} & \text { Transmission } \\ \text { out } & \text { Output } \\ \mathrm{OP} & \text { Operating Point } \\ \mathrm{W} & \text { Wind } \\ \mathrm{d}, \mathrm{q} & \mathrm{d} \text { and q axis quantity } \\ \mathrm{R}, \mathrm{s} & \text { Rotor and stator quantity } \\ \mathrm{l}, \mathrm{m} & \text { Leakage and mutual inductance } \\ \mathrm{f}, \mathrm{k} & \text { Field and damper winding quantity }\end{array}$




\section{Chapter 1: Background}

\subsection{Introduction}

The main sources of electrical power have been fuel-burning power generators which use the energy from non-renewable fuels to rotate a shaft connected to an electric generator [5]. These systems have seen vast improvements in the areas of efficiency, emissions and controllability because they have always been the primary power sources. Also, electricity has always been supplied by the big utility companies who have monopolized the electric industry. This has led to price increases in electricity and with the increasing market, poorer quality and service [8]. In response, smaller utility companies have invested in research in alternative energy sources, which they will use to generate electricity possibly at a lower price. The deregulation of electricity in the US has seen rise in research geared towards alternative energy sources. Some of the major sources being investigated include fuel cells, micro-turbines and wind turbines. Wind turbines will be the main focus of this thesis.

Wind energy conversion is the fastest-growing source of new electric generation in the world and it is expected to remain so for some time [21]. Its long lifespan, emission-free operation and low cost have made it more attractive compared to the other sources. It is also attractive for its job creation and the ease with which its technology can be transferred to developing countries. Wind turbines complement the use of other electric power sources by providing a least cost approach under certain conditions. In many situations, the lowest cost system will be a hybrid system that has wind energy as one of its power resources. This expands the scope of potential electric generation 
projects pointing to the day when decentralized electric generation projects will be implemented on the same scale as current, centralized electric generation projects.

Although wind turbines have been used for several centuries, Denmark was the first country to use wind as a means of generating electricity [5]. By 1910, Denmark had several hundred wind turbines in operation. Large scale, commercial wind turbines appeared in the world electric market about 1925. These generated cheap alternative electricity, their primary uses were to recharge batteries and to pump water on farms. However, the low cost and reliability of the electricity produced by the utility industry led to the decline in the demand for wind turbines. In the early 1970's the cost of utilitygenerated electricity started to rise and consumers started complaining; this brought the need to reconsider wind turbines. In addition to home wind turbines, the utility companies started building large wind turbines to generate cheaper power and to offset emissions from coal plants. Palmer C. Putnam initiated the concept of using large wind turbines to supply a large amount of power. The S. Morgan Smith Company of York, PA agreed to fund his work and the Smith-Putnam wind turbine experiment was born. Over the years more research was geared towards designing bigger and better wind turbines. The Federal Wind Energy Program (FWEP) had its beginning in 1972 when the National Science Foundation (NSF) and the National Aeronautics and Space Administration recommended that wind energy be developed to broaden the nation's energy supply options. A few years later, the responsibility for wind turbine development was handed over to the Energy Research and Development Administration (ERDA), which later became part of the Department of Energy (DOE). Over the years, several hundred types 
of wind turbines have been invented and the research continues to find more efficient and more reliable wind turbines.

The most special feature about wind turbines is the fact that, unlike other generation systems, the power inflow rate is not controllable. In most power generation systems, the fuel flow rate, or the amount of energy, applied to the generator controls the output voltage and frequency. However, wind speed varies with time and so does the power demand. Therefore, other generation systems can be referred to as controlled energy sources, whereas the wind is an uncontrolled energy resource and the power demand is an uncontrolled energy sink. On occasion, the wind speed can be very high resulting in power generation that exceeds the demand of the load. This might lead to the turbine exceeding its rotational speed rating and subsequent damage to the turbine. On the other hand, the wind speed can be too low for any power production and therefore alternative energy sources should be used. The fact that one has no control over the energy source input, the unpredictability of wind and the varying power demand are more than enough concerns to justify the need for a controller, which will regulate all the parameters that need to be controlled for a matched operation of the wind turbine. Most of the major energy sources have been in place for a long time and the economics of changing the way these energy sources operate far outweigh the need to reinvent them. The best compromise is to add controllers to improve the existing energy sources. In the electric industry, wind turbines are mostly add-on energy sources to supplement the amount of power. Therefore there is a need for wind turbines to be designed and controlled such that their output interfaces with the already existing electrical power grids. 


\subsection{Project Research}

This thesis was a part of a research project to study the dynamics and control of distributed resources (DRs) in the deregulated electric power industry. The project titled "Integrated Computing, Communication and Distributed Control of Deregulated Electric Power Systems" is sponsored by the USDOE EPSCoR and conducted by West Virginia University and West Virginia University Institute of Technology. This project is divided into three smaller projects. Project I deals with economics of the energy market, management and balancing. Project II deals with real time operation of power system and addresses the dynamics of the power system following considerable structural changes. The objective is to investigate the effects of deregulation on control strategies and to design and coordinate intelligent distributed controllers to effectively operate the power system. This thesis was a part of Project III, which focuses on determining the effects of DRs on power quality, developing tools that can be used for the analysis of the dynamics of the power distribution, investigating the effects of DRs on transmission system dynamics, determining a critical level of DR penetration and developing control design algorithms suitable for power distribution systems. Wind turbines were chosen as a DR of study because of the fact that they are fueled by a renewable, inexhaustible and natural resource. This thesis is also being pursued as part of the Projects with Industry program in the Mechanical and Aerospace Engineering Department at West Virginia University.

Recently, a lot of research has been done on different types of wind turbine control strategies that can be used $[1,3,4,14,16,21]$. These strategies include variablepitch, stall-regulated controllers [1] whose main control strategy is to control the output by varying the pitch angle of the rotor blade. Other researchers have considered rotational 
speed controllers [2], which have a brake system to regulate the turbine speed. Extensive research is being done also to model hybrid power systems where the wind turbine can either be the primary resource or a DR [3]. This continued research illustrates the fact that the optimum wind turbine has not yet been build and that most of the needed enhancement lies in way the wind turbine is controlled. Additional design and control strategy improvements can be expected as more experience is gained with wind turbines.

\subsection{Industrial Connections}

The dependence on a continuous supply of electric power in industrial, commercial, and personal applications requires the ability to maintain electric power service in the event of a failure on the utility grid. In order to avoid blackouts due to technical errors, all the electric grid components and their dynamic interactions have to be fully understood. In the case of distributed power systems that involve wind turbines, mathematical models, dynamic behavior and control requirements for them have to be developed and the effects of wind turbines on the grid to which they are connected have to be studied to avoid their causing grid instabilities, which subsequently might lead to blackouts.

All these industrial concerns need to be appreciated and researched. Also, there is a research need to derive mathematical models and to design system controllers. This research will help improve the understanding of wind turbines, their applicability and limitations, which will subsequently increase the reliability of electric grids in which wind turbines are connected. 


\subsection{Research Focus}

The main focus of this thesis is the modeling and control of a wind turbine. The goal of this thesis is to have a significant contribution on the ongoing wind turbine research in the areas of modeling and control. A complete model will be developed and it will be used as a basis for the design of a controller. The main strategy of the controller will be to fulfill the desired power profile, regulate the wind turbine power production in case of high winds and also maximize the power production in times of slow wind. Also, the control strategy will be designed to recognize the fact that the wind turbine will be connected to an electric grid as a distributed resource. With the successful completion of this thesis, the results will provide an understanding of wind turbine modeling, control and the connectivity to with electric grids as DRs. In addition to the modeling and control analysis, the wind turbine economics will be studied in order to evaluate the economic feasibility of the energy from the wind.

Control systems are generally reduced to two components, the plant and the controller. The plant is the process being controlled, and the controller uses the output from the plant to adjust its input to the plant to achieve the desired plant action. Control design revolves around an appropriate model of the plant. Wind turbine design has been aided with the recent development of sophisticated design codes [20,22,26] that accommodate numerous degrees of freedom. However, control design does not require complex models of each component [4]. For the mathematical model and dynamic analysis, the rotor dynamics of the wind turbine were modeled using the Matlab software and the generator was modeled using the Power System Blockset in Simulink [33]. 


\subsection{Research Objectives}

The following list describes the overall objectives of this research:

1. Develop a wind turbine mathematical model.

2. Design a controller for constant frequency and to maintain a constant turbine output.

3. Assess the output variables or deviations and keep them within acceptable ranges and comparable to other grid connected distributed resources.

4. Show Applicability of Wind Turbines as DRs in Electric Grids.

5. Evaluate the economical feasibility of wind turbine integration in the electric grid 


\section{Chapter 2: Wind turbine performance}

\subsection{Description of Wind Turbine}

Figure 2.1 shows the general wind turbine plant under consideration. The wind turbine rotor is connected to a constant-speed generator. The generator output can be controlled to follow the commanded voltage. The wind turbine has pitchable blades to control the aerodynamic power extracted from the wind. Also shown is a mechanical component (gearbox) between the low-speed rotor shaft and the high-speed generator shaft. The low-speed shaft is driven by the turbine blades, which generates aerodynamic power. The high-speed shaft is loaded by the electric generator in the form of an electrical load. As the wind speed fluctuates, the wind turbine is controlled by changing the pitch angle to avoid the rotor speed following the variation of the wind speed.

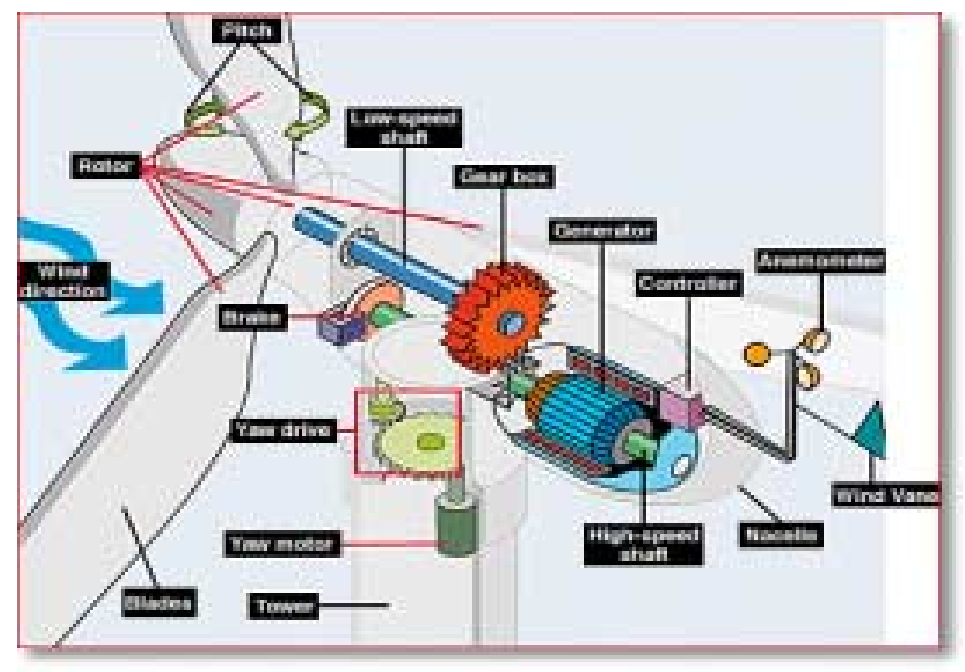

Figure 2.1: Wind Turbine Plant Courtesy of American Wind Energy Association 
The wind turbine changes wind energy to rotational energy through the use of airfoils. This rotational energy is then converted using an electrical generator into electrical energy, which is usually supplied to the utility grid at the distribution level.

\subsection{Wind Power Assumptions}

The Rankine-Froude Actuator disc theory was used to define the wind profile over the rotor swept area for the analysis of wind turbine performance. The following assumptions apply:

1. Steady homogenous wind

2. No obstructions to wind flow either upstream or downstream of the rotor

3. Uniform flow speed at the disc

4. Wind flow passing through the disc is separable from the remaining flow by a well-defined stream tube.

5. Wind is incompressible

6. Wind flow passing through the disk is irrotational.

\subsection{Wind Power Available}

The kinetic energy, $U$ of a packet of wind of mass $m$ flowing at upstream speed $u$ in the axial direction ( $\mathrm{x}$ - direction) of the wind turbine is given by Equation 2.1, where A is the cross-sectional (swept) area of the wind turbine, $\rho$ is the air density and $\mathrm{x}$ is the thickness of the wind packet.

$\mathrm{U}=\frac{1}{2} m u^{2}=\frac{1}{2}(\rho A x) u^{2}$ 
The power, $\mathrm{P}_{\mathrm{w}}$ in the wind is the time derivative of the kinetic energy and is given by Equation 2.2, which represents the total power available for extraction.

$$
\mathrm{P}_{\mathrm{w}}=\frac{\mathrm{dU}}{\mathrm{dt}}=\frac{1}{2} \rho \mathrm{Au}^{2} \frac{\mathrm{dx}}{\mathrm{dt}}=\frac{1}{2} \rho A u^{3}
$$

It can be shown [5] that under optimum conditions, a tube of air approaching a wind turbine follows the profiles shown in Figure 2.2.

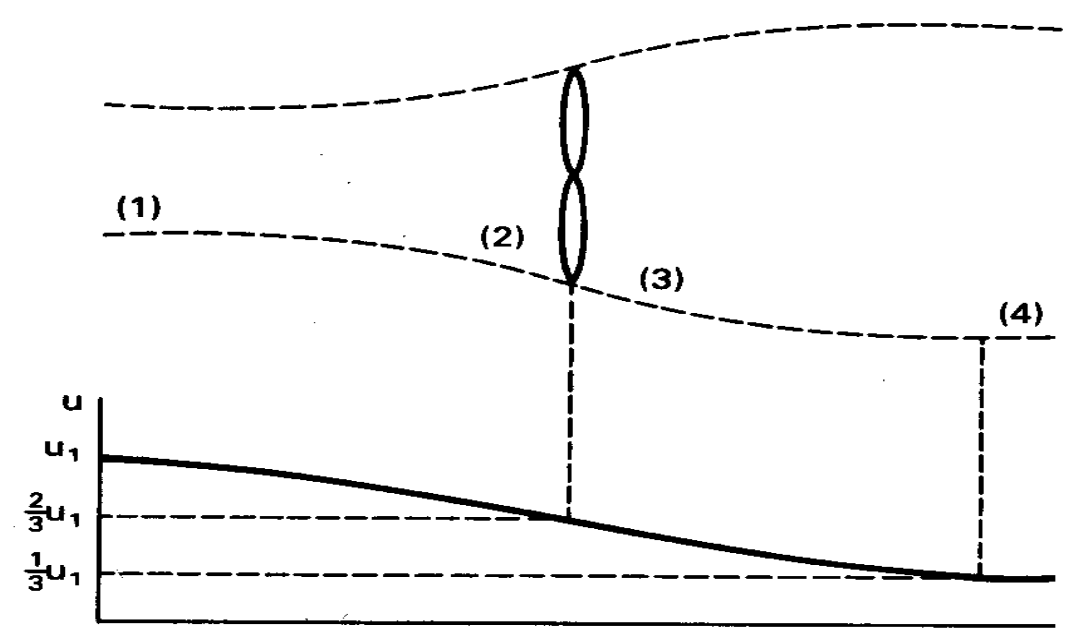

Figure 2.2: Circular Tube of Air Flowing Through a Wind Turbine

The relations for the wind velocities and the cross-sectional areas in the following equation apply.

$\mathrm{u}_{2}=\mathrm{u}_{3}=\frac{2}{3} \mathrm{u}_{1}$

$\mathrm{u}_{4}=\frac{1}{3} \mathrm{u}_{1}$

$\mathrm{A}_{2}=\mathrm{A}_{3}=\frac{3}{2} \mathrm{~A}_{1}$

$\mathrm{A}_{4}=3 \mathrm{~A}_{1}$

As the wind passes over the turbine, the wind will lose power equal to the power extracted by the turbine, as given in Equation 2.4. 


$$
\mathrm{P}_{\mathrm{m}, \text { ideal }}=\mathrm{P}_{1}-\mathrm{P}_{4}=\frac{1}{2} \rho\left(\mathrm{A}_{1} \mathrm{u}_{1}{ }^{3}-\mathrm{A}_{4} \mathrm{u}_{4}{ }^{3}\right)=\frac{1}{2} \rho\left(\frac{8}{9} \mathrm{~A}_{1} \mathrm{u}_{1}{ }^{3}\right)
$$

This shows that for a given upstream tube-area $A_{1}$, an ideal turbine will extract $8 / 9$ of the total power available in the wind. Since the upstream cross-sectional area is not physically measurable, in contrast the cross-sectional area of the wind turbine, the extracted power is usually conveniently expressed in terms of the wind turbine swept area $\mathrm{A}_{2}$, which will be referred to as A. Using Equation 2.3, Equation 2.5 can be obtained and shows that a turbine cannot extract more than $59 \%$ of the total power in an undisturbed tube of air with the cross-sectional area equal to the wind turbine swept area. This is known as Bertz theorem and it limits all wind turbines to an efficiency of not more than $59 \%$.

$$
\mathrm{P}_{\mathrm{m}, \text { ideal }}=\frac{1}{2} \rho\left[\frac{8}{9}\left(\frac{2}{3} \mathrm{~A}_{2}\right) \mathrm{u}_{1}{ }^{3}\right]=\frac{1}{2} \rho\left(\frac{16}{27} \mathrm{~A}_{2} \mathrm{u}_{1}^{3}\right)=\frac{16}{27}\left(\frac{1}{2} \rho \mathrm{A}_{2} \mathrm{u}_{1}{ }^{3}\right)=0.59 \mathrm{P}_{\mathrm{w}}
$$

\subsection{Wind Power Extracted}

The fraction of power $\mathrm{P}_{\mathrm{m}}$ extracted from the available power in the wind $\mathrm{P}_{\mathrm{w}}$ by practical turbines is expressed by the coefficient of performance, $\mathrm{C}_{\mathrm{p}}$. The power extracted $\mathrm{P}_{\mathrm{m}}$ can then be expressed as shown in Equation 2.6.

$$
\mathrm{P}_{\mathrm{m}}=\mathrm{C}_{\mathrm{p}} \mathrm{P}_{\mathrm{w}}=\mathrm{C}_{\mathrm{p}}\left(\frac{1}{2} \rho A \mathrm{u}^{3}\right)
$$

The value of $C_{p}$ varies with the wind speed, the rotational speed of the turbine, the rotor pitch angle, and the turbine blade parameters. It cannot exceed 0.59 , as seen from Equation 2.5. The tip speed ratio, $\lambda$, is a variable that combines the effects of the 
rotational speed and the wind speed. It is defined as the ratio between the rectilinear speed of the turbine tip, $\omega \mathrm{R}$, and the wind speed $\mathrm{u}$ as shown in Equation 2.7.

$\lambda=\frac{\omega \mathrm{R}}{\mathrm{u}}$

The parameter $\mathrm{R}$ is the maximum radius of the wind turbine swept area.

\subsection{Variation of $C_{p}$ with tip speed ratio and pitch angle}

Figure 2.3 illustrates the relationship between the coefficient of performance, $C_{p}$, and the tip speed ratio, $\lambda$, for various blade pitch angles $\beta$ for a typical wind turbine.

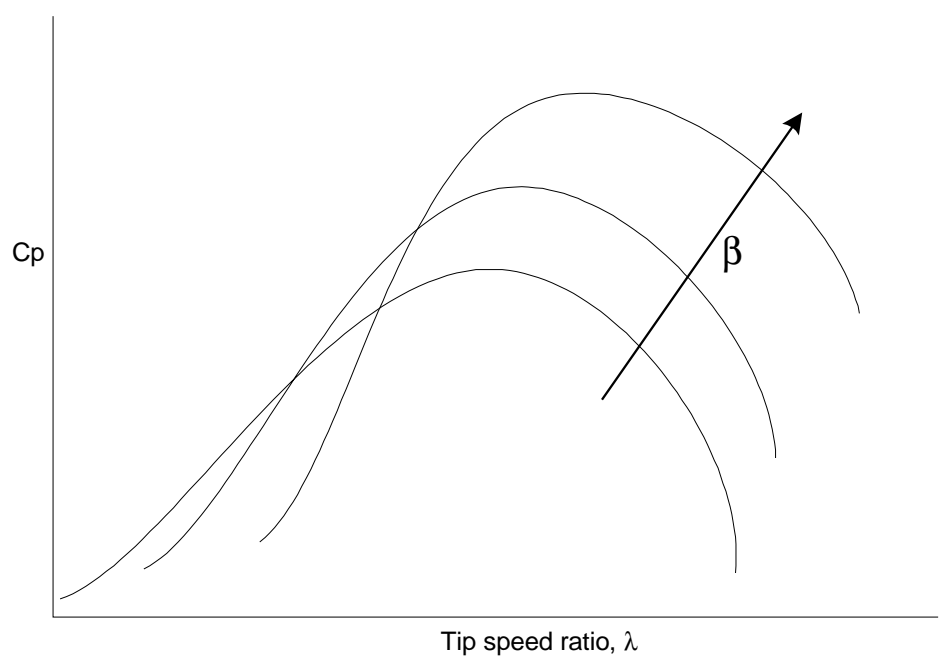

Figure 2.3: General trend of $C_{p}$ vs $\lambda$ and $\beta$

If the power performance of a wind turbine rotor is to be evaluated, its $C_{p}(\lambda, \beta)$ curve might be obtained from the wind turbine manufacturer and a look-up table can be created to evaluate the coefficient of performance for each tip speed ratio and blade pitch angle. If the rotational speed, $\omega$, and pitch angle, $\beta$, are known, $\left(\omega=\omega_{\mathrm{o}}\right.$ and $\beta=\beta_{\mathrm{o}}$ for a 
constant rpm fixed pitch rotor), then the mechanical power output, $\mathrm{P}_{\mathrm{m}}$, at any upstream wind speed, $u$, can be found using Equation 2.6.

Sometimes the full $\mathrm{C}_{\mathrm{p}}(\lambda, \beta)$ data are not available so that Equation 2.6 cannot be used directly in power performance evaluations. According to Justus [30], for any operation pitch angle, a good approximation to $\mathrm{C}_{\mathrm{p}}$ as a function of the speed is found by using Equation 2.8.

$$
\begin{array}{ll}
\mathrm{C}_{\mathrm{p}}=\mathrm{C}_{\mathrm{pm}}\left[1-\mathrm{F}\left(\frac{\mathrm{u}_{\mathrm{m}}}{\mathrm{u}}-1\right)^{2}-\mathrm{G}\left(\frac{\mathrm{u}_{\mathrm{m}}}{\mathrm{u}}-1\right)^{3}\right] & \mathrm{u}_{\mathrm{c}} \leq \mathrm{u} \leq \mathrm{u}_{\mathrm{R}} \\
\mathrm{C}_{\mathrm{p}}=\mathrm{C}_{\mathrm{pR}}\left[\frac{\mathrm{u}_{\mathrm{R}}^{3}}{\mathrm{u}^{3}}\right] & \mathrm{u}_{\mathrm{R}} \leq \mathrm{u} \leq \mathrm{u}_{\mathrm{F}}
\end{array}
$$

The coefficients $\mathrm{F}$ and $\mathrm{G}$ can be found using boundary conditions given by Equations 2.9 and 2.10, which are derived from the fact that the coefficient of performance $\mathrm{C}_{\mathrm{p}}$ is zero at the cut-in speed, and is $\mathrm{C}_{\mathrm{pR}}$ at the rated speed.

$$
\begin{aligned}
& \mathrm{C}_{\mathrm{p}}\left(\mathrm{u}_{\mathrm{c}}\right)=0=\mathrm{C}_{\mathrm{pm}}\left[1-\mathrm{F}\left(\frac{\mathrm{u}_{\mathrm{m}}}{\mathrm{u}_{\mathrm{c}}}-1\right)^{2}-\mathrm{G}\left(\frac{\mathrm{u}_{\mathrm{m}}}{\mathrm{u}_{\mathrm{c}}}-1\right)^{3}\right] \\
& \mathrm{C}_{\mathrm{p}}\left(\mathrm{u}_{\mathrm{R}}\right)=\mathrm{C}_{\mathrm{pR}}=\mathrm{C}_{\mathrm{pm}}\left[1-\mathrm{F}\left(\frac{\mathrm{u}_{\mathrm{m}}}{\mathrm{u}_{\mathrm{R}}}-1\right)^{2}-\mathrm{G}\left(\frac{\mathrm{u}_{\mathrm{m}}}{\mathrm{u}_{\mathrm{R}}}-1\right)^{3}\right]
\end{aligned}
$$

Combining these equations gives the solutions for $\mathrm{F}$ and $\mathrm{G}$ in matrix form, as given by Equation 2.11.

$$
\left[\begin{array}{l}
F \\
G
\end{array}\right]=\left[\begin{array}{cc}
\left(\left(u_{m} / u_{c}\right)-1\right)^{2} & \left(\left(u_{m} / u_{c}\right)-1\right)^{3} \\
\left(\left(u_{m} / u_{R}\right)-1\right)^{2} & \left(\left(u_{m} / u_{R}\right)-1\right)^{3}
\end{array}\right]\left\{\begin{array}{c}
1 \\
1-C_{p R}
\end{array}\right\}
$$

If the $\mathrm{C}_{\mathrm{p}}$ given in Equation 2.8 is substituted into Equation 2.6, the variation of mechanical power, $\mathrm{P}_{\mathrm{m}}$, as a function of wind speed, $\mathrm{u}$, can be evaluated as shown in Equation 2.12. Equation 2.12a relates the input (wind speed, u) and the output 
(mechanical power, $\mathrm{P}_{\mathrm{m}}$ ) for the wind turbine rotor for $\mathrm{u}_{\mathrm{c}} \leq \mathrm{u} \leq \mathrm{u}_{\mathrm{R}}$. Equation $2.12 \mathrm{~b}$ is valid for $\mathrm{u}_{\mathrm{R}} \leq \mathrm{u} \leq \mathrm{u}_{\mathrm{F}}$.

$$
\begin{aligned}
& P_{m}=P_{R}\left[\frac{C_{p m}}{C_{p R} u_{R}^{3}}\right]\left[(1-(F+G)) u^{3}+(2 F-3 G) u_{m} u^{2}+(3 G-F) u_{m}^{2} u-G_{m}^{3}\right] \\
& P_{m}=P_{R}
\end{aligned}
$$

For each pitch angle, this approximation method requires knowledge of the cut-in speed, $\mathrm{u}_{\mathrm{c}}$, which is a function of the rotational moment of inertia of the rotor and the shaft, the maximum coefficient of performance, $\mathrm{C}_{\mathrm{pm}}$, the rated coefficient of performance, $\mathrm{C}_{\mathrm{pR}}$, the rated wind speed, $\mathrm{u}_{\mathrm{R}}$, the wind speed at which $\mathrm{C}_{\mathrm{pm}}$ occurs, $\mathrm{u}_{\mathrm{m}}$, and the rated power $\mathrm{P}_{\mathrm{m}}$ of the wind turbine. Fortunately, $\mathrm{u}_{\mathrm{c}}, \mathrm{u}_{\mathrm{R}}, \mathrm{C}_{\mathrm{pR}}, \mathrm{C}_{\mathrm{pm}}$ and $\mathrm{P}_{\mathrm{R}}$ are given for a wind turbine and the coefficients $F$ and $G$ can be found by applying the boundary conditions that $\mathrm{C}_{\mathrm{p}}\left(\mathrm{u}_{\mathrm{c}}\right)=0$ and $\mathrm{C}_{\mathrm{p}}\left(\mathrm{u}_{\mathrm{R}}\right)=\mathrm{C}_{\mathrm{pR}}$.

The wind turbine rotor performance can also be evaluated as a function of the coefficient of torque $\mathrm{C}_{\mathrm{q}}$. The wind turbine power, $\mathrm{P}_{\mathrm{w}}$, is equal to the product of the torque, $\mathrm{T}$ and the rotational speed $\omega$. It follows that the torque coefficient, $\mathrm{C}_{\mathrm{q}}$, can be related to the power coefficient, $\mathrm{C}_{\mathrm{P}}$, through the relation shown in Equation 2.13.

$\mathrm{C}_{\mathrm{p}}(\lambda, \beta)=\lambda \mathrm{C}_{\mathrm{q}}(\lambda, \beta)$

Therefore, manipulation of the torque coefficient using $\lambda$ and $\beta$ will result in manipulation of the power produced by the turbine.

It is important to recognize the relationship between the aerodynamic torque $T_{A}$ and the torque coefficient $C_{\mathrm{q}}$. Using Equations 2.6 and 2.13, the aerodynamic torque, $\mathrm{T}_{\mathrm{A}}$, that turns the rotor shaft is therefore represented by Equation 2.14. 


$$
\mathrm{T}_{\mathrm{A}}=\frac{1}{2} \rho \mathrm{ARC}_{\mathrm{q}}(\lambda, \beta) \mathrm{u}^{2}
$$

The air density, $\rho$, swept area of the wind turbine, A, and the maximum radius of the wind turbine $\mathrm{R}$, are constant. The upstream wind speed is given by $\mathrm{u}$. The torque coefficient, $\mathrm{C}_{\mathrm{q}}$, just like the coefficient of performance, $\mathrm{C}_{\mathrm{p}}$, is a highly non-linear function of tip-speed ratio, $\lambda$, and blade-pitch angle, $\beta$.

For variable pitch wind turbines, the coefficient of performance can be evaluated by the user for each pitch angle as outlined above and a surface representing the variation of $C_{p}$ as a function of both $\lambda$ and $\beta$ can be generated. For a fixed tip speed ratio, the variation of $C_{p}$ with the pitch angle can be approximated by fitting a curve to any $C_{p}(\beta)$ data points that might be given for the wind turbine. This is done while paying attention to the pitch angle than gives maximum coefficient of performance.

\subsection{Gearbox}

The rotor angular speed, $\omega$, is usually not fast enough to drive the generator to produce the required electrical frequency, $60 \mathrm{~Hz}$. Gear trains can provide a mechanical increase or decrease in speeds for rotational systems. In the case of wind turbines, gear trains are used to step up the angular speed of the low-speed shaft to that of the highspeed shaft connected to the generator. For many applications, gear trains exhibit backlash, which occurs because of the loose fit between two meshed gear teeth. The drive gear tooth rotates through an angle before making contact with the meshed gear tooth. The result is that the angular rotation of the output gear does not occur until a small angular rotation of the input gear has occurred. In the model for the gearbox in this 
research, the behavior of the gears will be idealized and an assumption will be made that there is no backlash.

The input parameters for the gearbox are the angular speed and the torque for the low-speed shaft that connects the rotor to the gearbox. The output parameters are the angular speed and the torque for the high-speed shaft that connects the gearbox to the generator.

\subsection{Electricity Generation}

Three-phase generators are the primary source of most electrical energy. These generators are the largest mechanical to electrical energy converters in the world. They convert rotational mechanical energy, which for the wind turbine plant is extracted from the wind energy by the rotor, to electrical energy. As the generator shaft is rotated, a three-phase voltage is generated, whose value depends upon the speed of rotation and the dc exciting current, which induces the magnetic field.

The generator converts mechanical energy into electrical energy. It consists of three main components; namely, the stator, the rotor and the exciter. The stator is the stationary cylindrical laminated core containing a set of slots that carry the three-phase lap winding as shown in Figures 2.4 and 2.5. 


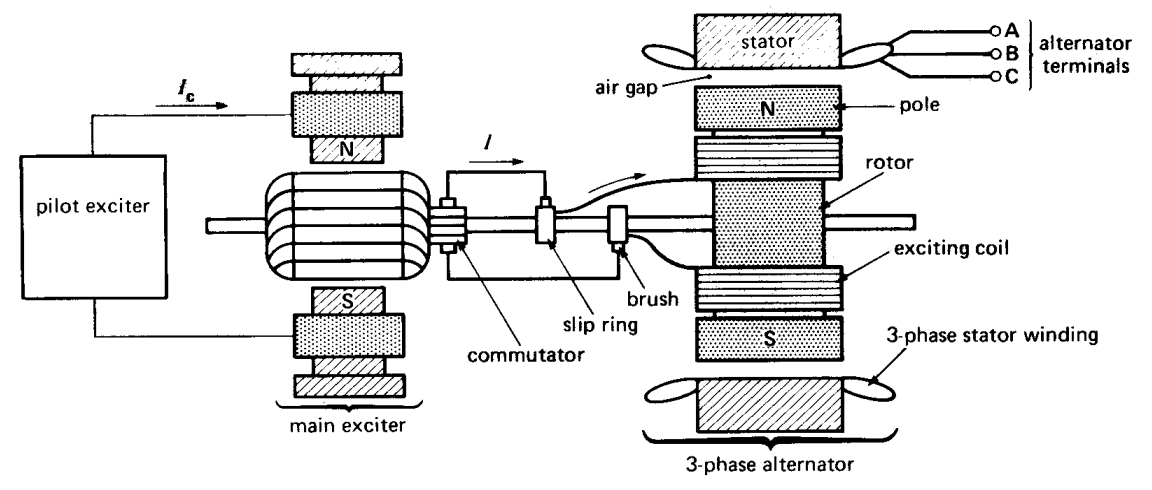

Figure 2.4: Schematic diagram of a typical generator and its dc exciter with brush and slip ring [34]

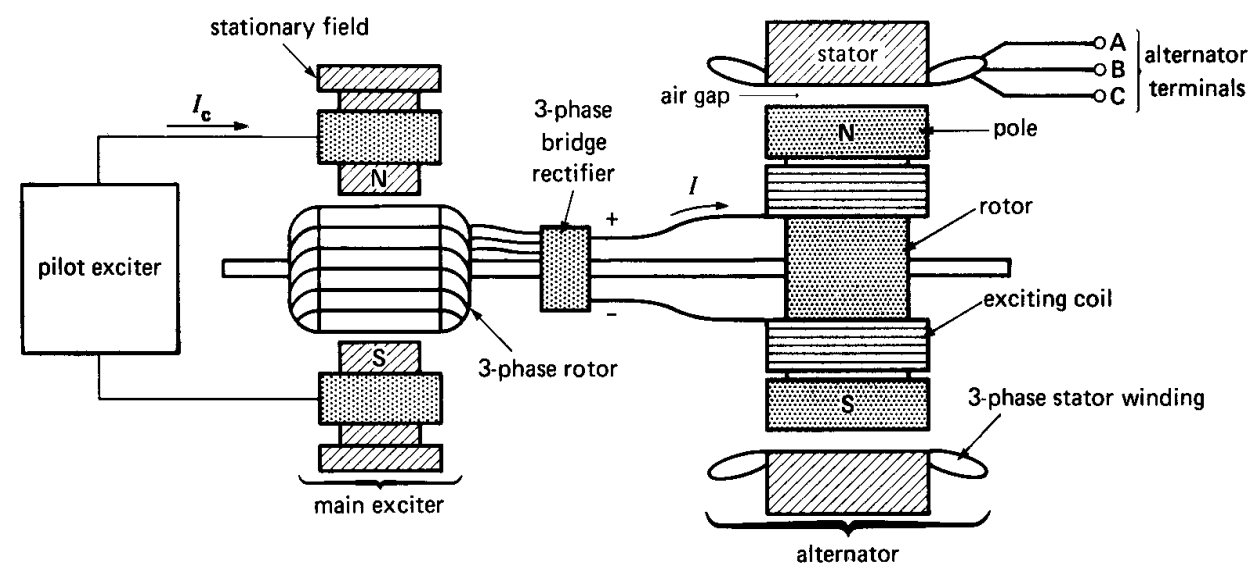

Figure 2.5: Schematic diagram of a typical generator and its brushless dc exciter [34]

The rotor of the generator is fixed to the rotating shaft that is connected to the mechanical power source. The rotor carries the magnetic field that induces electricity in the windings attached to the stator. Finally, the exciter is a dc generator that feeds the exciting current to the main rotor of the generator. This current is the one that creates polarity on the rotor as opposed to using a permanent magnet.

Almost all electrical power is generated by three-phase ac generators which are synchronized with the utility grid $[2,13,15]$. A three-phase generator would normally be 
used whenever the wind turbine is adjacent to a three-phase transmission or distribution line. Wind turbines with generators are unusual compared to other generating units one ordinarily finds attached to the electrical grid. One reason is that the electrical generator has to work with a mechanical power source (the wind turbine), which can supply fluctuating mechanical power if the variation of the input wind speed not well accommodated. Three-phase generators tend to be smaller, less expensive and more efficient that single-phase generators of the same power rating. A schematic diagram for a three-phase generator is shown in Figure 2.6.

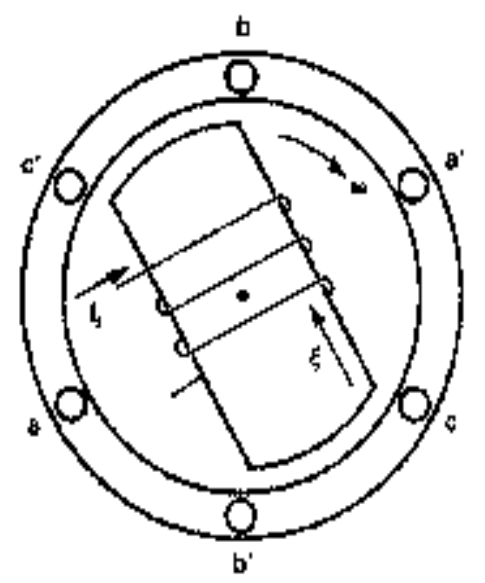

Figure 2.6: Three-Phase Generator

The rotor is supplied with direct current, $\mathrm{I}_{\mathrm{f}}$, from the exciter and the current produces a flux $\phi$ in the air gap. The flux couples into three identical coils marked aa', bb' and cc' spaced $120^{\circ}$ apart and produces three waveforms of the same magnitude but 120 electrical degrees apart. Each phase of the stator winding possesses a resistance R, and a certain inductance L. The schematic diagram of Figure 2.7 shows the impedances and voltages in a three-phase generator. Its connected load is in a Y-connection. 


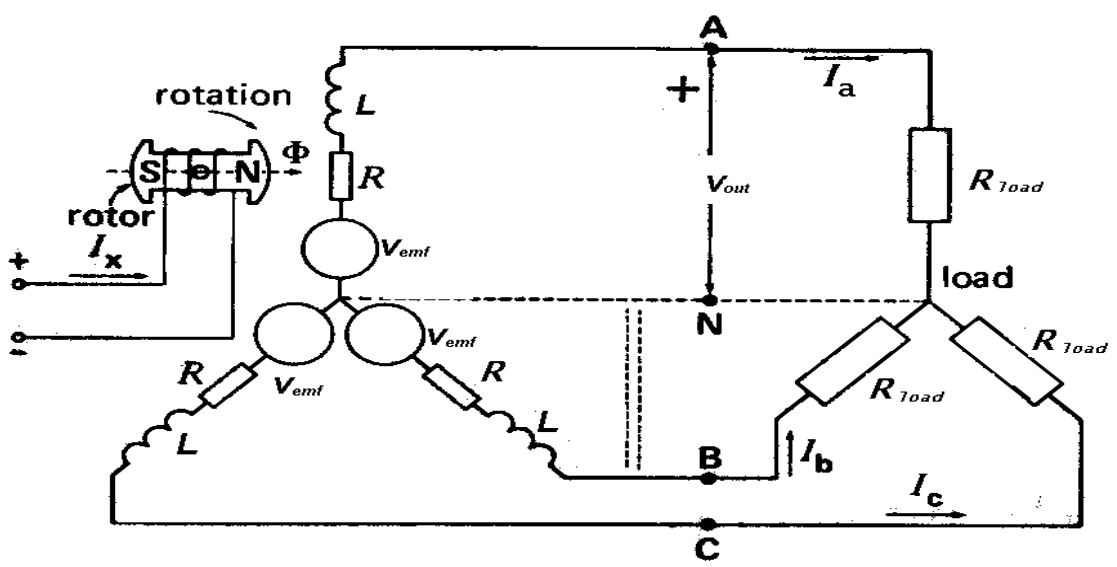

Figure 2.7: Voltages and Impedances in a three-phase generator with connected load

All the phases are identical except that their respective voltages and currents are out of phase by $120^{\circ}$. Analysis of only one phase is therefore sufficient for the description of three-phase generators. Figure 2.8 shows the equivalent circuit of a three-phase generator showing only one phase.

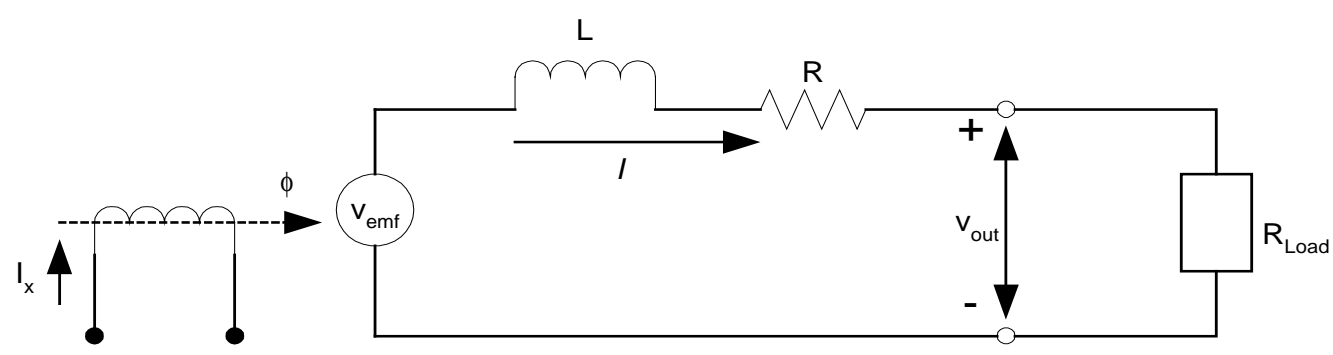

Figure 2.8: Equivalent circuit of a three-phase generator showing only one phase

In the circuit in Figure 2.8, the exciting voltage, $\mathrm{v}_{\mathrm{fd}}$, produces the flux $\phi$ that induces the internal voltage $\mathrm{v}_{\mathrm{emf}}$. The voltage, $\mathrm{v}_{\text {out }}$, at the terminal of the generator 
depends upon $\mathrm{v}_{\mathrm{emf}}$ and the load $\mathrm{R}_{\text {load }}$. It should be noted that $\mathrm{v}_{\mathrm{emf}}$ and $\mathrm{v}_{\text {out }}$ are line-to-line voltages and I is the line current.

Equation 2.15 gives the frequency, $\mathrm{f}$, of the induced output voltage.

$$
f=\frac{p}{2} \frac{\omega}{60}
$$

In this equation, $\mathrm{p}$ is the number of poles and $\omega$ is the rotational speed of the generator in rpm. Most wind turbines use generators with four or six poles. The reasons for using these relatively high-speed generators are savings on size and cost. For a given power output, there is a choice between a slow-moving, larger (expensive) generator and a highspeed (less expensive) smaller generator.

The principle that governs the voltage generating operation of the generator is Faraday's law, which is given in Equation 2.16.

$$
\mathrm{v}_{\mathrm{emf}}=\mathrm{N} \frac{\mathrm{d} \phi}{\mathrm{dt}}
$$

where $\mathrm{v}_{\mathrm{emf}}$ is the voltage induced on the coil, $\lambda$ is the total flux passing through the coil, $\phi$ is the flux passing through one turn of the coil and $\mathrm{N}$ is the number of turns in the coil. The voltage equation for this generator can then be written as shown in Equation 2.17 where the induced voltage, $\mathrm{v}_{\mathrm{emf}}$, is given in Equation 2.16.

$$
\mathrm{v}_{\mathrm{out}}=\mathrm{v}_{\mathrm{emf}}-\mathrm{RI}-\mathrm{L} \frac{\mathrm{dI}}{\mathrm{dt}}
$$

Typically, the generator electrical output is found by solving the differential equations shown in Equations 2.16 and 2.17. The derivative of the flux $(\mathrm{d} \phi / \mathrm{dt})$ in Equation 2.16 is a function of the rotational speed of the generator and the exciting current. For a given exciting voltage, the variation of the derivative of the flux and the 
rotational speed of the generator can be found. A more detailed mathematical description of a three-phase generator is given in Appendix B.

\subsection{Power Transmission and Generator Efficiencies}

The power flow in a general wind turbine system is illustrated in Figure 2.9.

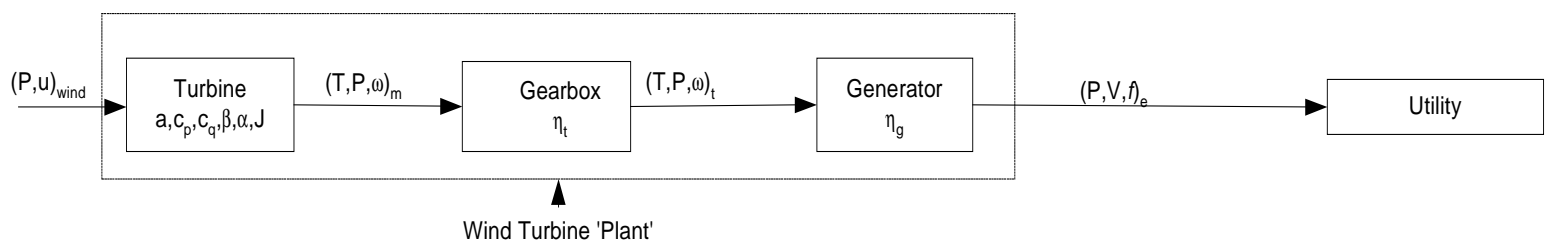

Figure 2.9: General wind turbine plant connected to utility

The power in the wind, $\mathrm{P}_{\mathrm{w}}$, passes through the turbine and it is changed into mechanical power, $\mathrm{P}_{\mathrm{m}}$, which is then transmitted to the generator through the gearbox with its efficiency $\eta_{\mathrm{T}}$. Similarly, the generator output power, $\mathrm{P}_{\mathrm{e}}$, will be given by the product of the transmission output and the generator efficiency $\eta_{\mathrm{G}}$.

\subsection{Wind Turbine Operation}

\subsubsection{Constant Rotational Speed}

Most wind turbines operate at a constant rotational speed, except when starting and stopping. This simplifies the wind turbine operation when using synchronous generators paralleled with the utility grid. However, constant-speed operation means that the maximum coefficient of performance is available only at a particular range of wind 
speeds. At low wind speeds, the generated power increases with wind speed, and beyond the rated speed, the generated power decreases.

\subsubsection{Variable Rotational Speed}

In the variable-speed mode of operation, the wind turbine is controlled to operate near maximum efficiency for all speeds. The turbine shaft accelerates whenever the aerodynamic torque from the wind is more than the load torque, and the turbine shaft decelerates when the aerodynamic torque is less than the load torque.

\subsection{Wind Turbine Control Strategies}

\subsubsection{Variable-Pitch Controlled Wind Turbines}

For the variable-pitch type of turbine, the rotor blade pitch is varied to control both the rotational speed and the coefficient of performance. The wind turbine's controller checks the power output of the turbine several times per second. When the power output becomes too high, the controller sends a signal to the blade pitch mechanism, which immediately pitches (turns) the rotor blades slightly out of the wind. Conversely, the blades are turned back into the wind whenever the wind speed drops. The rotor blades thus have to be able to turn around their longitudinal axis (that is, to pitch). During normal operation the blades will pitch a fraction of a degree at a time and the rotor will be turning at the same time. Figure 2.10 shows the general block diagram for pitch-controlled wind turbines. The controlled output can either be the shaft rotational speed, the mechanical power, or both. 


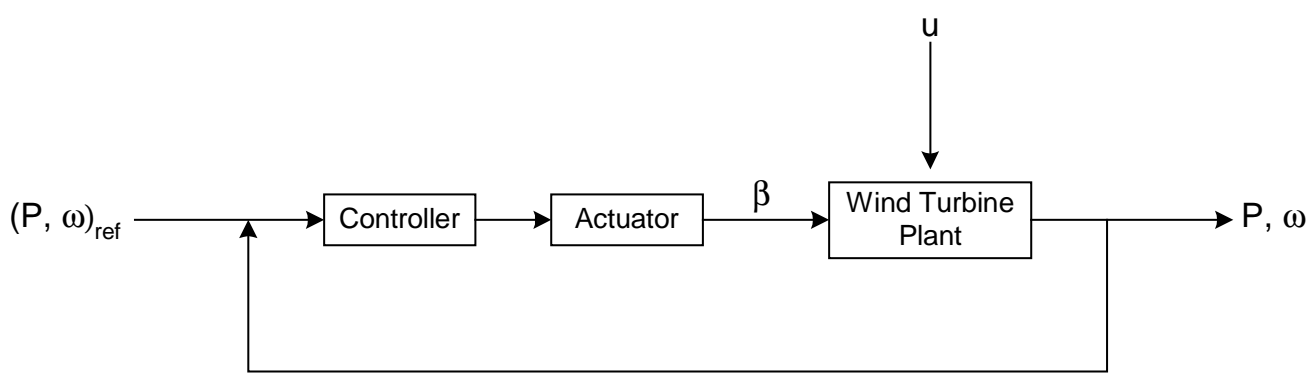

Figure 2.10: Basic block diagram for pitch-controlled wind turbines

On a pitch-controlled wind turbine, the computer will generally pitch the blades a few degrees every time the wind speed changes in order to keep the rotor blades at the optimum angle in order to maximize the power output for all wind speeds. The pitch mechanism is usually operated using hydraulics. This feature helps improve the average coefficient of performance but it also increases complexity and cost. Hence, pitch control may not be the most economical solution for all applications.

\subsubsection{Stall-Controlled Wind Turbines}

Stall controlled wind turbines have the rotor blades bolted onto the hub at a fixed angle. The geometry of the rotor blade has been aerodynamically designed to ensure that the moment the wind speed becomes too high, it creates turbulence on the side of the rotor blade. This stall prevents the lifting force of the rotor blade from acting on the rotor. The rotor blade is twisted slightly along its longitudinal axis. This is done in part in order to ensure that the rotor blade stalls gradually rather than abruptly when the wind speed reaches its critical value. The basic advantage of stall control is that one avoids moving parts in the rotor itself, and thus requiring a complex control system. On the other hand, stall control represents a very complex aerodynamic design phenomena, and introduces 
related design challenges in the structural dynamics of the whole wind turbine plant. Figure 2.11 shows the basic block diagram for stall-controlled wind turbines. The control strategy is incorporated in the rotor design and there is no control flexibility.

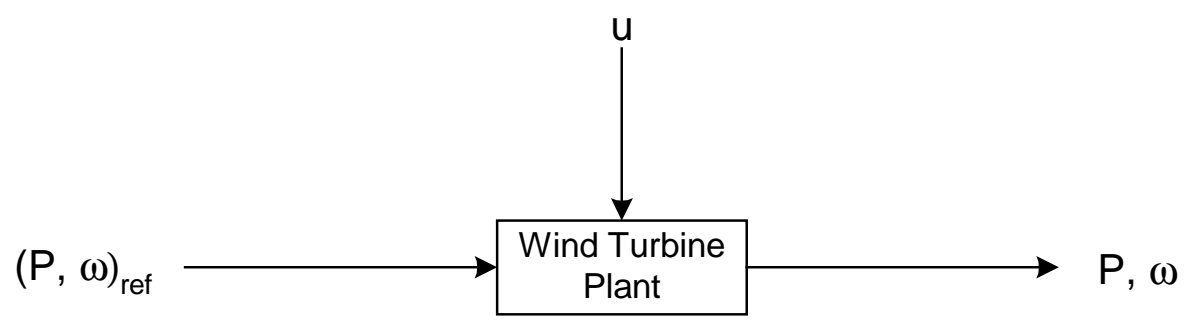

Figure 2.11: Basic block diagram for stall-controlled wind turbines

\subsubsection{Power Profile for Controlled Wind Turbines}

After evaluating the wind power, $\mathrm{P}_{\mathrm{w}}$, and $\mathrm{C}_{\mathrm{p}}$ trends, the control strategy of the wind turbine is to extract as much power as possible at low speeds and then regulate the power at high speeds to protect the turbine. Figure 2.12 shows the general desired power profile as a function of wind speed.

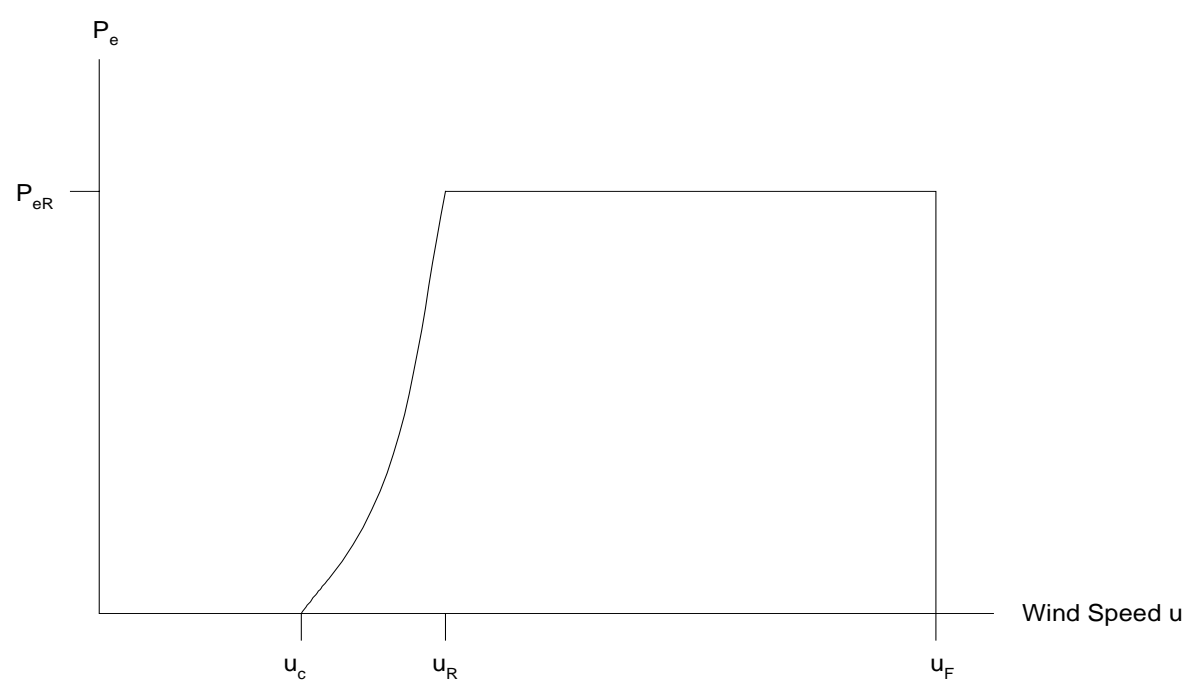

Figure 2.12: Target wind turbine output profile 
Equation 2.18 is then defined for the electrical power output of a wind turbine.

$$
\begin{array}{ll}
\mathrm{P}=0 & \left(\mathrm{u} \leq \mathrm{u}_{\mathrm{c}}\right) \\
\mathrm{P}=\frac{1}{2} \rho \mathrm{C}_{\mathrm{p}}(\lambda, \beta) A \mathrm{u}^{3} & \left(\mathrm{u}_{\mathrm{c}} \leq \mathrm{u} \leq \mathrm{u}_{\mathrm{R}}\right) \\
\mathrm{P}=\mathrm{P}_{\mathrm{R}} & \left(\mathrm{u}_{\mathrm{R}} \leq \mathrm{u} \leq \mathrm{u}_{\mathrm{F}}\right) \\
\mathrm{P}=0 & \left(\mathrm{u}>\mathrm{u}_{\mathrm{F}}\right)
\end{array}
$$

The parameter $\mathrm{u}_{\mathrm{c}}$ is the cut-in wind speed at which electrical power production starts, $\mathrm{u}_{\mathrm{R}}$ is the rated wind speed, which is the minimum speed that produces the maximum electric power, $\mathrm{P}_{\mathrm{m}}$, and $\mathrm{u}_{\mathrm{F}}$ is the furling speed where the turbine is shut down to protect it from high speed winds. However, for a wind turbine connected to a power grid, a control strategy that can follow the load demand has to be used. Therefore, there are two modes of operation for the controller. One provides constant (or maximum) power and the other mode follows the load demand. Figure 2.13 shows the general block diagram for the wind turbine plant, the controller and the voltage regulator.

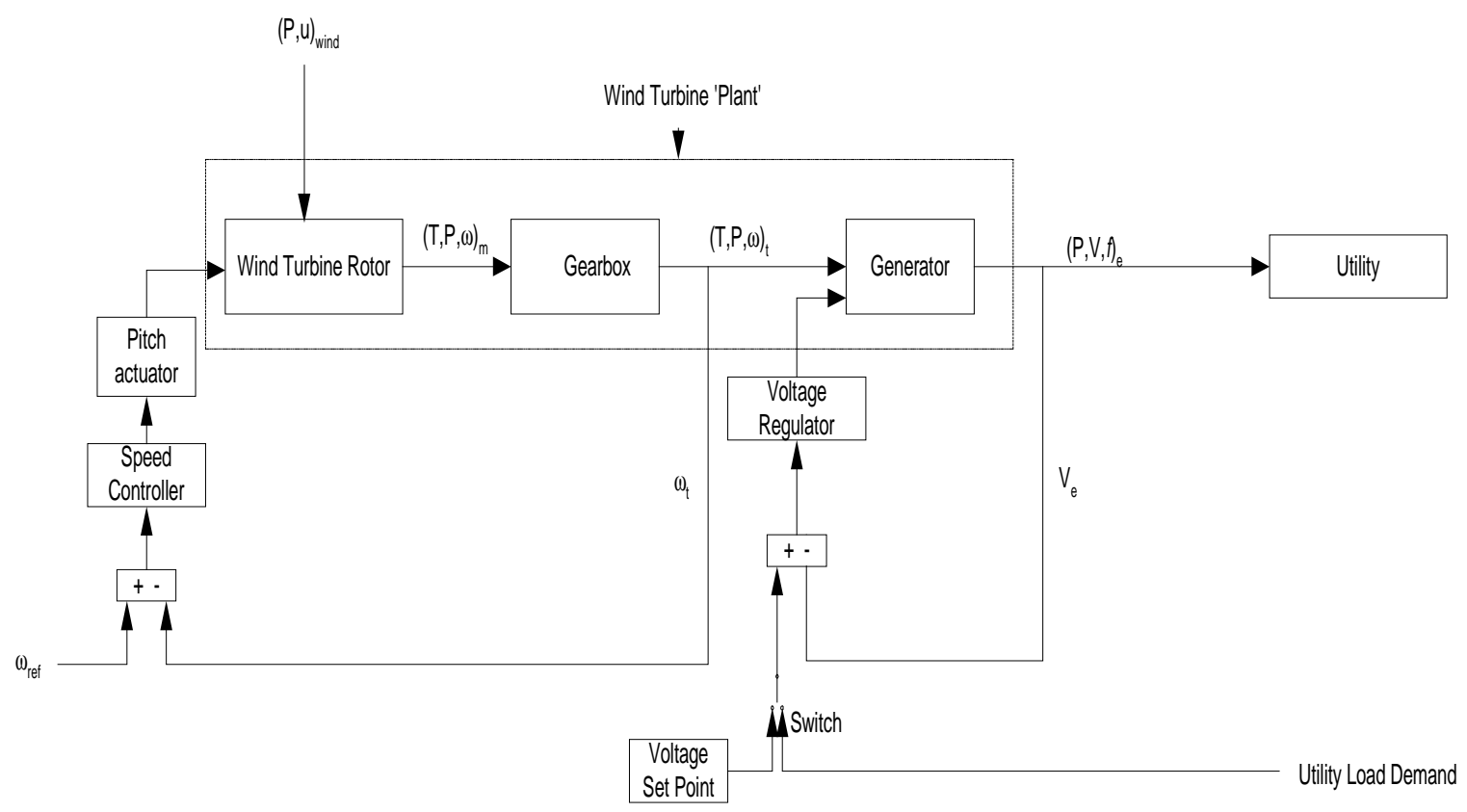

Figure 2.13: Basic block diagram for the wind turbine plant with control strategies 


\section{Chapter 3: Wind Turbine Modeling}

\subsection{Introduction}

The development of power generation using wind turbines has been expanding during the past ten years. The global market for the electrical power produced by the wind turbine generator has been increasing steadily, which directly makes wind technology more competitive. Recently, there have been positive trends shown by the utilities to offer renewable energy to customers [18]. Many customers who are environmentally conscious now have the option of subscribing to green energy such as energy generated from wind turbines from the power provider. The combination of increasing demand for distributed resources of electricity and the desire for green energy has placed increased emphasis on wind turbine research. There are many different ways of applying wind turbines but the main application is their integration into the existing electric grids. The main objective of this thesis is to model and control a wind turbine. Other secondary objectives include simulating the applicability of a wind turbine in an electric grid system. Also, the wind turbine reliability and controllability will to be shown together with its economic attractiveness and feasibility.

The specific steps for this thesis will be to:

1. Choose a wind turbine and its basic operation. Derive the mathematical model of the wind turbine and document its physical properties.

2. Design a controller to maintain a constant rotor frequency and a constant wind turbine power output. 
3. Make sure the output variables or deviations are within the accepted ranges and comparable to other grid connected distributed resources.

\subsection{Wind Turbine Operation}

In deriving a wind turbine mathematical model, a specific wind turbine had to be selected. This involved choosing the type of wind turbine operation. Variable-speed, constant-speed, pitch-control and stall-control were all analyzed and they are discussed in Chapter 2.

For the purposes of this research, to accomplish the analysis of wind turbine modeling and controls, a relatively simple wind turbine had to be selected and the complexity of the model had to be reduced. Therefore, a constant speed turbine was chosen not only to reduce the model complexity but also to eliminate additional components that are needed to maintain constant frequency for variable-speed wind turbines. The variable blade pitch angle control strategy was chosen based on the fact that a constant-speed operation was desired. Pitch-controlled wind turbines were found more attractive based on the fact that they can operate in a wider range of wind speeds because of their ability to maintain constant power extraction at low and high wind speeds. The mode of operation and the control mechanism are used to classify wind turbines. In this research, a pitch-controlled constant-speed wind turbine was selected.

One of the key factors is to find values for the constant parameters in the transfer functions representing the wind turbine system at operating conditions. The variation of the coefficient of torque $C_{q}$ with the pitch angle, $\beta$, and the tip speed ratio, $\lambda$, is highly nonlinear and unique for each wind turbine. It would be useful to obtain some 
experimental data for the variation of $\mathrm{C}_{\mathrm{q}}$ with $\beta$ and $\lambda$ because there are no general linear equations relating these parameters. Therefore, in choosing the wind turbine for the model, it would be better to choose a wind turbine whose experimental data $C_{q}(\beta, \lambda)$ is available. The geometry and aerodynamic characteristics of the simulated wind turbine resemble those of a Grumman Windstream-33, 10-m diameter, $20 \mathrm{~kW}$ turbine. The National Renewable Energy Laboratory's (NREL) National Wind Technology Center modified this wind turbine to operate at variable speeds using blade-pitch regulation [4]. Table 3.1 shows the list of the Grumman Windstream-33 parameters.

Table 3.1: Grumman Windstream-33 parameters

\begin{tabular}{|l|l|}
\hline Rated Power, $\mathrm{P}_{\mathrm{R}}$ & $20 \mathrm{~kW}$ \\
\hline Radius, $\mathrm{R}$ & $5 \mathrm{~m}$ \\
\hline Drive Train Inertia, $\mathrm{J}_{\mathrm{T}}$ & $1270 \mathrm{~kg} \cdot \mathrm{m}^{2}$ \\
\hline Gear Ratio, $\mathrm{n}$ & 11.43 \\
\hline Operation Angular Speed, $\omega$ & $105 \mathrm{RPM}$ \\
\hline Cut-in speed, $\mathrm{u}_{\mathrm{c}}$ & $6.5 \mathrm{~m} . \mathrm{s}^{-1}$ \\
\hline Rated wind speed, $\mathrm{u}_{\mathrm{R}}$ & $11.5 \mathrm{~m} . \mathrm{s}^{-1}$ \\
\hline Furling speed, $\mathrm{u}_{\mathrm{f}}$ & $23 \mathrm{~m} \cdot \mathrm{s}^{-1}$ \\
\hline$\beta$ range & 0 to $12 \mathrm{deg}$ \\
\hline
\end{tabular}

With the wind turbine characteristics chosen, the next step was to derive the mathematical model of a pitch-controlled constant-speed wind turbine. Section 3.3 discusses the basic equations for such a wind turbine and shows the derivation of the mathematical model.

\subsection{Wind Turbine Mathematical Modeling}

\subsubsection{Wind Turbine Plant Model}


The wind turbine plant model was divided into two main parts. The first part was the wind turbine, which included a turbine rotor on a low-speed shaft, a gearbox and high-speed shaft. The inputs for this part of the plant were the wind speed and the blade pitch angle while the outputs were the high-speed shaft angular rotation and the mechanical power, $\mathrm{P}_{\mathrm{m}}$. The second part was the electric generator whose input was constant angular rotation from the turbine plant and whose output was electrical power. Figure 3.1 illustrates the general block diagram of the wind turbine system.

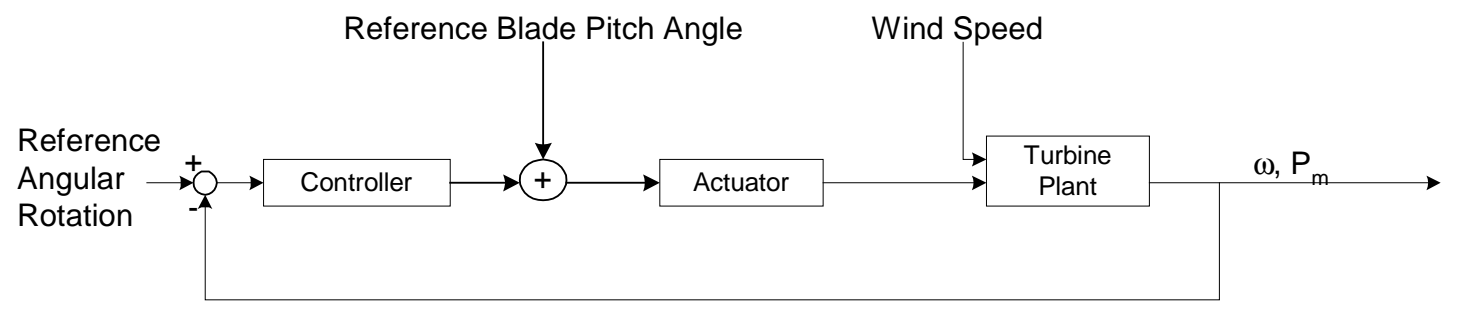

Figure 3.1: Block diagram of wind turbine system dynamics and control

The following six steps show the sequence of events in the block diagram:

1. Wind and blade pitch angle are input into wind turbine plant, which causes the rotor to spin.

2. The low-speed shaft angular speed is fed back and compared to reference lowspeed shaft angular speed.

3. The angular speed error is input to the controller, which commands a change in blade-pitch angle.

4. A new blade pitch angle is applied to the actuator.

5. The actuator changes the blade pitch angle.

6. Wind at a new wind speed is input into the wind turbine plant and the six steps are repeated. 
Although the goal of this control sequence is to maintain a constant angular speed and constant power, $\mathrm{P}_{\mathrm{m}}$, only the angular speed is fed back to accommodate the wind speed fluctuations. This is because, controlling the angular speed automatically means that the aerodynamic torque, $\mathrm{T}_{\mathrm{A}}$ that causes the rotation, is controlled and hence the extracted mechanical power, $\mathrm{P}_{\mathrm{m}}$. This is derived from the fact that these three quantities, $\mathrm{P}_{\mathrm{m}}, \mathrm{T}_{\mathrm{A}}$ and $\omega$ are related by Equation 3.1.

$\mathrm{P}_{\mathrm{m}}=\mathrm{T}_{\mathrm{A}} \omega$

Therefore controlling $\mathrm{T}_{\mathrm{A}}$ and $\omega$ to remain constant will cause the power $\mathrm{P}_{\mathrm{m}}$ to remain constant as well. Throughout this thesis only angular speed control will be mentioned because its output profile will be closely related to that of the power Pm as will be seen in Chapter 4.

The aerodynamic torque, $\mathrm{T}_{\mathrm{A}}$, must be opposed by an equal and opposite load torque, $T_{L}$, for the turbine to operate at steady speed. If $T_{A}$ is greater than $T_{L}$, the turbine will accelerate, while if $T_{A}$ is less than $T_{L}$, the turbine will decelerate. Equation 3.2 gives this mathematical description, where $\mathrm{J}_{\mathrm{T}}$ is the equivalent combined moment of inertia of the rotor, gear reducer and both the low-speed and high-speed shafts.

$\mathrm{J}_{\mathrm{T}} \dot{\omega}_{\mathrm{T}}=\mathrm{T}_{\mathrm{A}}-\mathrm{T}_{\mathrm{L}}$

$\mathrm{T}_{\mathrm{L}}$ is the mechanical torque necessary to turn the generator and was assumed to be a constant value derived from the wind turbine plant physical properties. The aerodynamic torque, $\mathrm{T}_{\mathrm{A}}$, is represented by Equation 2.14. It is important to recognize the relationship between the power coefficient and the torque coefficient. Power extracted from the wind is shown in the Equation 3.3: 


$$
\mathrm{P}_{\mathrm{A}}=\frac{1}{2} \rho A C_{\mathrm{p}}(\lambda, \beta) \mathrm{u}^{3}
$$

The turbine plant power, $\mathrm{P}_{\mathrm{m}}$, is equal to the product of the aerodynamic torque, $\mathrm{T}_{\mathrm{A}}$, and the rotational speed $\omega$ as shown in Equation 3.1. The torque coefficient, $\mathrm{C}_{\mathrm{q}}$, can be related to the power coefficient, $\mathrm{C}_{\mathrm{P}}$, through the relation shown in Equation 3.4.

$\mathrm{C}_{\mathrm{p}}(\lambda, \beta)=\lambda \mathrm{C}_{\mathrm{q}}(\lambda, \beta)$

Therefore, manipulation of the torque coefficient using $\lambda$ and $\beta$ will result in manipulation of the power produced by the turbine.

Equation 3.3 is non-linear because it is a function of $\mathrm{C}_{\mathrm{p}}$, which is highly nonlinear. A traditional approach is to design a commonly used linear controller, such as proportional-integral-derivative (PID) and linearize the non-linear turbine dynamics about a specified operating point.

Assuming, $\left.\mathrm{T}_{\mathrm{A}}\right|_{\mathrm{OP}}=\left.\mathrm{T}_{\mathrm{L}}\right|_{\mathrm{OP}}$, linearization of the Equation 3.2 results in Equation 3.5 .

$\mathrm{J}_{\mathrm{T}} \dot{\omega}=\left.\mathrm{J}_{\mathrm{T}} \frac{\partial \dot{\omega}}{\partial \mathrm{u}}\right|_{\mathrm{OP}} \Delta \mathrm{u}+\left.\mathrm{J}_{\mathrm{T}} \frac{\partial \dot{\omega}}{\partial \omega}\right|_{\mathrm{OP}} \Delta \omega+\left.\mathrm{J}_{\mathrm{T}} \frac{\partial \dot{\omega}}{\partial \beta}\right|_{\mathrm{OP}} \Delta \beta$

Simplifying this equation yields Equation 3.6.

$\dot{\omega}=\alpha \Delta \mathrm{u}+\gamma \Delta \omega+\delta \Delta \beta$

In this equation, $\Delta \omega_{\mathrm{T}}, \Delta \mathrm{u}$ and $\Delta \beta$ represent deviations from the chosen operating point $\omega_{\mathrm{TOP}}, \mathrm{u}_{\mathrm{OP}}$ and $\beta_{\mathrm{OP}}$. The parameters $\alpha, \gamma$ and $\delta$ represent the coefficients in Equation 3.5 and they are given by Equations 3.7 to 3.9. Their detailed derivations are shown in Appendix A. 


$$
\begin{aligned}
& \alpha=\left.\frac{\partial \dot{\omega}}{\partial \mathrm{u}}\right|_{\mathrm{OP}}=\frac{1}{2 \mathrm{~J}_{\mathrm{T}}} \rho \mathrm{ARu}_{\mathrm{OP}}\left[\left.2 \mathrm{C}_{\mathrm{q}}\right|_{\mathrm{OP}}-\left.\lambda_{\mathrm{OP}} \frac{\partial \mathrm{C}_{\mathrm{q}}}{\partial \lambda}\right|_{\mathrm{OP}}\right] \\
& \gamma=\left.\frac{\partial \dot{\omega}}{\partial \omega}\right|_{\mathrm{OP}}=\left.\frac{1}{2 \mathrm{~J}_{\mathrm{T}}} \rho \mathrm{AR}^{2} \mathrm{u}_{\mathrm{OP}} \frac{\partial \mathrm{C}_{\mathrm{q}}}{\partial \lambda}\right|_{\mathrm{OP}} \\
& \delta=\left.\frac{\partial \dot{\omega}}{\partial \beta}\right|_{\mathrm{OP}}=\left.\frac{1}{2 \mathrm{~J}_{\mathrm{T}}} \rho \mathrm{ARu}_{\mathrm{OP}}^{2} \frac{\partial \mathrm{C}_{\mathrm{q}}}{\partial \beta}\right|_{\mathrm{OP}}
\end{aligned}
$$

The parameters $\alpha, \gamma$ and $\delta$ represent the wind turbine dynamics at the linearization point. Their quantities depend on the wind speed and the partial derivatives of the coefficient of torque, $\mathrm{C}_{\mathrm{q}}$ with respect to $\lambda$ and $\beta$ at the operation point. The magnitudes of $\alpha$ and $\delta$ show the relative weight of the effect wind speed $u$ and the pitch angle $\beta$, respectively, on the wind turbine angular speed. Equation 3.6 is the linear equation describing the wind turbine dynamics. Applying Laplace transforms yields:

$\mathrm{s} \Delta \omega(\mathrm{s})=\alpha \Delta \mathrm{u}(\mathrm{s})+\gamma \Delta \omega(\mathrm{s})+\delta \Delta \beta(\mathrm{s})$

Rearranging Equation 3.10 yields:

$$
\Delta \omega=[\alpha \Delta \mathrm{u}(\mathrm{s})+\delta \Delta \beta(\mathrm{s})] \frac{1}{\mathrm{~s}-\gamma}
$$

After linearization about the chosen operating point for which the angular rotation speed is $\omega_{\mathrm{TOP}}$, the wind speed $\mathrm{u}_{\mathrm{OP}}$, and the pitch angle is $\beta_{\mathrm{OP}}$, Equation 3.11 is a linear equation that describes the wind turbine dynamics in the Laplace domain. It represents the change in rotor speed output from the wind turbine. The inputs $\Delta \mathrm{u}$ and $\Delta \beta$ represent deviations from the chosen operating points. Figure 3.2 shows the block diagram representation for Equation 3.11. 


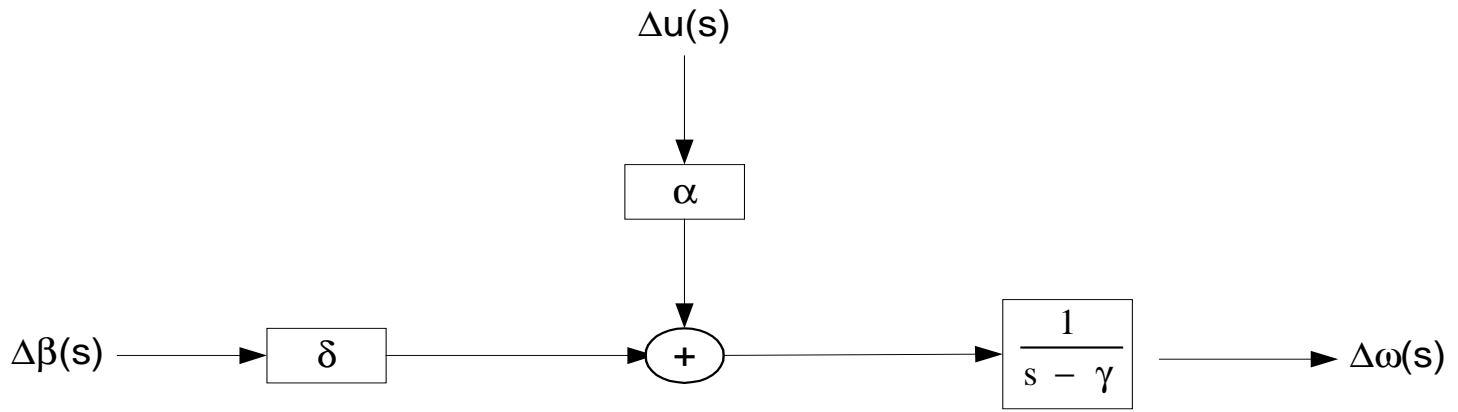

Figure 3.2: Block diagram of the linear turbine plant model

The wind turbine is therefore represented by the first-order transfer function, $G_{p}(s)$ shown in Equation 3.12.

$\mathrm{G}_{\mathrm{P}}(\mathrm{s})=\frac{\Delta \omega(\mathrm{s})}{\alpha \Delta \mathrm{u}+\delta \Delta \beta}=\frac{\Delta \omega(\mathrm{s})}{\left(\Delta \mathrm{T}_{\mathrm{A}} / \mathrm{J}_{\mathrm{T}}\right)}=\frac{1}{\mathrm{~s}-\gamma}$

\subsubsection{Actuator Model}

The block diagram for the hydraulic actuator that changes the blade pitch angle is shown in Figure 3.3, which also illustrates the actuator's operation.

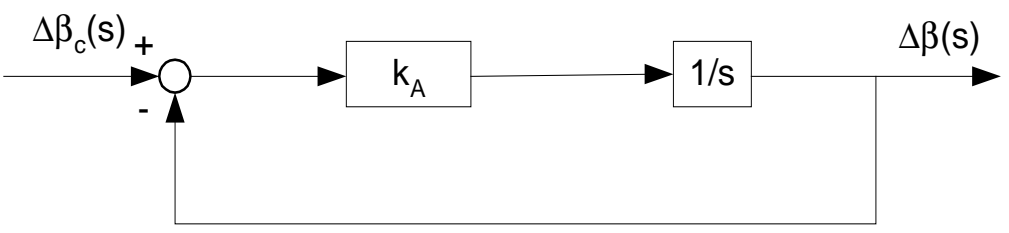

Figure 3.3: Actuator block diagram

The block diagram in Figure 3.3 illustrates the actuator dynamics where $\Delta \beta_{\mathrm{C}}(\mathrm{s})$ is the Laplace transform of the input pitch angle change from the controller and $\Delta \beta(\mathrm{s})$ is the Laplace transform of the output pitch angle change. The actuator is represented by the first-order transfer function shown in Equation 3.13. 


$$
\mathrm{G}_{\mathrm{A}}(\mathrm{s})=\frac{\Delta \beta(\mathrm{s})}{\Delta \beta_{\mathrm{C}}(\mathrm{s})}=\frac{\mathrm{k}_{\mathrm{A}} / \mathrm{s}}{1+\mathrm{k}_{\mathrm{A}} / \mathrm{s}}=\frac{\mathrm{k}_{\mathrm{A}}}{\mathrm{s}+\mathrm{k}_{\mathrm{A}}}
$$

\subsubsection{Controller Model}

The block diagram of the Proportional-Integral-Derivative (PID) controller is shown in Figure 3.4.

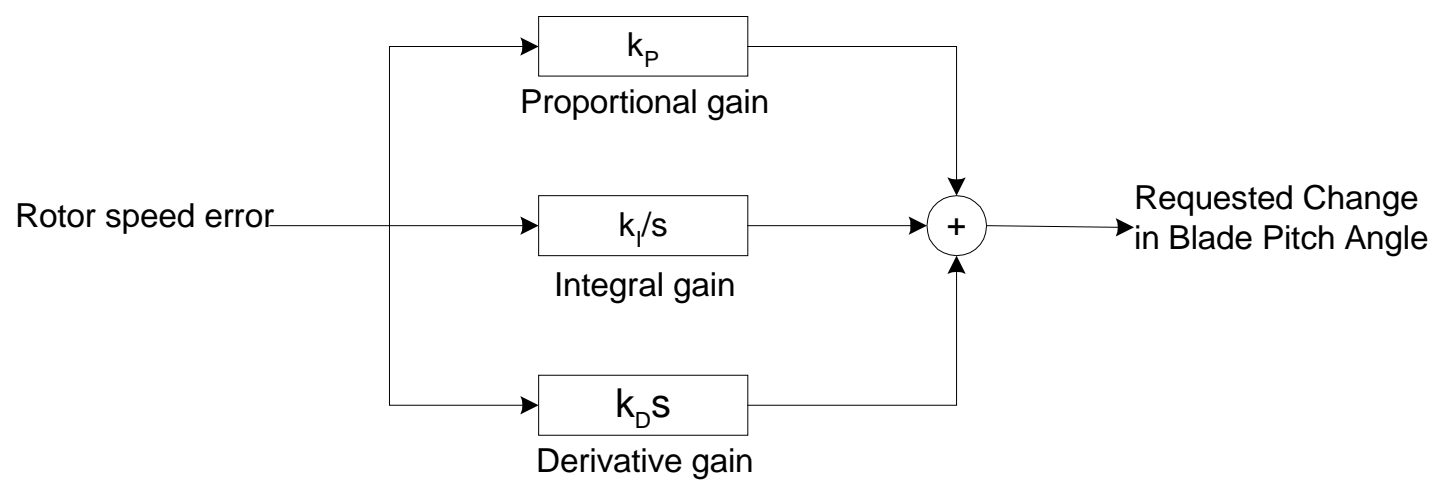

Figure 3.4: Block diagram of Proportional-Integral-Derivative (PID) controller

The rotor speed error is manipulated with three gain values, resulting in the change in blade pitch angle necessary to eliminate the rotor speed error. A proportional value, $\mathrm{k}_{\mathrm{P}}$, multiplies the error signal. The integral with respect to time of the error signal is multiplied by the gain, $\mathrm{k}_{\mathrm{I}}$. The gain $\mathrm{k}_{\mathrm{D}}$ multiplies the derivative of the error signal. The summation of these three terms produces the desired change in blade pitch angle.

The PID controller is shown in Figure 3.5, where $\Delta \omega(\mathrm{s})$ is the input rotor speed error and $\Delta \beta_{\mathrm{C}}(\mathrm{s})$ is the requested blade pitch angle change. 


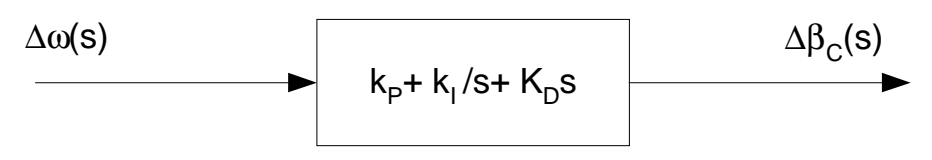

Figure 3.5: Controller block diagram

The transfer function $\mathrm{G}_{\mathrm{C}}(\mathrm{s})$ for the controller between the input rotational speed error and the output pitch angle change is then:

$\mathrm{G}_{\mathrm{C}}(\mathrm{s})=\frac{\Delta \beta_{\mathrm{C}}(\mathrm{s})}{\Delta \omega(\mathrm{s})}=\frac{\mathrm{k}_{\mathrm{D}} \mathrm{s}^{2}+\mathrm{k}_{\mathrm{P}} \mathrm{s}+\mathrm{k}_{\mathrm{I}}}{\mathrm{s}}$

\subsubsection{Overall Transfer Function for Turbine Plant, Actuator and Controller}

Figures 3.6a, 3.6b and 3.6c show the system block diagrams in the Laplace domain. The block diagram represents a constant load output, which is controlled through rotational speed control.

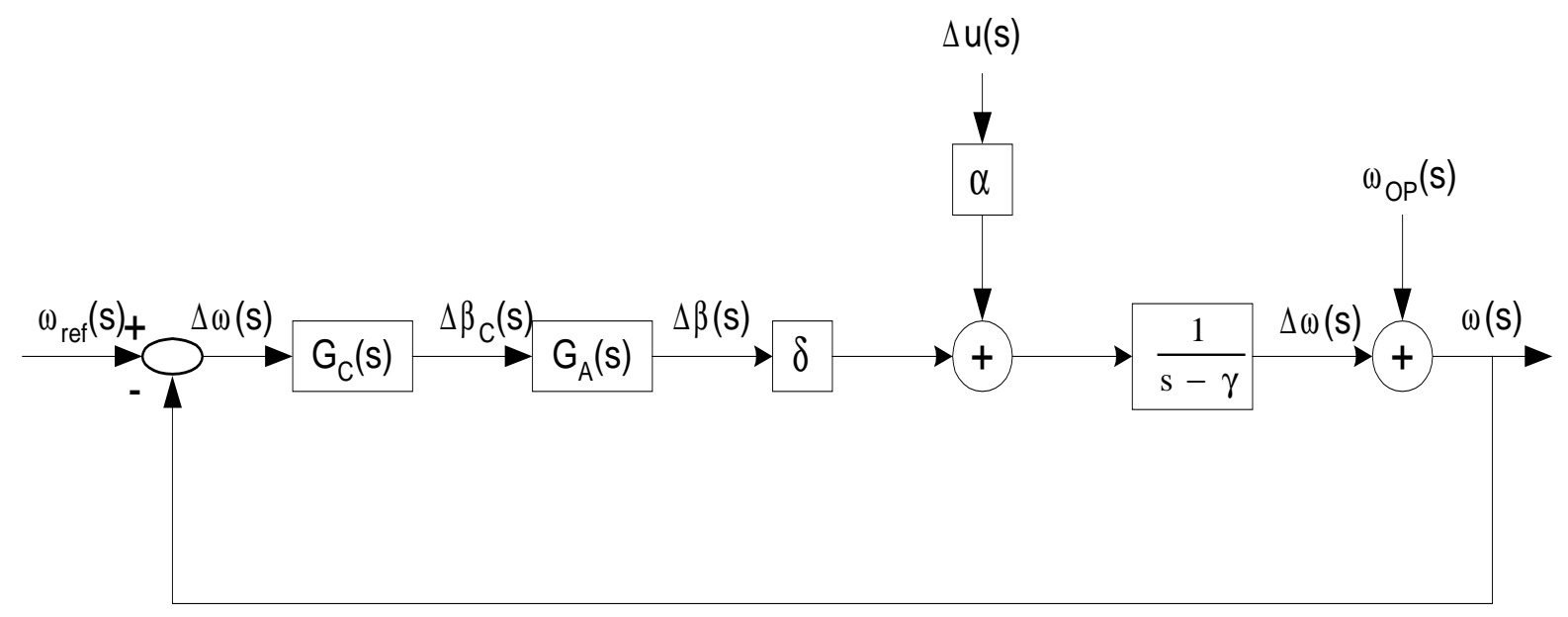

Figure 3.6a: Block Diagram for the Turbine Plant with Actuator and Controller 


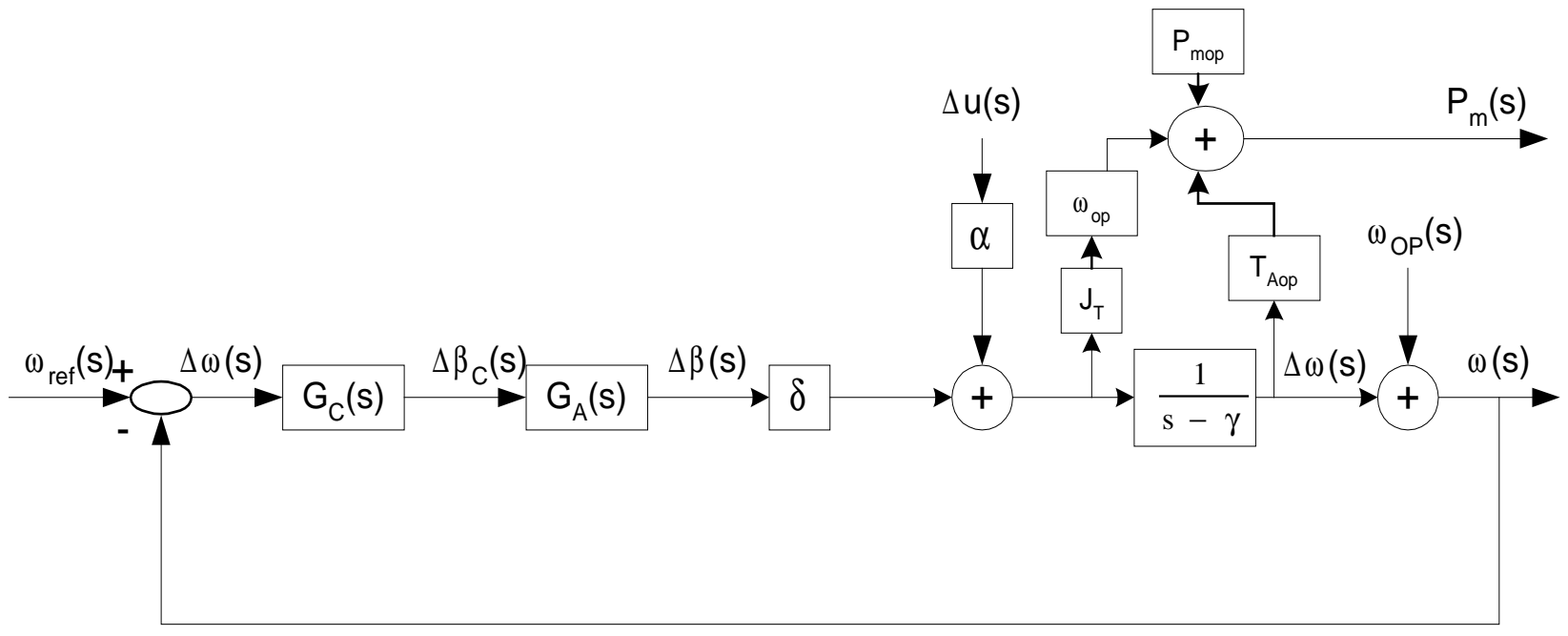

Figure 3.6b Wind turbine plant block diagram with power output shown

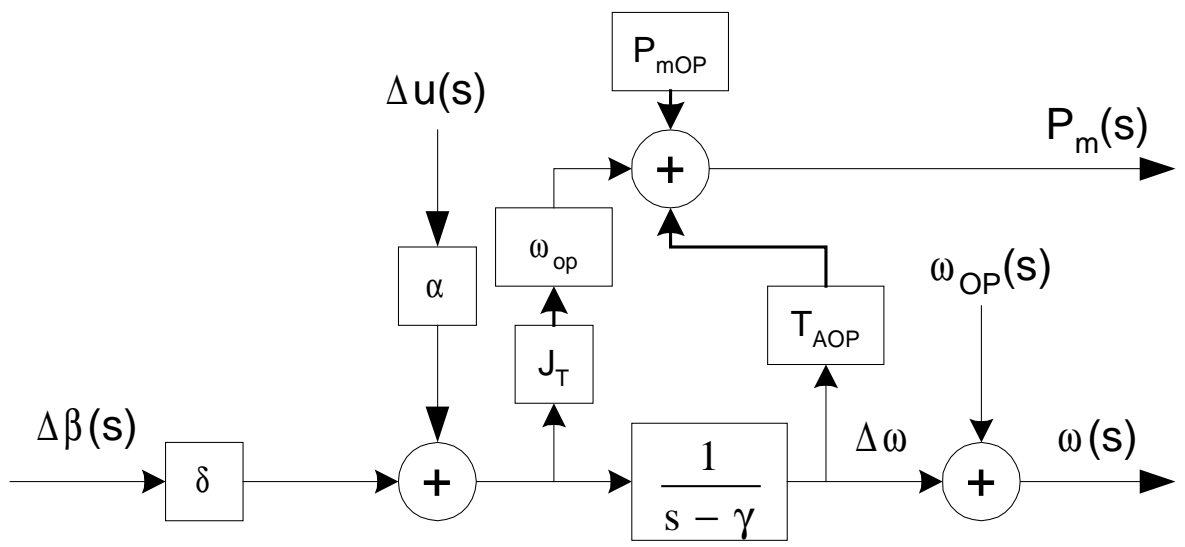

Figure 3.6c: Power output loop for wind turbine plant

Figure 3.6a illustrates the wind turbine plant, controller and actuator. Figure 3.6b and 3.6c show the overall system together with the on the power output loop of the system. This loop is derived from Equation 3.15.

$\mathrm{P}_{\mathrm{m}}=\mathrm{T}_{\mathrm{A}} \omega=\mathrm{P}_{\mathrm{mOP}}+\left(\frac{\partial \mathrm{P}_{\mathrm{m}}}{\partial \mathrm{T}_{\mathrm{A}}}\right)_{\mathrm{OP}} \Delta \mathrm{T}_{\mathrm{A}}+\left(\frac{\partial \mathrm{P}_{\mathrm{m}}}{\partial \omega}\right)_{\mathrm{OP}} \Delta \omega=\mathrm{P}_{\mathrm{mOP}}+\omega_{\mathrm{OP}} \Delta \mathrm{T}_{\mathrm{A}}+\mathrm{T}_{\mathrm{AOP}} \Delta \omega$ 
The transfer functions representing the relationships between the output $\omega(\mathrm{s})$ and the individual inputs $\Delta \mathrm{u}(\mathrm{s}), \omega_{\mathrm{ref}}(\mathrm{s})$ and $\omega_{\mathrm{OP}}(\mathrm{s})$ for the controller, the actuator and the rotor speed can be obtained. For each input-output analysis, it is assumed that all the other inputs are zero and since there are three inputs and one output, there will be three transfer functions, representing the relationships between the output and each of the inputs.

$$
\begin{aligned}
& \frac{\omega(\mathrm{s})}{\Delta \mathrm{u}(\mathrm{s})}=\frac{\alpha(1 / \mathrm{s}-\gamma)}{1-\mathrm{G}_{\mathrm{C}}(\mathrm{s}) \delta\left(\mathrm{k}_{\mathrm{A}} / \mathrm{s}+\mathrm{k}_{\mathrm{A}}\right)(1 / \mathrm{s}-\gamma)} \\
& \frac{\omega(\mathrm{s})}{\omega_{\mathrm{OP}}(\mathrm{s})}=\frac{1}{1-\mathrm{G}_{\mathrm{C}}(\mathrm{s}) \delta\left(\mathrm{k}_{\mathrm{A}} / \mathrm{s}+\mathrm{k}_{\mathrm{A}}\right)(1 / \mathrm{s}-\gamma)} \\
& \frac{\omega(\mathrm{s})}{\omega_{\mathrm{ref}}(\mathrm{s})}=-\frac{\mathrm{G}_{\mathrm{C}}(\mathrm{s}) \delta\left(\mathrm{k}_{\mathrm{A}} / \mathrm{s}+\mathrm{k}_{\mathrm{A}}\right)(1 / \mathrm{s}-\gamma)}{1-\mathrm{G}_{\mathrm{C}}(\mathrm{s}) \delta\left(\mathrm{k}_{\mathrm{A}} / \mathrm{s}+\mathrm{k}_{\mathrm{A}}\right)(1 / \mathrm{s}-\gamma)}
\end{aligned}
$$

The angular speed output $\omega(\mathrm{s})$ is the sum of the outputs for each of the inputs as shown in equation 3.19 .

$$
\begin{gathered}
\omega=\frac{\Delta \mathrm{u}(\mathrm{s}) \alpha\left(\frac{1}{\mathrm{~s}-\gamma}\right)}{1-\mathrm{G}_{\mathrm{C}}(\mathrm{s}) \delta\left(\frac{\mathrm{k}_{\mathrm{A}}}{\mathrm{s}+\mathrm{k}_{\mathrm{A}}}\right)\left(\frac{1}{\mathrm{~s}-\gamma}\right)}+\frac{\omega_{\mathrm{OP}}(\mathrm{s})}{1-\mathrm{G}_{\mathrm{C}}(\mathrm{s}) \delta\left(\frac{\mathrm{k}_{\mathrm{A}}}{\mathrm{s}+\mathrm{k}_{\mathrm{A}}}\right)\left(\frac{1}{\mathrm{~s}-\gamma}\right)} \\
-\frac{\omega_{\mathrm{ref}} \mathrm{G}_{\mathrm{C}}(\mathrm{s})\left(\frac{\mathrm{k}_{\mathrm{A}}}{\mathrm{s}+\mathrm{k}_{\mathrm{A}}}\right)\left(\frac{1}{\mathrm{~s}-\gamma}\right)}{1-\mathrm{G}_{\mathrm{C}}(\mathrm{s}) \delta\left(\frac{\mathrm{k}_{\mathrm{A}}}{\mathrm{s}+\mathrm{k}_{\mathrm{A}}}\right)\left(\frac{1}{\mathrm{~s}-\gamma}\right)}
\end{gathered}
$$

The characteristic equation, $\mathrm{CE}$ for the closed loop all the transfer functions is given in Equation 3.20.

$$
\mathrm{CE}=\mathrm{s}^{3}+\left(\mathrm{k}_{\mathrm{A}}-\gamma-\mathrm{k}_{\mathrm{A}} \mathrm{k}_{\mathrm{D}} \delta\right) \mathrm{s}^{2}+\left(-\mathrm{k}_{\mathrm{A}} \gamma-\mathrm{k}_{\mathrm{A}} \mathrm{k}_{\mathrm{P}} \delta\right) \mathrm{s}+\left(-\mathrm{k}_{\mathrm{A}} \mathrm{k}_{\mathrm{I}} \delta\right)
$$




\subsubsection{Wind Turbine Aerodynamic Data Specifications}

The complete $C_{p}(\lambda, \beta)$ data was not available for the Grumman Windstream-33 wind turbine. There were a few key data points relating $C_{p}, \lambda$, and $\beta$, which were enough to evaluate the wind turbine performance. The available data is given in Table 3.2 and it was obtained from the study that was conducted in [4]. Based on the available data, the linearized operating point was chosen to be $\beta_{\mathrm{OP}}=9^{\circ}, \lambda_{\mathrm{OP}}=7, \mathrm{u}_{\mathrm{OP}}=7.5 \mathrm{~ms}^{-1}$ and $\mathrm{C}_{\mathrm{pOP}}=$ 0.2. This operating point was chosen because is represents operation at relatively aerodynamically stable conditions. At the $\beta=3^{\circ}$, the wind turbine is operating at maximum $\mathrm{C}_{\mathrm{p}}$ but it is also close to stalling conditions $\left(\beta<3^{\circ}\right)$. Therefore the blade pitch angle is restricted for lower operational blade pitch angles. This would also restrict the control scheme. At $\beta=12^{\circ}$, the blade pitch angle so much that the wind turbine can no longer extract any power from the wind. Therefore the operating point was set at $\beta=9^{\circ}$.

Table 3.2: Aerodynamic Parameters for the Grumman Windstream-33 wind turbine

\begin{tabular}{|c|c|c|}
\hline \multirow{3}{*}{$\left(\beta=3^{\circ}\right)$} & $\mathrm{C}_{\mathrm{p}}=\mathrm{C}_{\mathrm{pmax}}$ & 0.42 \\
\cline { 2 - 3 } & $\lambda$ & 7 \\
\cline { 2 - 3 } & $\mathrm{u}$ & $7.5 \mathrm{~ms}^{-1}$ \\
\hline \multirow{3}{*}{$\left(\beta=9^{\circ}\right)$} & $\mathrm{C}_{\mathrm{p}}$ & 0.20 \\
\cline { 2 - 3 } & $\mathrm{C}_{\mathrm{pmax}}$ & 0.28 at $\lambda=5, \mathrm{u}=11 \mathrm{~ms}^{-1}$ \\
\cline { 2 - 3 } & $\lambda$ & 7 \\
\cline { 2 - 3 } & $\mathrm{u}$ & $7.5 \mathrm{~ms}^{-1}$ \\
\hline \multirow{3}{*}{$\left(\beta=12^{\circ}\right)$} & $\mathrm{C}_{\mathrm{p}}$ & 0 \\
\cline { 2 - 3 } & $\lambda$ & 7 \\
\cline { 2 - 3 } & $\mathrm{u}$ & $7.5 \mathrm{~ms}^{-1}$ \\
\hline
\end{tabular}


The coefficient of performance, $\mathrm{C}_{\mathrm{p}}$ was evaluated at the linearized wind turbine operation blade pitch angle, $\beta$, of $9^{\circ}$. The variation of the coefficient of performance with the tip speed ratio was obtained using the method outlined in Chapter 2.

Figures 3.7 and 3.8 show the variation of $C_{p}$ with wind speed, $u$, and tip speed ratio, $\lambda$, at the fixed pitch angle $\beta$ of $9^{\circ}$ for the Grumman Windstream-33 wind turbine based on the data in Table 3.2. In comparison with the variation of $\mathrm{C}_{\mathrm{p}}$ for other wind turbines [5,6,7], this method of approximation gave satisfactory results. Figure 3.9 shows the variation of the rotor mechanical power with wind speed, $u$, at the fixed pitch angle $\beta$ of $9^{\circ}$ for the same wind turbine. At a wind speed of $7.5 \mathrm{~ms}^{-1}$, which corresponds to a tip speed ratio of 7 , the coefficient of performance and the mechanical power are regulated.

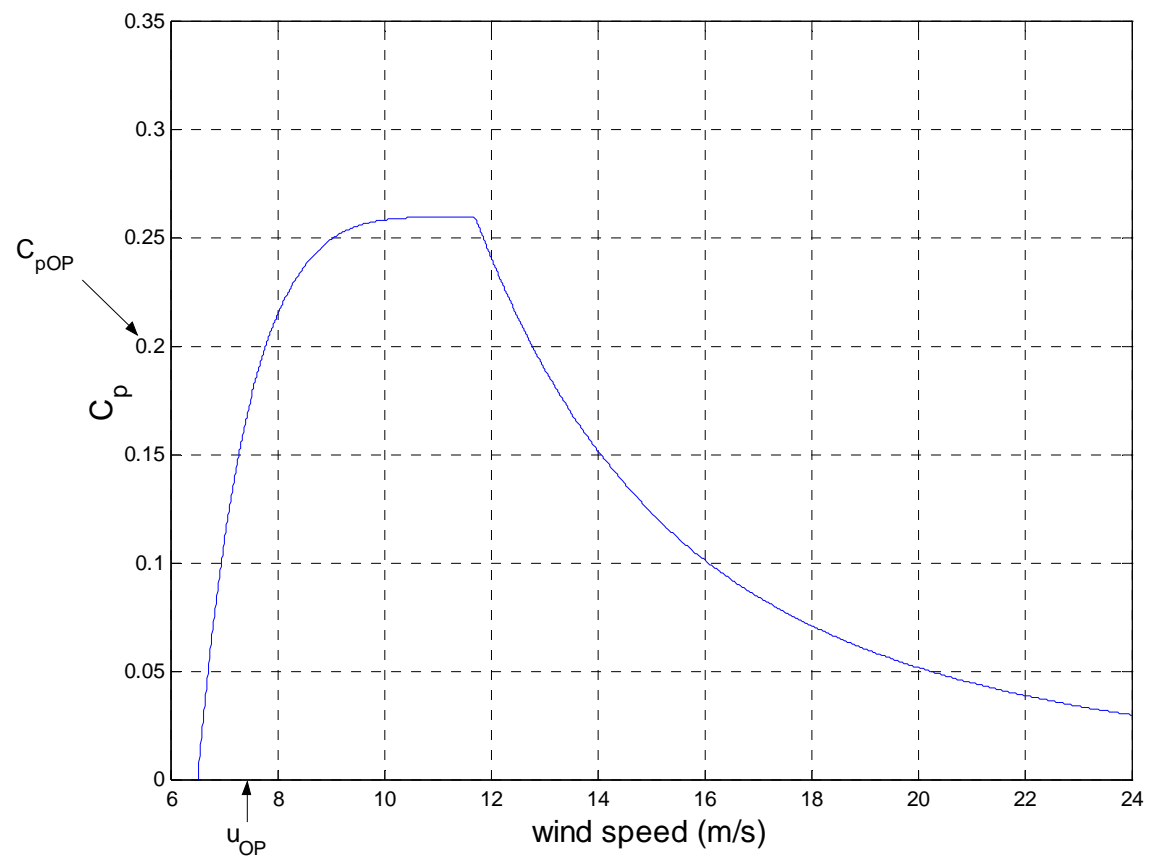

Figure 3.7: $\mathrm{Cp}$ vs $\mathrm{u}$ at fixed pitch angle $\beta$ of $9^{\circ}$ for the Grumman Windstream-33 


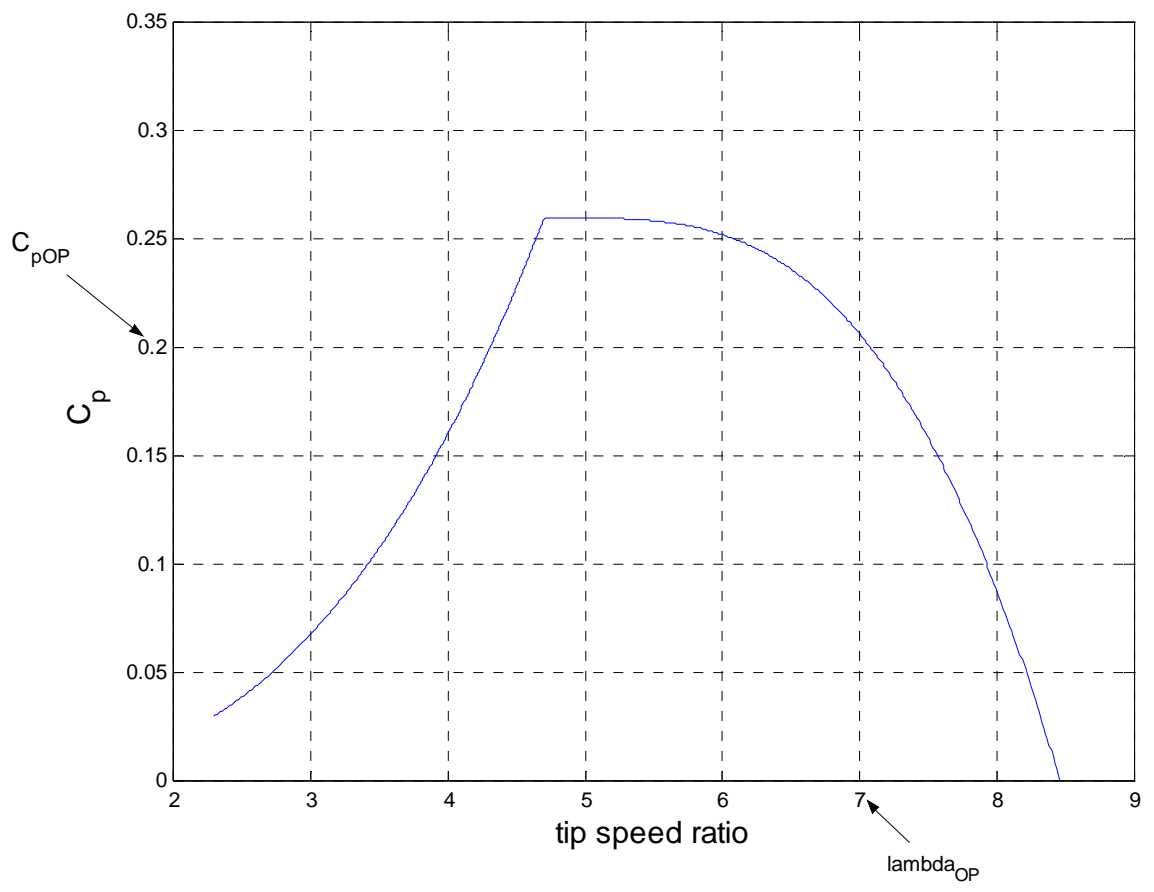

Figure 3.8: $\mathrm{Cp}$ vs $\lambda$ at fixed pitch angle $\beta$ of $9^{\circ}$ for the Grumman Windstream-33

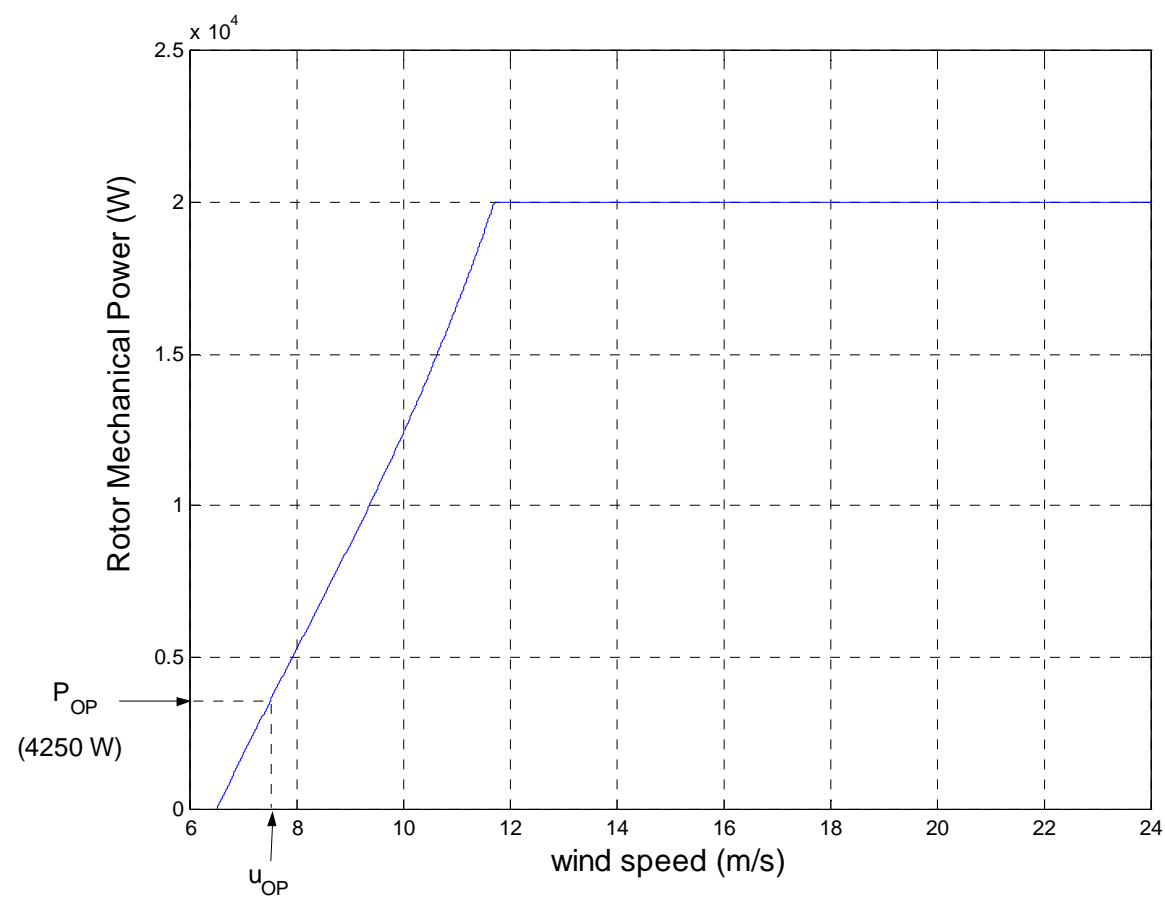

Figure 3.9: $\mathrm{P}_{\mathrm{m}} \mathrm{vs} \mathrm{u}$ at pitch angle $\beta$ of $9^{\circ}$ for the Grumman Windstream-33 wind turbine 
The profiles obtained from Figures 3.7 to 3.9 were all obtained from the approximation method presented in section 2.5. All the profiles are comparable to general wind systems as found in the references.

Figure 3.10 shows the variation of the coefficient of performance, $C_{p}$, with the pitch angle, $\beta$. This curve was derived from the three data points relating $C_{p}$ and $\beta$ (Table 3.2) by fitting a third-order polynomial.

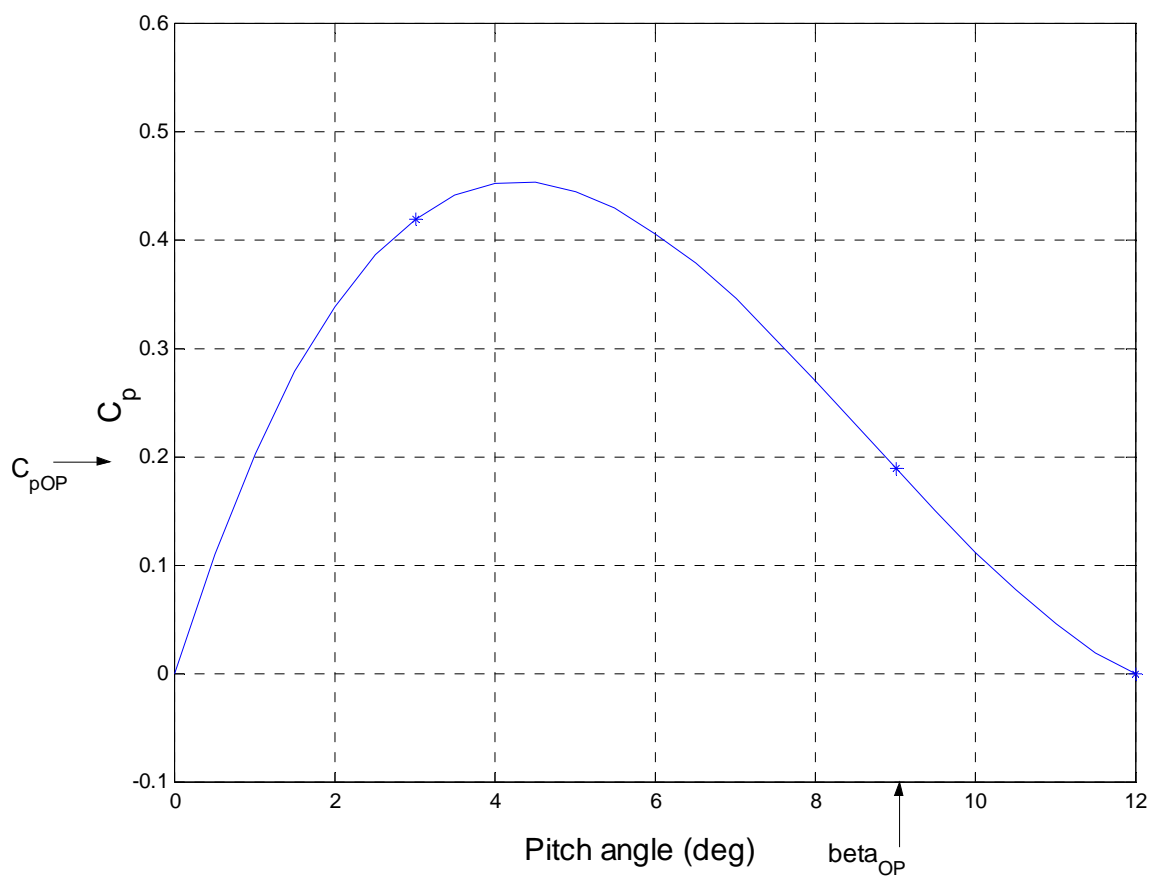

Figure 3.10: $\mathrm{Cp}$ vs $\beta$ at fixed tip speed ratio $\lambda$ of 7 for Grumman Windstream-33

The coefficient of performance as a function of the pitch angle was derived using the three $C_{p}(\beta)$ data points that were given at the operation (linearization) tip speed ratio of 7. A third-order polynomial was used to fit the data in order to derive the variation of the coefficient of performance, $C_{p}$, with the pitch angle, $\beta$. The constants at the operation point, the derived $C_{p}(\lambda, \beta)$ curves and the relation between $C_{p}$ and $C_{q}$ were used to 
calculate the wind turbine dynamic constants $\alpha, \delta$ and $\gamma$. Table 3.3 shows the values that were obtained for these parameters. The value of $\alpha$ is positive because any increase in the wind speed causes the rotor to accelerate. However, $\delta$ is negative because increasing the pitch angle leads to a decrease in the rotor speed. For the wind turbine plant to be stable, the value of $\gamma$ should be negative to make the pole of the wind turbine plant transfer function fall on the left hand side of the s-domain.

Table 3.3: Wind turbine linearization constants

\begin{tabular}{|c|c|}
\hline$\alpha$ & $0.117 \mathrm{~s}^{-2}$ \\
\hline$\delta$ & $-0.8582 \mathrm{~s}^{-2}$ \\
\hline$\gamma$ & $-0.0256 \mathrm{~s}^{-1}$ \\
\hline
\end{tabular}

It should be noted that linearization is valid only when the wind turbine is to be analyzed at near linearization conditions. At the specified operating points, all the wind turbine performance parameters fall on the derived $C_{p}(\lambda, \beta)$ curves. Therefore, the wind turbine dynamic model was fairly accurate for simulations at or near the operating conditions.

\subsubsection{Uncontrolled Plant Response}

After using the method outlined in section 2.5, the constant $\gamma$, which represents the wind turbine dynamics, was found to be $-0.0256 \mathrm{~s}^{-1}$. The transfer function, $\mathrm{G}_{\mathrm{P}}(\mathrm{s})$, of the uncontrolled turbine plant, is then given by Equation 3.21.

$\mathrm{G}_{\mathrm{P}}(\mathrm{s})=\frac{\Delta \omega(\mathrm{s})}{\alpha \Delta \mathrm{u}+\delta \Delta \beta}=\frac{\Delta \omega(\mathrm{s})}{\left(\Delta \mathrm{T}_{\mathrm{A}} / \mathrm{J}_{\mathrm{T}}\right)}=\frac{1}{\mathrm{~s}-\gamma}=\frac{1}{\mathrm{~s}+0.0256}$

Figure 3.11a shows the plot of the change in angular speed for a unit step in wind speed input for the uncontrolled wind turbine plant. The graph shows that for every unit step 
change in the wind speed in $\mathrm{ms}^{-1}$, there is a change of about 44 RPM in the angular speed, $\omega$. This value depends on the rotational inertia and the of the wind turbine. The rotational inertia for the Grumman Windstream-33 is $1270 \mathrm{~kg} \cdot \mathrm{m}^{2}$. Figure $3.11 \mathrm{~b}$ shows the plot of the change in angular speed for a unit step in pitch angle input for the uncontrolled wind turbine plant. For every unit step change in the pitch angle in degrees, there is a change of about -320 RPM in the angular speed, $\omega$.

It can be seen from Figures 3.11a and 3.11b that the wind speed and the pitch angle affect the wind turbine angular speed in different ways. The plant input representing the effect of the wind speed is the quantity $\alpha \Delta u$ which is positive for a positive step in the wind speed input. The quantity $\delta \Delta \beta$ is the plant input representing the effect of the pitch angle and this input is negative for a positive step in the pitch angle. The parameters $\alpha$ and $\delta$ are very important because they are scaling factors, which determine how much the wind speed and the pitch angle affect the wind turbine plant response, respectively. For the Grumman Windstream-33, the magnitude of $\alpha$ is less than that of $\delta$ which means that changes in the pitch angle carry more weight and have more effect on the wind turbine plant than the same amount of changes in the wind speed.

The parameter $\gamma$ represents the wind turbine aerodynamic characteristics and it does not affect the wind turbine plant inputs. 


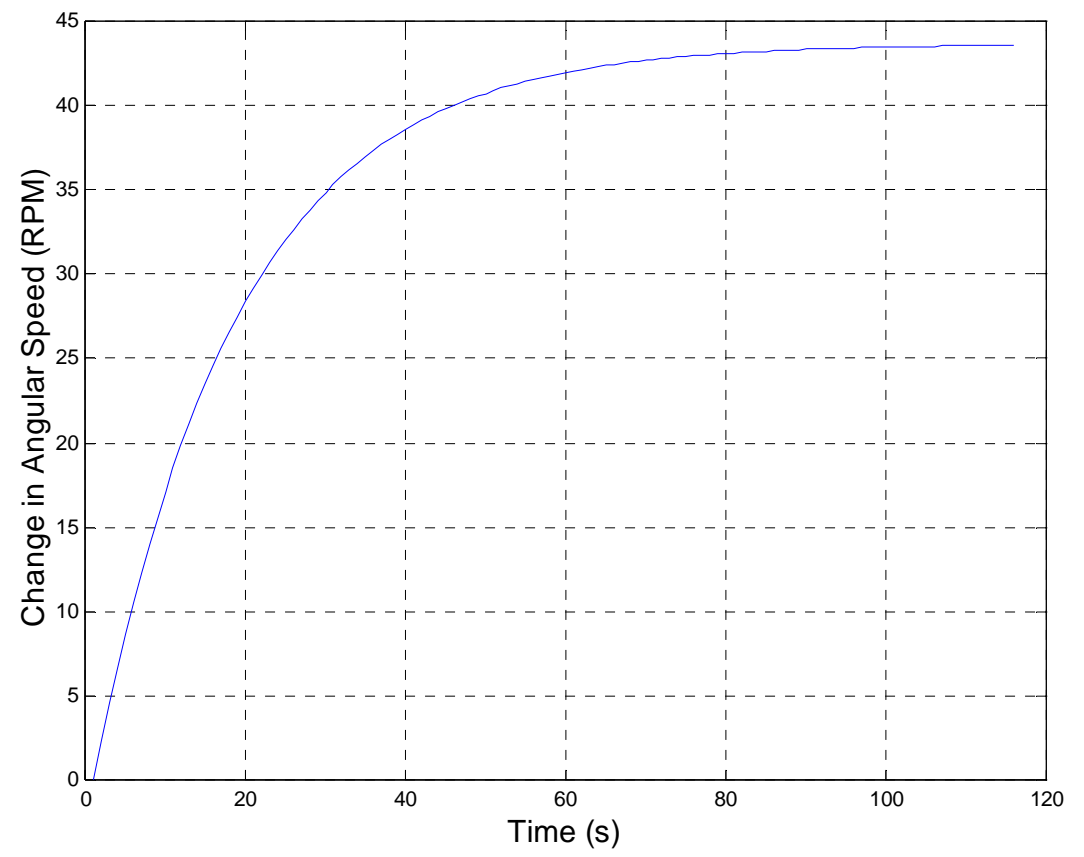

Figure 3.11a: Change in angular speed for a unit step in wind speed input

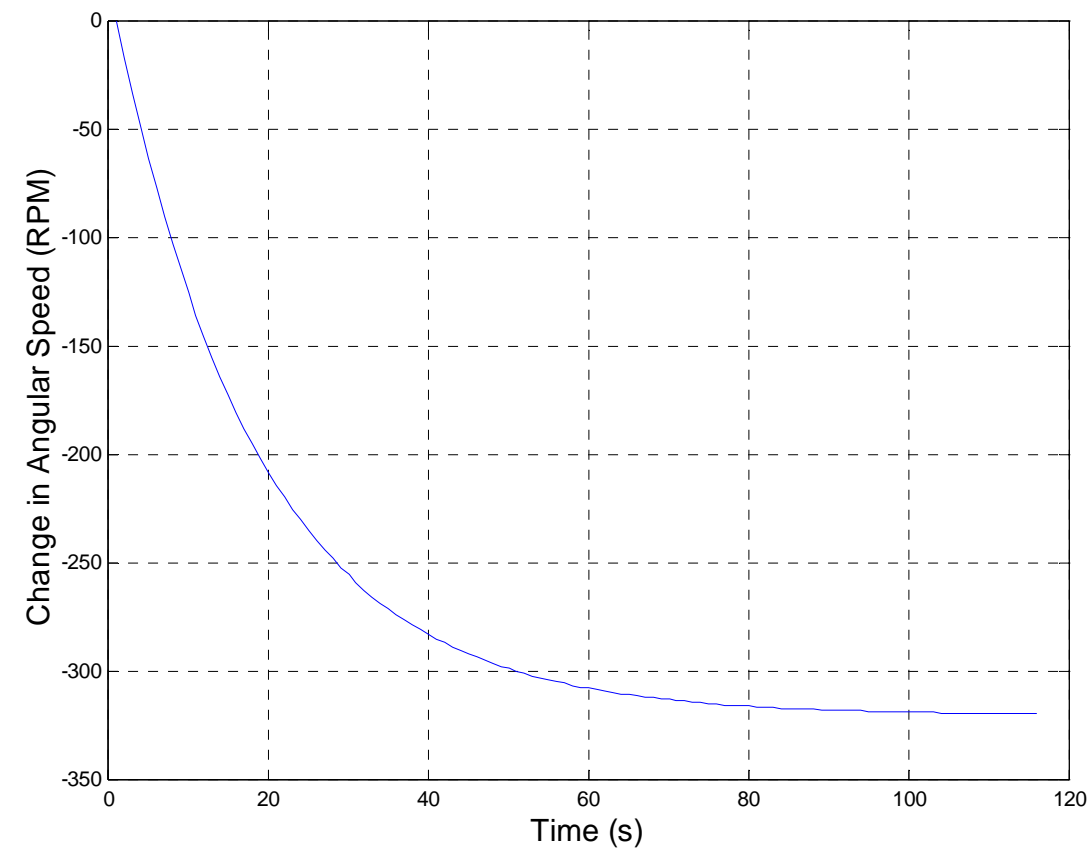

Figure 3.11b: Change in angular speed for a unit step in pitch angle input 


\subsubsection{Electric Generator Model}

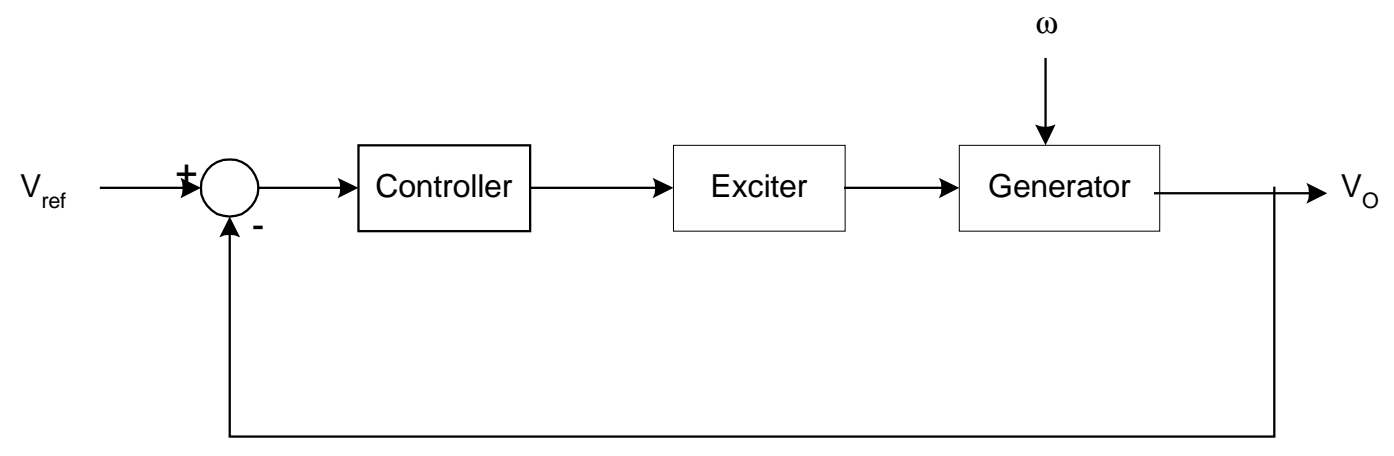

Figure 3.12: Block diagram of electric generator

Electric produced from wind power has motivated the need to study the dynamics and control of the electric generator whose block diagram is shown in Figure 3.12. It is a generator with three-phase ac voltage output. Field voltage is provided to the generator by means of a separate, smaller synchronous machine, called an exciter. The exciter is constructed with field winding on the stator and armature winding on the rotor; that makes it possible to rectify the exciter's armature ac voltages by a diode bridge, and connect the rectifier's output directly to the field winding of the generator.

The system shown in Figure 3.12 has to work in a closed-loop mode, where the generator output voltage, $V_{O}$, is determined by the reference input, $V_{\text {ref. }}$. Since the frequency of the output signal depends on the rotational speed of the generator shaft, the frequency will not be controlled at the generator. The rotational speed is already controlled at the drive train by means of a controller $\mathrm{G}_{\mathrm{C}}(\mathrm{s})$. Therefore, only the generator's output voltage will be controlled by adjusting the exciter's field voltage $v_{\mathrm{fd}}$ as outlined in Figure 2.13. 
In general, there are two approaches for electric machine modeling. One approach is the model in the natural frame, also called the abc model. The other approach is in the rotor reference frame, called qd model. The abc model has the advantage of using machine variables, and is easy to compare with the actual measurement. But the problem is that the inductances are time variant and the model is hard to use to explain the steady state performance. This is the main reason why the qd model is widely used in generator analysis.

In order to design the controller in Figure 3.12, it is necessary to have a good representing the generator's dynamic behavior. A three-phase, salient pole, wound field synchronous generator is characterized by relatively complex dynamics. In order to describe properly its electrical behavior, it is necessary to deal with at least a third-order system, which becomes fifth (or higher) order if there are damper windings present in the generator. These high-order models contain complete information about the generator's dynamics, but are often quite demanding to use, both from parameters identification and computational burden points of view. In particular, for the generator's control-loop design, it is a common practice to model a generator as a first-order system. For that simplification to be legitimate, two assumptions need to be true. First, the generator has to behave as a good voltage source; i.e., its synchronous impedance needs to be small. Second, the generator must operate at constant speed.

For the purpose of this research, the generator was modeled using the Power System Blockset in Simulink [33]. The equations describing the generator are given in Appendix $\mathrm{B}$ together with the definitions of all the parameters. In modeling the synchronous generator, the Matlab Power System Blockset has the mechanical power as 
its input. The voltage output is controlled through the excitation field voltage $\mathrm{v}_{\mathrm{fd}}$, which produced the magnetic flux that induces the emf on the coils. The synchronous generator block operates in generating or motoring modes. The operating mode is dictated by the sign of the mechanical power (positive for generating, negative for motoring). The electrical part of the machine is represented by a fifth-order model and it takes into account the dynamics of the stator, field, and damper windings. The equivalent circuit of the model is represented in the rotor reference frame (qd frame). All rotor parameters and electrical quantities are viewed from the stator. Figure 3.13 shows the general block diagram of the synchronous generator.

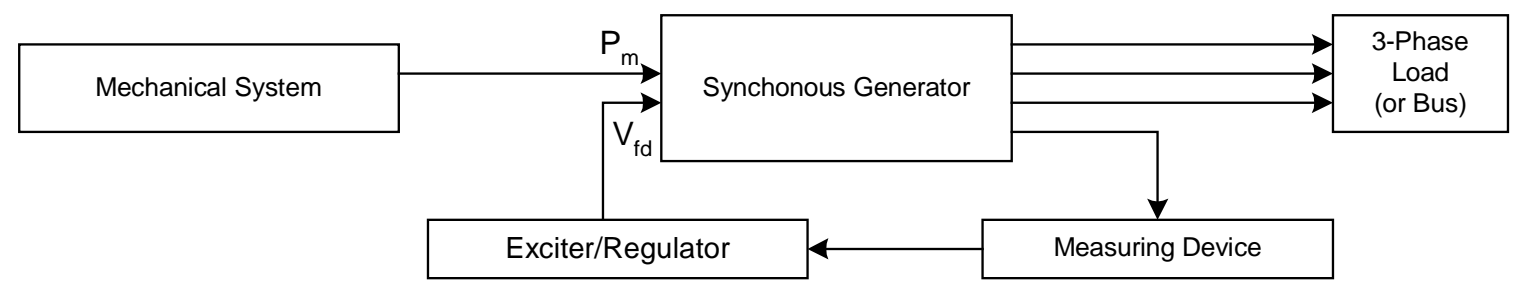

Figure 3.13: Block Diagram of Synchronous Generator system (using Matlab Power System Blockset)

This thesis focused more on the mechanical control of wind turbines. Also a lot of studies have been done in the modeling and control of synchronous generators $[2,13,15]$. Therefore, the existing generator models that are built within the Power System Blockset were used. This blockset allows the user to specify the physical and dynamic characteristics of the synchronous generator and the mechanical power input, $\mathrm{P}_{\mathrm{m}}$. It then outputs all the measurable parameters, namely:

- $\quad$ stator currents (flowing out of generator) $i_{\mathrm{sa}}, i_{\mathrm{sb}}$ and $i_{\mathrm{sc}}$

- $\quad \mathrm{q}$ and $\mathrm{d}$ axis stator currents (flowing out of generator) $\mathrm{i}_{\mathrm{q}}, \mathrm{i}_{\mathrm{d}}$ 
- Field and damper winding currents (flowing into generator) $i_{\mathrm{fd}}, \mathrm{i}_{\mathrm{kq}}$ and $\mathrm{i}_{\mathrm{kd}}$

- $\mathrm{q}$ and $\mathrm{d}$ axis mutual fluxes and stator voltages $\mathrm{v}_{\mathrm{q}}, \mathrm{v}_{\mathrm{d}}$

- Rotor electrical angle, $\theta$, Rotor speed, $\omega$ and Rotor speed deviation, $\mathrm{d} \omega$

- Electrical power, $\mathrm{P}_{\mathrm{e}}$

All these outputs are very important in assessing the electrical performance of a generator. They are used to determine the excitation voltage $\mathrm{v}_{\mathrm{fd}}$ which is used to control the generator.

For synchronous generators, one ordinarily specifies the desired terminal voltage and the electric power that one wants to generate (positive power for generator mode) or absorb (negative power for motor mode). This is possible as long as one has a bus that will generate or absorb the excess power required to balance the power throughout the grid. The bus can be either a voltage source or any synchronous generator.

The modeled synchronous generator was a $150 \mathrm{~kW}$ generator, which was extensively studied by Jadric [12]. The specific generator parameters are listed in Table 3.4.

Table 3.4: Synchronous generator Parameters

\begin{tabular}{|l|l|}
\hline$p$ & 6 poles \\
\hline $\mathrm{R}_{\mathrm{s}}$ & $0.137 \Omega$ \\
\hline $\mathrm{L}_{\mathrm{ls}}$ & $0.897 \mathrm{mH}$ \\
\hline $\mathrm{L}_{\mathrm{md}}$ & $43.2 \mathrm{mH}$ \\
\hline $\mathrm{R}_{\mathrm{fd}}$ & $0.0266 \Omega$ \\
\hline $\mathrm{L}_{\mathrm{lfd}}$ & $3.37 \mathrm{mH}$ \\
\hline $\mathrm{R}_{\mathrm{kd}}$ & $0.120 \Omega$ \\
\hline $\mathrm{L}_{\mathrm{lkd}}$ & $0.164 \mathrm{mH}$ \\
\hline $\mathrm{L}_{\mathrm{mq}}$ & $20.8 \mathrm{mH}$ \\
\hline $\mathrm{R}_{\mathrm{kq}}$ & $0.120 \Omega$ \\
\hline $\mathrm{L}_{\mathrm{lkq}}$ & $0.347 \mathrm{mH}$ \\
\hline
\end{tabular}




\section{Chapter 4: Controller Design}

\subsection{Introduction}

As utility-scale wind turbines have become more prominent, the PID controller has become the industry standard for blade-pitch control. This controller regulates the error, or difference between the measured input and the desired input. This error value along with its derivative and integral with respect to time provides a signal to the actuator(s), which affects the controlled plant. The PID controller is a linear, single-inputsingle-output controller limited to three gains. Often the three gains are determined based on intuition and experience. These values are determined through a variety of methods, one of which will be chosen and used.

In this chapter, the appropriate gains necessary for the required outputs will be determined. There will be two controllers for the wind turbine system. One controller will be for the wind turbine dynamics, to keep the rotational speed, hence the frequency, constant. The other controller will be for the electric generator, which will determine the voltage and power output from the system through the exciter.

As described in Section 3.2, the complete wind turbine system was broken down into two parts, the wind turbine and the electric generator. The turbine plant was the first to be analyzed and modeled. As seen in Section 3.2.2 and 3.2.3, all the transfer functions for the turbine plant $\mathrm{G}_{\mathrm{P}}(\mathrm{s})$, and its actuator, $\mathrm{G}_{\mathrm{A}}(\mathrm{s})$ and the controller, $\mathrm{G}_{\mathrm{C}}(\mathrm{s})$ were derived. The electric generator dynamics were modeled using the power system blockset in Matlab; hence, the transfer functions were not derived. However, the equations describing the generator dynamics are given in Appendix A. 


\subsection{Routh Analysis}

The transfer function that was obtained for the turbine plant dynamics is given in terms of the controller gains $\mathrm{k}_{\mathrm{P}}, \mathrm{k}_{\mathrm{I}}$ and $\mathrm{k}_{\mathrm{D}}$. The denominator of this equation is a thirdorder polynomial. The actuator gain, $\mathrm{k}_{\mathrm{A}}$ was chosen to be 2 , which means that the actual pitch rate will be twice the pitch rate required to correct the blade pitch in one time step. At the operating point, $\beta_{\mathrm{OP}}=9^{\circ} ; \lambda_{\mathrm{OP}}=7 ; \mathrm{u}_{\mathrm{OP}}=7.5 \mathrm{~ms}^{-1}$ and $\omega_{\mathrm{OP}}=11 \mathrm{rads}^{-1}, \gamma=-0.0256$ and $\delta=-0.858$. Note: $\gamma<0$ and $\delta<0$. To find the range of values for the constants to keep the system stable, the Routh analysis was performed. The table was set up as shown below.

Table 4.1: Routh Table

\begin{tabular}{|c|c|c|}
\hline $\mathrm{s}^{3}$ & 1 & $\left(-\mathrm{k}_{\mathrm{A}} \gamma-\mathrm{k}_{\mathrm{A}} \mathrm{k}_{\mathrm{P}} \delta\right)$ \\
\hline $\mathrm{s}^{2}$ & $\left(\mathrm{k}_{\mathrm{A}}-\gamma-\mathrm{k}_{\mathrm{A}} \mathrm{k}_{\mathrm{D}} \delta\right)$ & $\left(-\mathrm{k}_{\mathrm{A}} \mathrm{k}_{\mathrm{I}} \delta\right)$ \\
\hline $\mathrm{s}^{1}$ & $\frac{\left(\mathrm{k}_{\mathrm{A}}-\gamma-\mathrm{k}_{\mathrm{A}} \mathrm{k}_{\mathrm{D}} \delta\right)\left(-\mathrm{k}_{\mathrm{A}} \gamma-\mathrm{k}_{\mathrm{A}} \mathrm{k}_{\mathrm{P}} \delta\right)+\left(\mathrm{k}_{\mathrm{A}} \mathrm{k}_{\mathrm{I}} \delta\right)}{\left(\mathrm{k}_{\mathrm{A}}-\gamma-\mathrm{k}_{\mathrm{A}} \mathrm{k}_{\mathrm{D}} \delta\right)}$ & 0 \\
\hline $\mathrm{s}^{0}$ & $\left(-\mathrm{k}_{\mathrm{A}} \mathrm{k}_{\mathrm{I}} \delta\right)$ & 0 \\
\hline
\end{tabular}

For stability, each term in the first column of Table 4.1 must be positive and the coefficients in the denominator of the transfer function must also be positive. Thus,

$$
\begin{array}{lll}
\mathrm{s}^{2}: & \left(\mathrm{k}_{\mathrm{A}}-\gamma-\mathrm{k}_{\mathrm{A}} \mathrm{k}_{\mathrm{D}} \delta\right)>0 \Rightarrow \mathrm{k}_{\mathrm{A}}+|\gamma|+\mathrm{k}_{\mathrm{A}} \mathrm{k}_{\mathrm{D}}|\delta|>0 & \Rightarrow \mathrm{k}_{\mathrm{D}}>-1.1 \\
\mathrm{~s}^{1}: & \left(-\mathrm{k}_{\mathrm{A}} \gamma-\mathrm{k}_{\mathrm{A}} \mathrm{k}_{\mathrm{P}} \delta\right)>0 \Rightarrow \mathrm{k}_{\mathrm{A}}|\gamma| \mathrm{k}_{\mathrm{A}} \mathrm{k}_{\mathrm{P}}|\delta|>0 & \Rightarrow \mathrm{k}_{\mathrm{P}}>-0.029 \\
\mathrm{~s}^{1}: & \left(\mathrm{k}_{\mathrm{A}}-\gamma-\mathrm{k}_{\mathrm{A}} \mathrm{k}_{\mathrm{D}} \delta\right)\left(-\mathrm{k}_{\mathrm{A}} \gamma-\mathrm{k}_{\mathrm{A}} \mathrm{k}_{\mathrm{P}} \delta\right)>-\left(\mathrm{k}_{\mathrm{A}} \mathrm{k}_{\mathrm{I}} \delta\right) & \\
& \Rightarrow\left(\mathrm{k}_{\mathrm{A}}+|\gamma|+\mathrm{k}_{\mathrm{A}} \mathrm{k}_{\mathrm{D}}|\delta|\right)\left(\mathrm{k}_{\mathrm{A}}|\gamma|+\mathrm{k}_{\mathrm{A}} \mathrm{k}_{\mathrm{P}}|\delta|\right)>\left(\mathrm{k}_{\mathrm{A}} \mathrm{k}_{\mathrm{I}}|\delta|\right) & \\
& \Rightarrow\left(1.1+\mathrm{k}_{\mathrm{D}}\right)\left(0.029+\mathrm{k}_{\mathrm{P}}\right)>\mathrm{k}_{\mathrm{I}} & \\
\mathrm{s}^{0}: & \left(-\mathrm{k}_{\mathrm{A}} \mathrm{k}_{\mathrm{I}} \delta\right)>0 & \Rightarrow \mathrm{k}_{\mathrm{A}} \mathrm{k}_{\mathrm{I}}|\delta|>0
\end{array}
$$


The gains must be as follows in order to maintain stability: $\mathrm{k}_{\mathrm{P}}>-0.029$ deg.s. $\mathrm{rad}^{-1}, \mathrm{k}_{\mathrm{I}}>0$ deg.rad ${ }^{-1}, \mathrm{k}_{\mathrm{D}}>-1.1$ deg.s ${ }^{2} \operatorname{rad}^{-1}$, and $\left(1.1+\mathrm{k}_{\mathrm{D}}\right)\left(0.029+\mathrm{k}_{\mathrm{P}}\right)>\mathrm{k}_{\mathrm{I}}$. For this linear approximation of the wind turbine control system, stability can be maintained over a wide range of controller gain. The designer may now examine the system response to a unit step input in order to select values for each of the three controller gains.

\subsection{Controller design methodology}

Controller design has been centered mainly proportional-integral-derivative (PID) controllers, which are easily implemented in the field. Gain selection for these controllers has generally been a trial-and-error process relying on experience and intuition from the field control engineers. A systematic approach to gain selection provides visualization of the potential performance enhancements to the system control. This work presents a methodology for selecting gain values for a PID controller that regulates the rotor speed of a constant-speed wind turbine by adjusting the blade-pitch angle. The dynamic model used to describe the turbine and its operating environment has been discussed. A traditional approach to PID controller gain selection is presented. The traditional approach consists of linearizing the wind turbine model about an operating point. The response to a step input is examined, and the gains are altered until an appropriate system behavior is observed. This approach relies heavily on trial-and-error.

The power control regime is entered when the turbine reaches the design rotor speed for desired power production. Under this condition, the rotational speed is constrained to a specified desired value through blade-pitch angle control. Fluctuations in wind speed are accommodated to prevent large excursions from the desired rotational 
speed. Thus, the power production is also constrained to a relatively constant level. In addition to maintaining a constant rotational speed, the actuator movement must be restrained to prevent fatigue and overheating. The combination of maintaining a constant rotational speed and minimizing the actuator motion are the control objectives specified for the power control regime.

Selection of the operating point is critical to preserving aerodynamic stability in this wind turbine system. The rotational speed operating point, $\omega_{\mathrm{OP}}$, was selected to be the desired constant speed of the turbine, 105 RPM (11 rad/s). The blade-pitch angle and wind speed operating points were selected using the normal operating conditions for the Grumman Windstream-33 wind turbine, as given in Table 3.2. The maximum $C_{p}$ value over the entire surface occurs at a pitch angle of $\beta=9^{\circ}$ and a tip speed ratio of 7 . Using the constant rotational speed of $11 \mathrm{rads}^{-1}$, this tip speed ratio corresponds to a wind speed of $7.5 \mathrm{~ms}^{-1}$. At this point, the turbine would produce maximum power. However, slight deviation from this point toward negative pitch angles could result in stalled blades, which dramatically decreases the power produced. By changing the pitch angle to $9^{\circ}$, the magnitude of the power coefficient is reduced, but deviation around a tip-speed ratio of 7 could easily be tolerated. It is important to note that stalled blades can also occur in low tip-speed-ratio conditions.

A unit step function approximates an abrupt change in wind speed and was used by Kendall, et al. (1997) to tune a PI controller for a variable-speed wind turbine. Visual inspection of the rotor speed response and the pitch angle response may be used to determine the best combination of $\mathrm{k}_{\mathrm{P}}, \mathrm{k}_{\mathrm{I}}$ and $\mathrm{k}_{\mathrm{D}}$ gains to achieve appropriate damping of the system. However, when the third gain is introduced, this trial and error method 
becomes much more tedious and complicated. This method does not provide the control designer with a feel for the sensitivity of the controller to slight variations in the gain values, and a best possible range of gain values is not easily identified. Therefore a different PID tuning method will be used. Table 4.1 shows the statistics of the wind profile that was used to perform the simulations. Figure 4.1 shows the wind speed profile that was used as the input for the simulations. This figure represents a real wind speed profile courtesy of WindData [34]. From Figure 3.11a, the uncontrolled wing turbine has a time constant $\tau$ of 15 seconds; therefore the profile shown in Table 4.1 will allow the wind turbine to respond to the changes in the wind speed.

Table 4.2: Input wind profile statistics

\begin{tabular}{|c|c|}
\hline Mean value & $9.37 \mathrm{~ms}^{-1}$ \\
\hline Minimum value & $7.09 \mathrm{~ms}^{-1}$ \\
\hline Standard dev. & $1.02 \mathrm{~ms}^{-1}$ \\
\hline Maximum value & $10.92 \mathrm{~ms}^{-1}$ \\
\hline
\end{tabular}

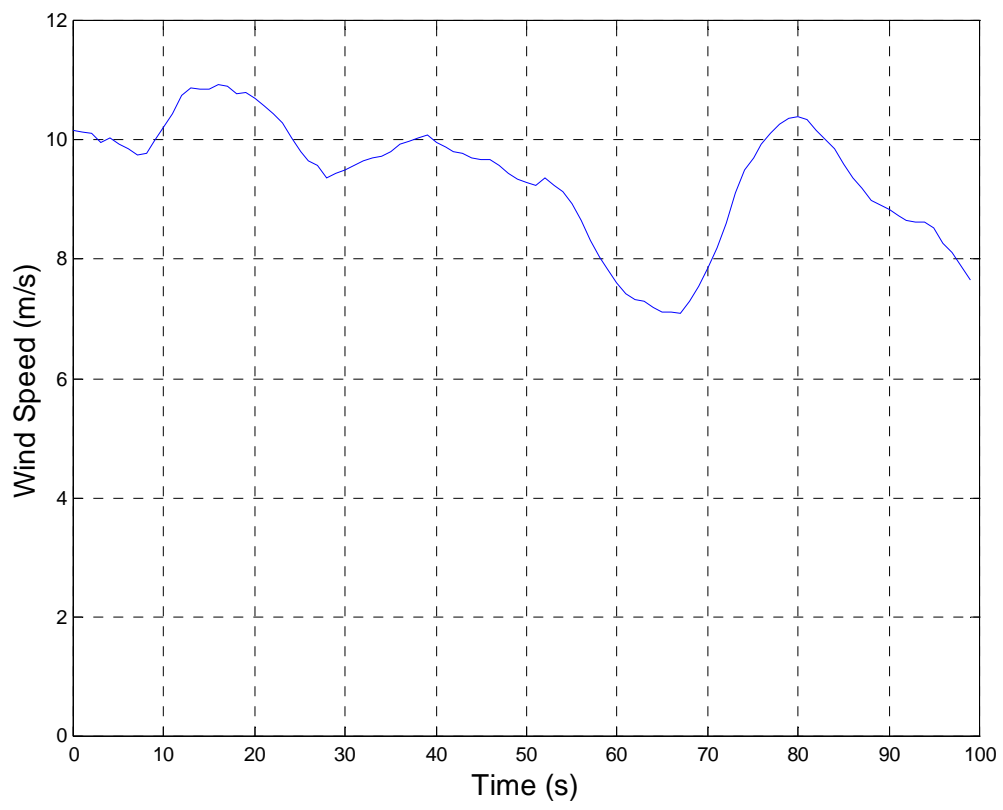

Figure 4.1: Wind speed profile 


\subsection{Controller Design: Gain Selection}

The main controller requirement is to compensate the wind speed deviations by changing the pitch angle, $\beta$, to keep the rotor angular speed, $\omega$, constant. A Matlab code was written in order to determine the best combination of the controller gains, $\mathrm{k}_{\mathrm{P}}, \mathrm{k}_{\mathrm{I}}$ and $\mathrm{k}_{\mathrm{D}}$. The design was based on the minimization of two parameters. The first parameter was the root mean square (RMS) of the error between the actual rotational speed and the desired rotational speed. The root mean square of the error indicates the capability of the controller to reject the wind speed fluctuations. The second parameter was the actuator duty cycle (ADC), which was proposed by Kendall, et al. (1997) as a measure of actuator motion during a simulation run. It is simply the total number of degrees the blades are pitched over the time period of the simulation. In order to prevent over-heating of the hydraulic fluid, this value must remain below a certain value provided by the manufacturer. This parameter is related to the economic cost of the controller. The higher the controller gains, the higher the $\mathrm{ADC}$ and the less economically attractive the controller. Therefore, minimization of the controller gains was used to keep the ADC as low as possible. For each simulation run, these two parameters were analyzed, and both were considered in determining acceptable operating conditions.

In order to systematically determine combinations of the three gains that produce acceptable operating conditions, the simulation was used repeatedly. Each of the gains was varied over a wide region, and the two minimization parameters were analyzed for each run. Contour plots for both parameters were created while the $\mathrm{k}_{\mathrm{P}}$ and $\mathrm{k}_{\mathrm{D}}$ gains were varied at a specific $k_{\mathrm{I}}$. This was done for a range of $\mathrm{k}_{\mathrm{I}}$ values from 1 to 12 . Trade-off studies between the series of surfaces were performed to determine the region where 
acceptable operating conditions existed. Lastly, time-series traces of rotational speed and pitch angle for gain combinations within this region were produced to verify acceptable operation.

Figures 4.2 to 4.5 depict surfaces for four different values of $\mathrm{k}_{\mathrm{I}}$. All of the contour plots indicate wide, flat surfaces for the RMS of the rotational speed error. These surfaces illustrate that a wide range of gain value combinations may be chosen with similar results. Thus, the controller is robust and relatively insensitive to changes in the values of the gains. However, choosing the most acceptable operating set points for the gains requires a closer examination of the surfaces.

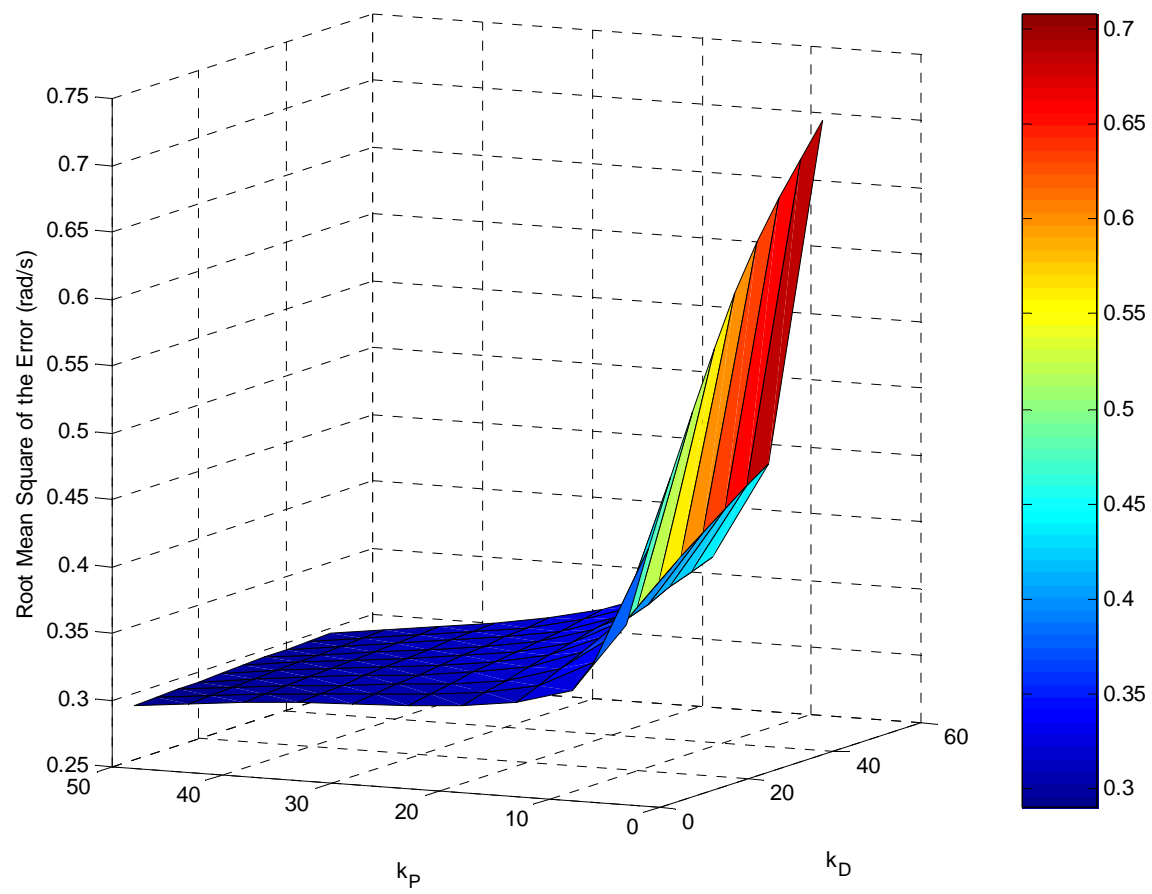

Figure 4.2a: Graph of $\mathrm{k}_{\mathrm{D}}, \mathrm{k}_{\mathrm{P}}$ versus the RMS of the angular speed error for $\mathrm{k}_{\mathrm{I}}=1$ 


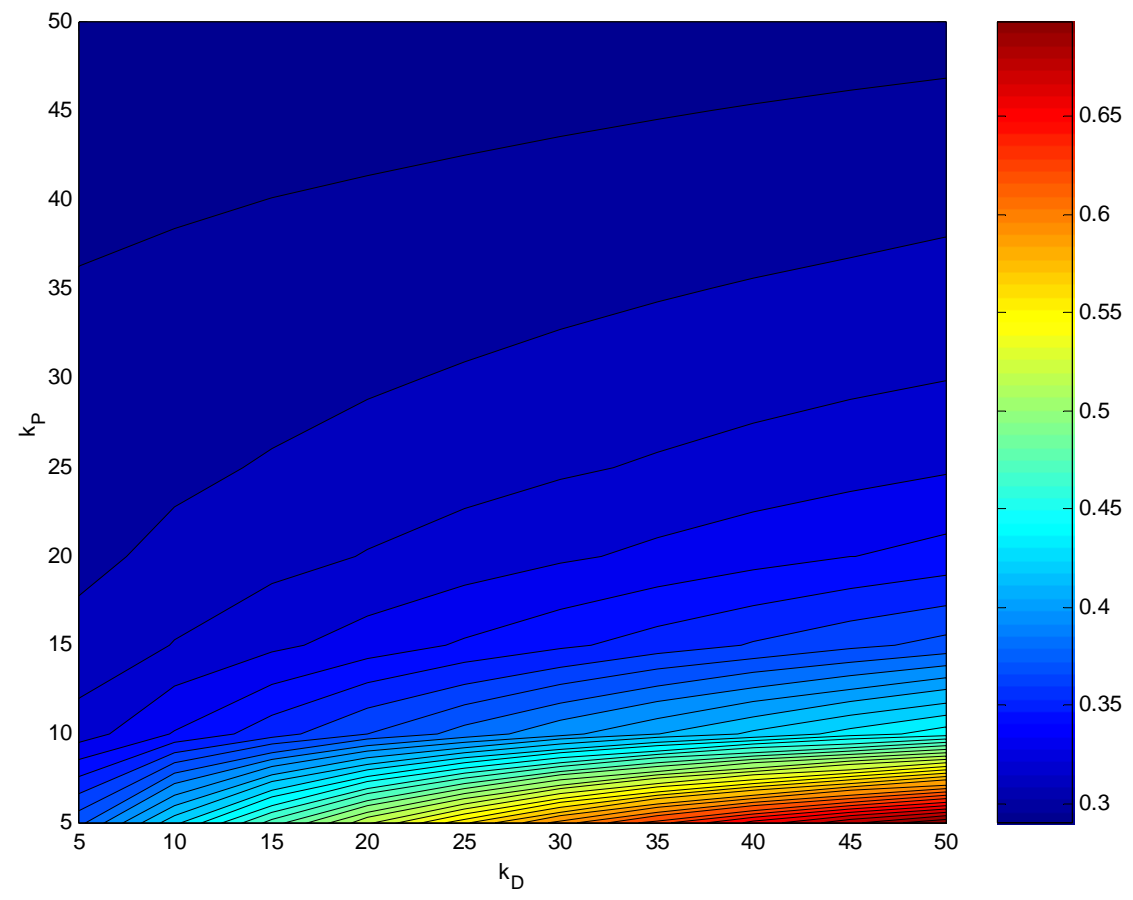

Figure 4.2b: Graph of $k_{D}, k_{P}$ versus RMS of angular speed error for $k_{I}=1$

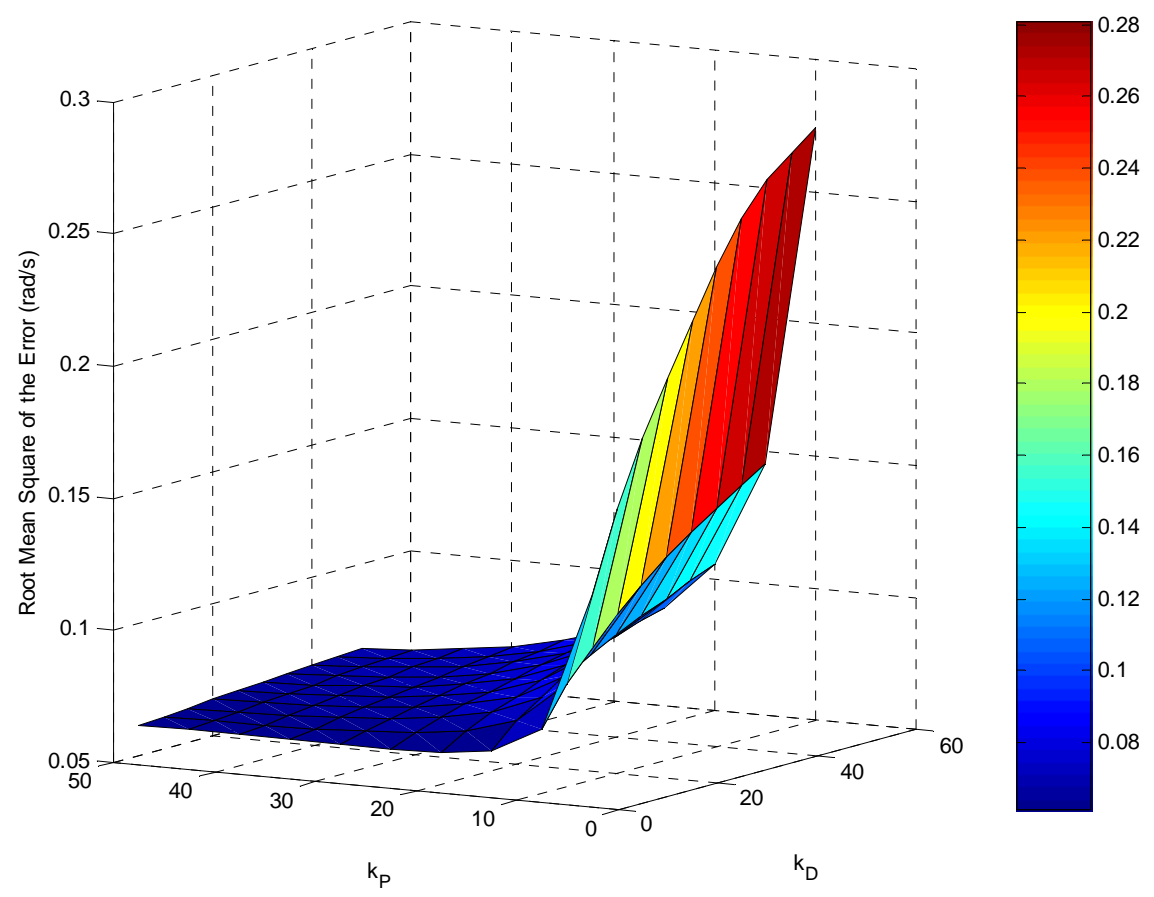

Figure 4.3a: Graph of $\mathrm{k}_{\mathrm{D}}$, $\mathrm{k}_{\mathrm{P}}$ versus RMS of angular speed error for $\mathrm{k}_{\mathrm{I}}=5$. 


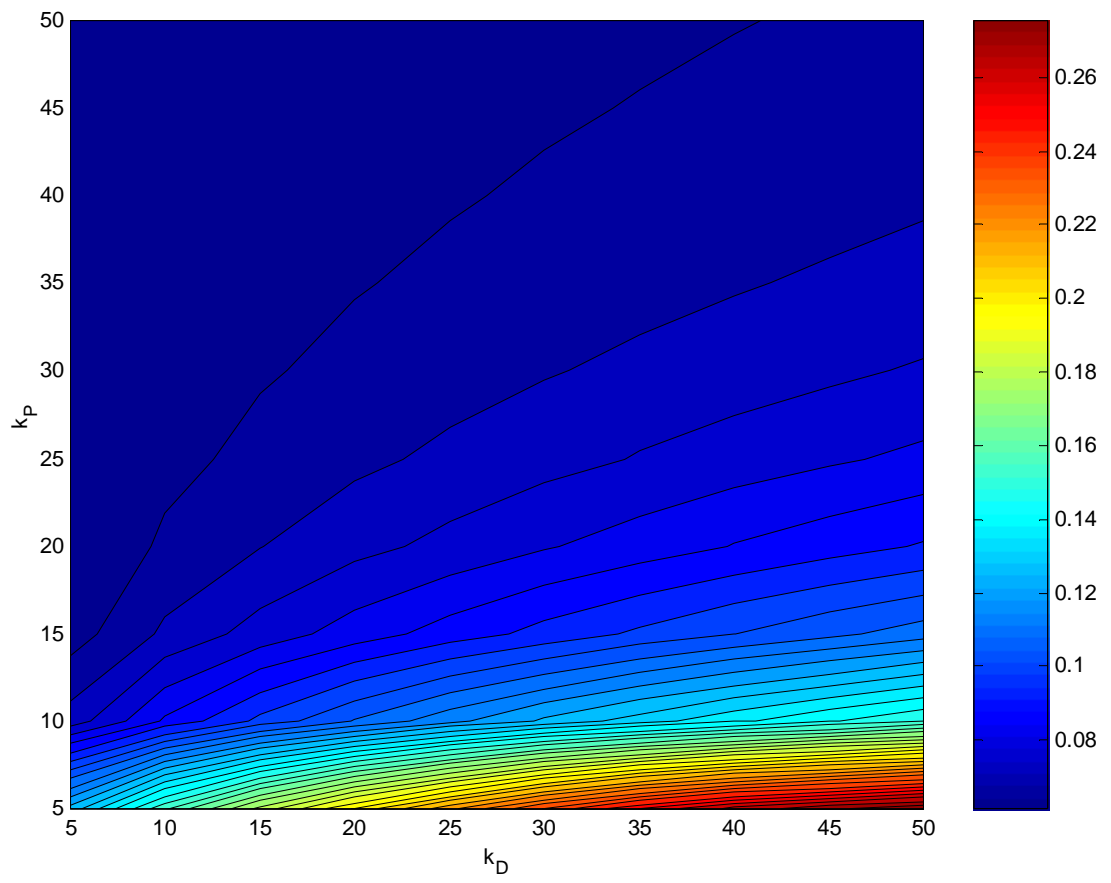

Figure 4.3b: Graph of $\mathrm{k}_{\mathrm{D}}$, $\mathrm{k}_{\mathrm{P}}$ versus RMS of angular speed error for $\mathrm{k}_{\mathrm{I}}=5$.

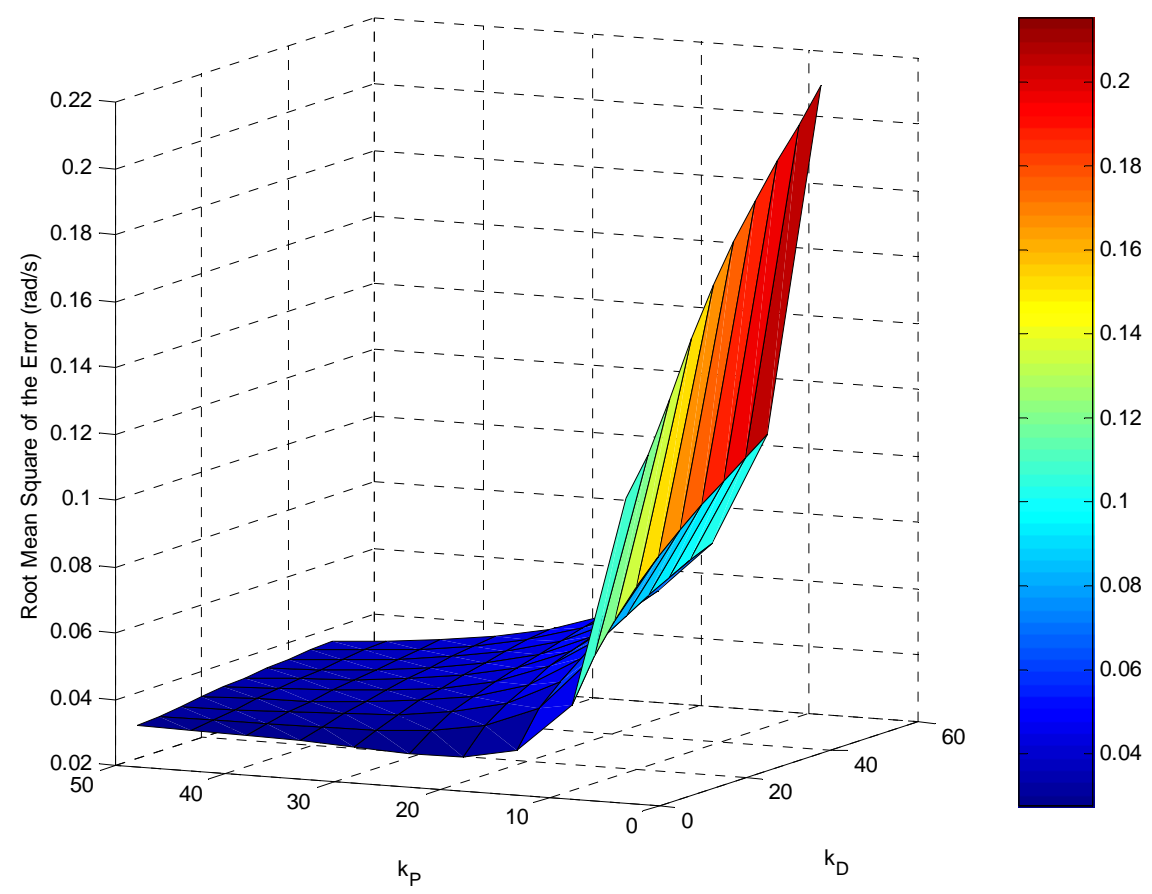

Figure 4.4a: Graph of $\mathrm{k}_{\mathrm{D}}, \mathrm{k}_{\mathrm{P}}$ versus RMS of angular speed error for $\mathrm{k}_{\mathrm{I}}=10$. 


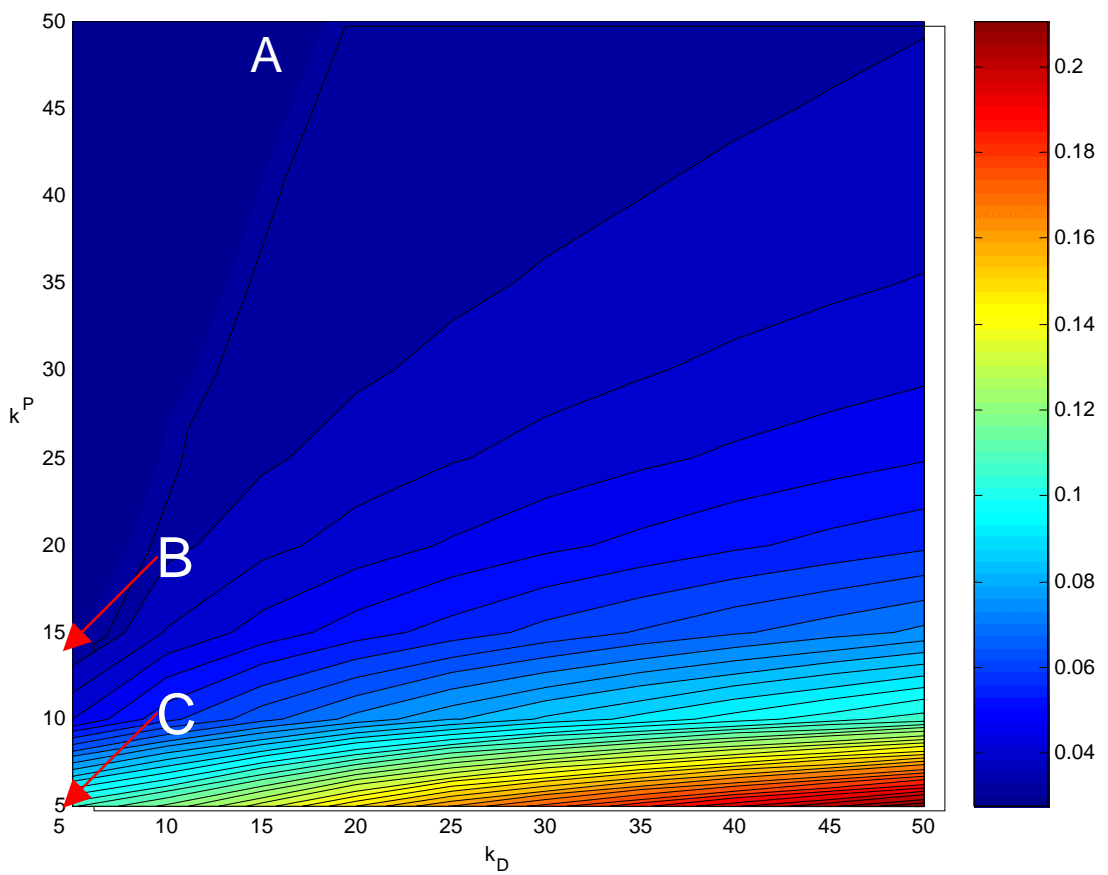

Figure 4.4b: Graph of $\mathrm{k}_{\mathrm{D}}$, $\mathrm{k}_{\mathrm{P}}$ versus RMS of angular speed error for $\mathrm{k}_{\mathrm{I}}=10$

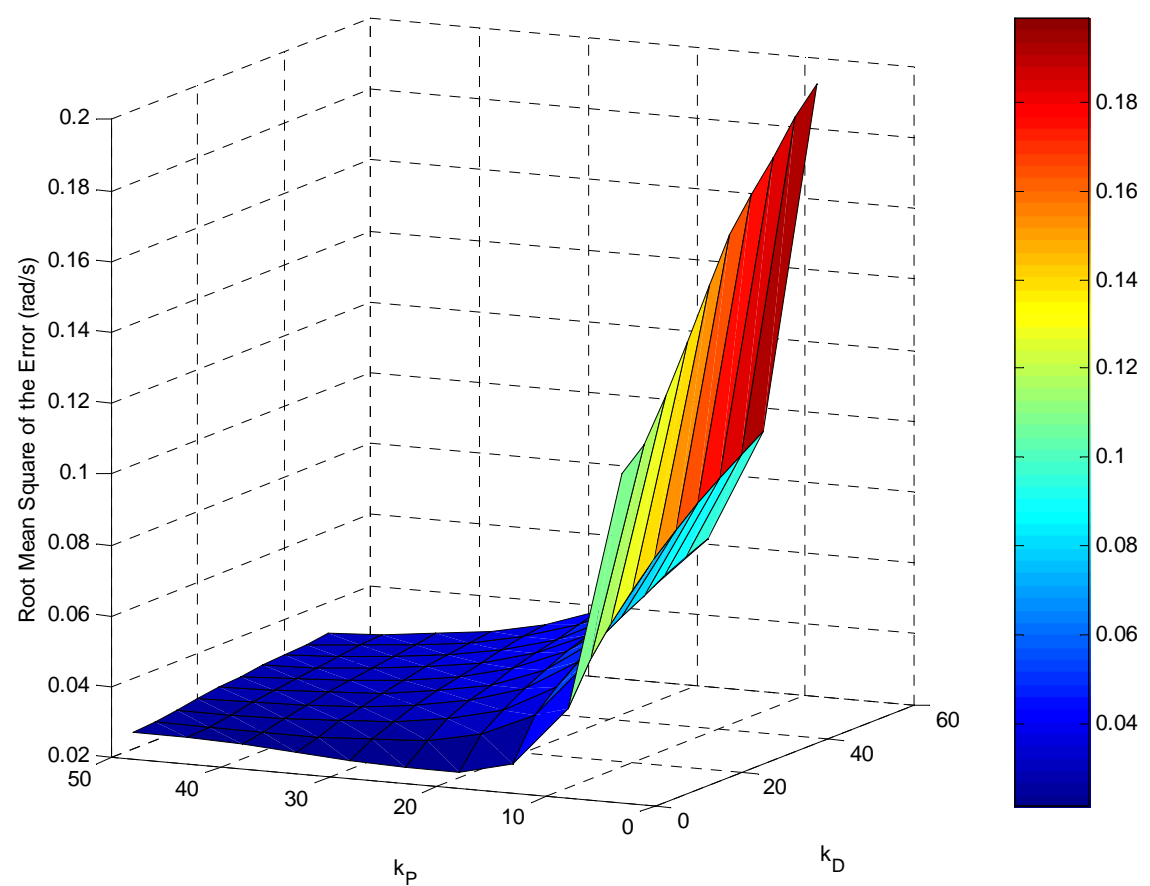

Figure 4.5a: Graph of $\mathrm{k}_{\mathrm{D}}$, $\mathrm{k}_{\mathrm{P}}$ versus RMS of angular speed error for $\mathrm{k}_{\mathrm{I}}=12$. 


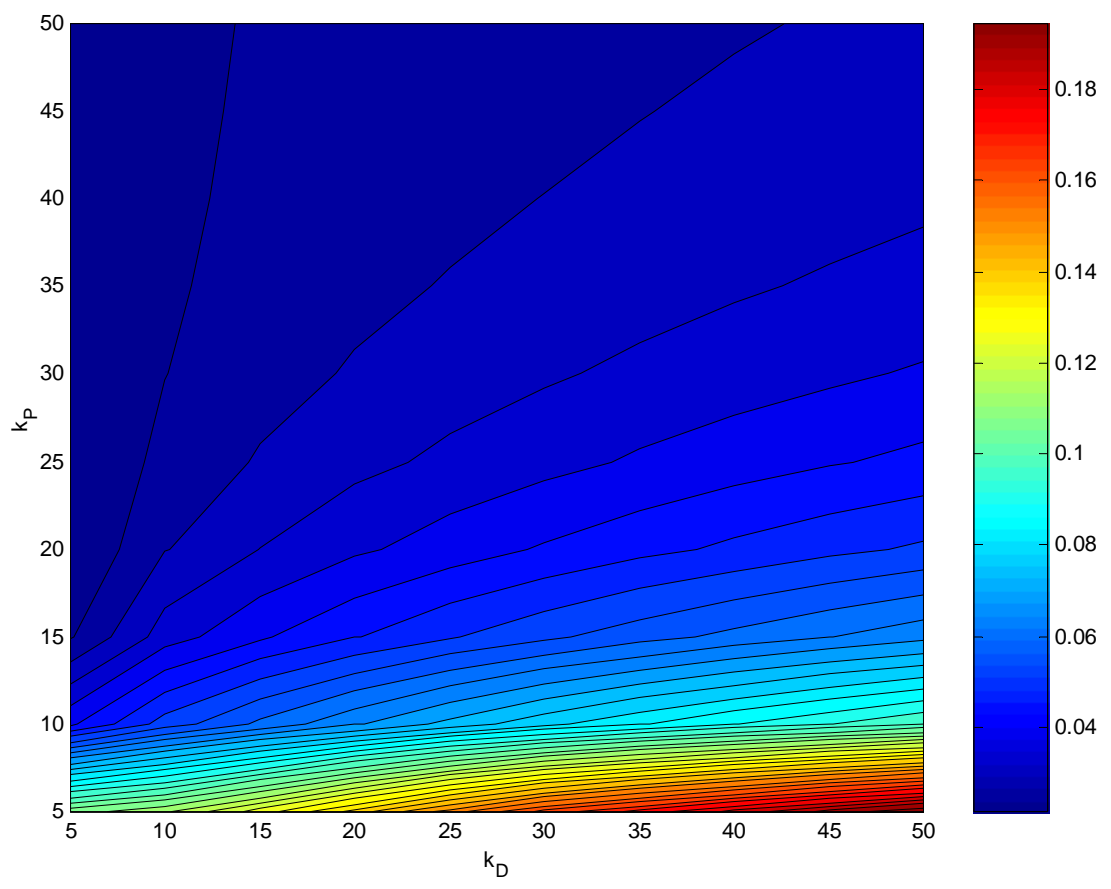

Figure 4.5b: Graph of $\mathrm{k}_{\mathrm{D}}$, $\mathrm{k}_{\mathrm{P}}$ versus RMS of angular speed error for $\mathrm{k}_{\mathrm{I}}=12$.

Figure $4.2 \mathrm{a}$ and $4.2 \mathrm{~b}$ indicate a sharply increasing slope in the RMS speed error for $\mathrm{k}_{\mathrm{P}}<10$. As the integral gain, $\mathrm{k}_{\mathrm{I}}$, increases from 1 to 5 in Figure $4.3 \mathrm{a}$ and $4.3 \mathrm{~b}$, this sharp slope boundary stays at $\mathrm{k}_{\mathrm{P}}=10$. Increasing the integral gain up to 12 , Figure $4.5 \mathrm{a}$ and 4.5b, still does not change the location of the boundary. The RMS speed error slowly decreases as $\mathrm{k}_{\mathrm{P}}$ increases such that the minimum value would occur beyond the range of the plot. However, as $\mathrm{k}_{\mathrm{P}}$ increases, the rate at which the error decreases becomes lower and therefore this puts a limit to the value of $\mathrm{k}_{\mathrm{P}}$ based on the benefit of decreasing the error versus the cost of the size of controller gain. As $\mathrm{k}_{\mathrm{I}}$ increases, mean RMS speed error decreases regardless of the values of $\mathrm{k}_{\mathrm{P}}$ and $\mathrm{k}_{\mathrm{D}}$. Thus, changing the value of $\mathrm{k}_{\mathrm{I}}$ alters the mean RMS of the error for all combinations of $\mathrm{k}_{\mathrm{P}}$ and $\mathrm{k}_{\mathrm{D}}$. The control gain $\mathrm{k}_{\mathrm{D}}$ barely 
influences the RMS of the speed error as seen from the relatively flat contours of $k_{P}$ vs RMS of the error, for each $\mathrm{k}_{\mathrm{I}}$ and $\mathrm{k}_{\mathrm{P}}$.

Both the RMS speed error and the size of the controller gains must be considered in choosing the best acceptable operating conditions. As the integral gain is increased from a value of 1 to 10 , the results become more favorable. Increasing $k_{\mathrm{I}}$ from 10 to 12 still reduces the error but the surface retains very similar characteristics. Therefore, in order to minimize the RMS speed error and at the same time minimizing the sizes of the gains, the integral gain was set at 10. This corresponds to an RMS speed error range of 0.04 to $0.06 \mathrm{rad} / \mathrm{s}$. An example of operation in the lowest RMS speed error range uses the operating condition at Point $\mathrm{A}\left(\mathrm{k}_{\mathrm{P}}=50, \mathrm{k}_{\mathrm{I}}=10, \mathrm{k}_{\mathrm{D}}=15\right)$ shown on Figure 4.4b. Because the RMS speed error slowly decreases as the proportional and derivative gains are increased, this point also indicates operation in the low end of the lowest RMS speed error contour.

The time-series traces of the rotor speed, the torque, the mechanical power and the pitch angle are presented in Figures 4.6a to 4.6d. The performance is shown for three different gain combinations shown in Figure 4.3b. These values are based on the value of $\mathrm{k}_{\mathrm{I}}=10$, that was chosen as the most preferred integral gain. The output power obtained from figure $4.6 \mathrm{c}$ is consistent with the power that corresponds to the operation wind speed $\left(\mathrm{u}=7.5 \mathrm{~ms}^{-1}\right)$ in Figure 3.10. 


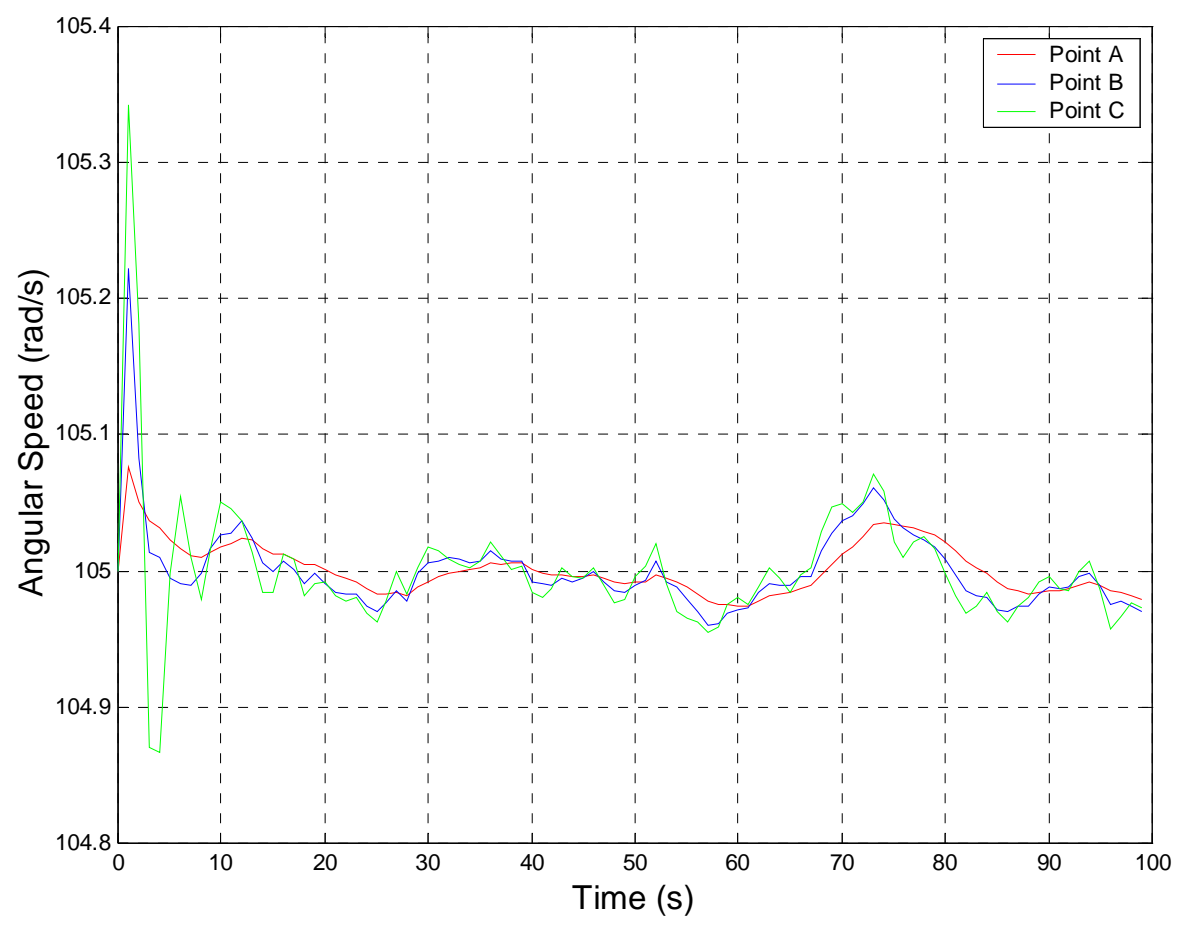

Figure 4.6a: Angular speed for three gain combinations

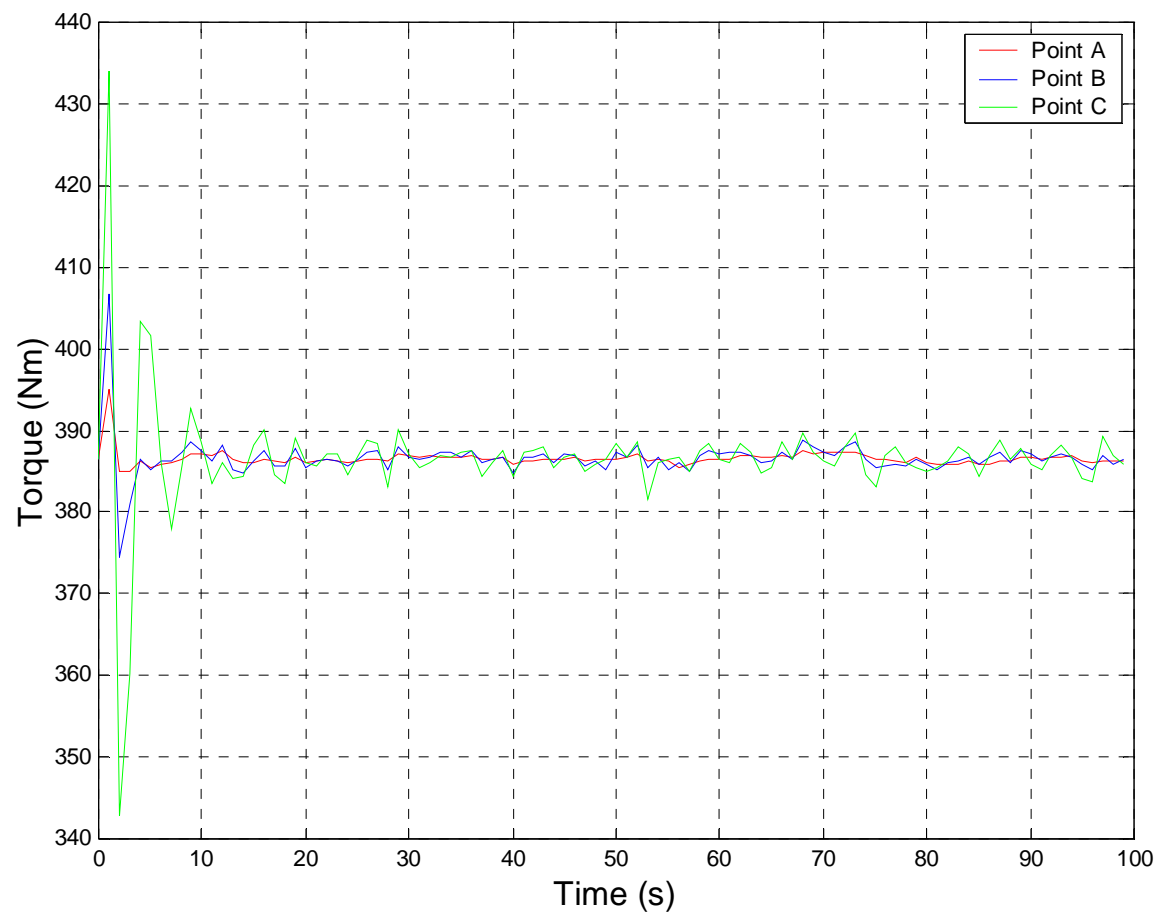

Figure 4.6b: Torque for three gain combinations 


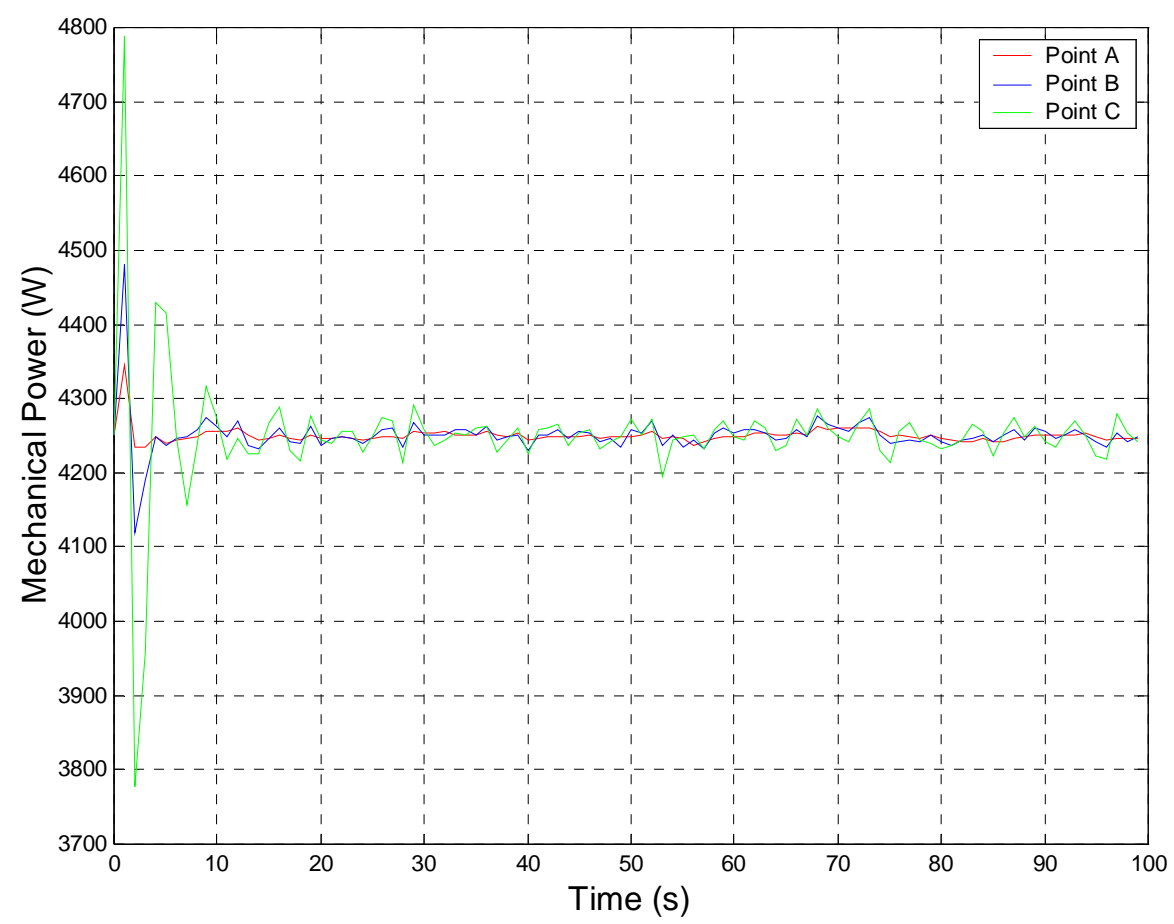

Figure 4.6c: Mechanical Power for three gain combinations

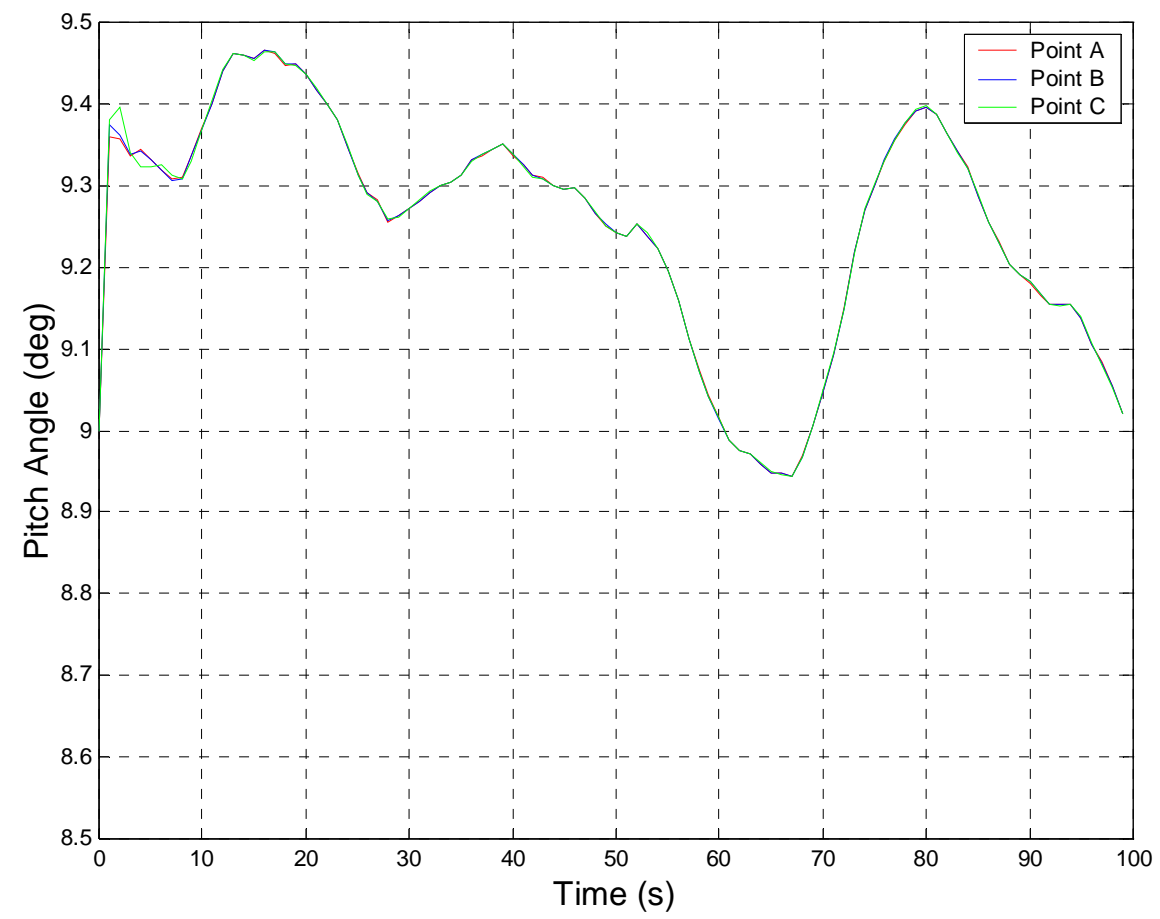

Figure 4.6d: Pitch angle for three gain combinations 
Operation at Point $\mathrm{C}\left(\mathrm{k}_{\mathrm{P}}=5, \mathrm{k}_{\mathrm{I}}=10, \mathrm{k}_{\mathrm{D}}=5\right)$ represents the trade-off between minimum controller gain values and a higher level of RMS speed error. The rotational speed deviation from the desired 105 RPM, shown in Figure 4.6a, is slightly greater than \pm 0.4 RPM. In this case the goal of maintaining constant rotational speed is not met satisfactorily.

Operation at Point A depicts the trade-off between minimum RMS speed error and a higher level of controller gains and the actuator duty cycle. The rotational speed deviation from the reference is less than $\pm 0.1 \mathrm{RPM}$. Also, the blade undergoes excessive motion at approximately in order to keep the speed constant. This type of motion is unacceptable when attempting to reduce fatigue and the potential for overheating. Also the very high controller gains are economically unattractive.

Point $\mathrm{B}\left(\mathrm{k}_{\mathrm{P}}=15, \mathrm{k}_{\mathrm{I}}=10, \mathrm{k}_{\mathrm{D}}=5\right)$ was chosen at the intersection of the minimum RMS speed error range and the lowest corresponding controller gain values. The rotational speed, the torque and the mechanical power obtained at this operating point are included in Figures $4.6 \mathrm{a}, 4.6 \mathrm{~b}$ and $4.6 \mathrm{~b}$. The rotational speed closely tracks the desired 105 RPM throughout the simulation with peak deviations of less than \pm 0.2 RPM. The actuator duty cycle is not as much as it is at point A. Operation within this region results in the most acceptable combination of the two performance metrics.

When using a traditional design methodology, the control engineer would subject the system to step inputs and examine the responses in order to adjust the gain values. For a constant-speed wind turbine, one would presume that the rotor speed response should be overdamped and have a short settling time in the order of less than 5 seconds. This means that the wind turbine should respond quickly to wind gusts, and the rotor speed 
should return to the desired speed without dropping below the stated value. The pitch angle response would also be expected to respond in an overdamped manner to reduce unnecessary motion as the speed returned to its constant value. Again, a quick response ( $<5$ seconds) seems appropriate.

From Figures 4.6a and 4.6c it can be seen that the percentage errors of the two output parameters, the angular speed $\omega$ and the mechanical power $P_{m}$ are different; the angular velocity error is less than that of the power. This is because the mechanical power $\mathrm{P}_{\mathrm{m}}$ is the product of the torque $\mathrm{T}_{\mathrm{A}}$ and the angular speed $\omega$ as given in Equation 3.15. Although the angular speed does not vary much, the torque varies significantly and this affects the variation of the mechanical power. This makes the mechanical power percentage error comparable to the torque percentage error.

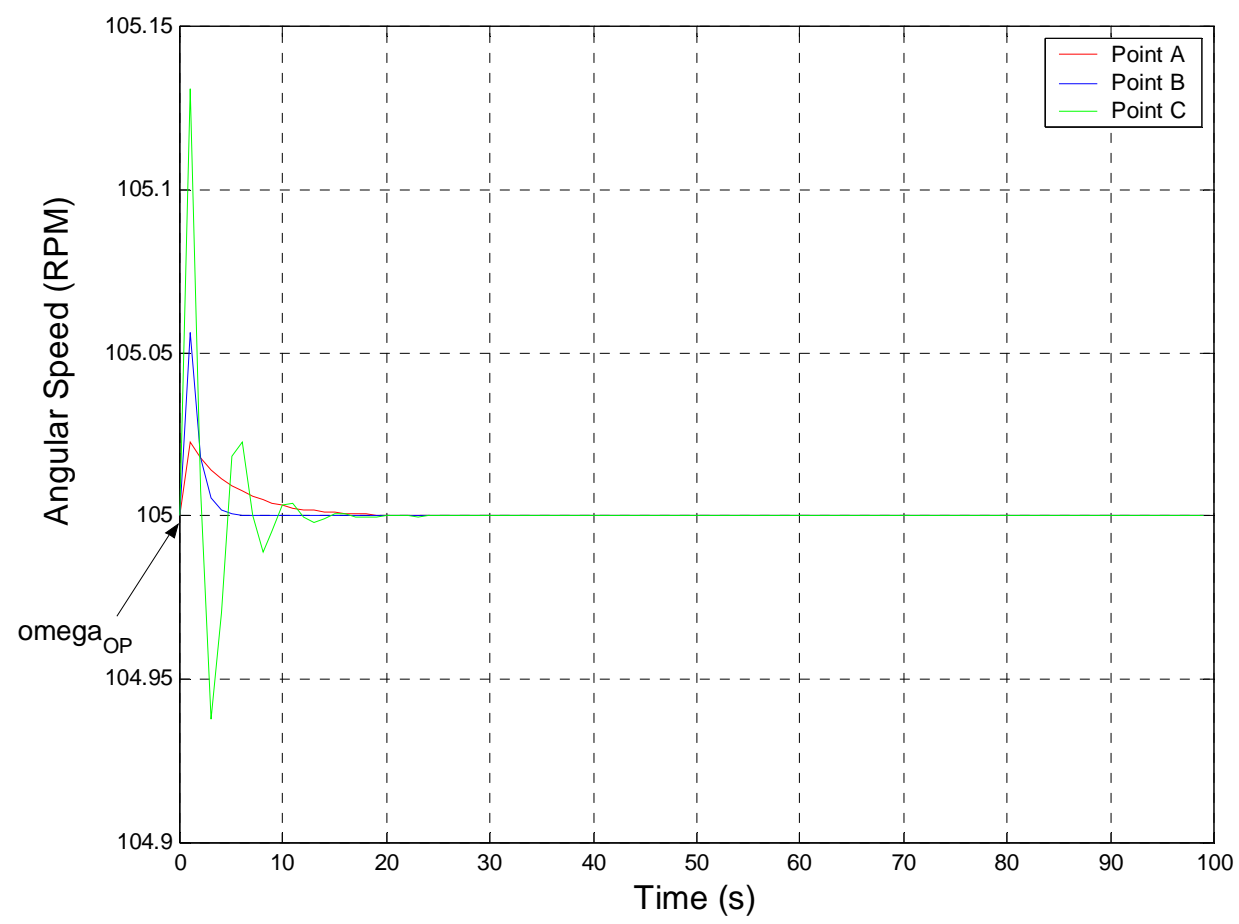

Figure 4.7a: Angular speed response to unit step in wind speed for controlled turbine 


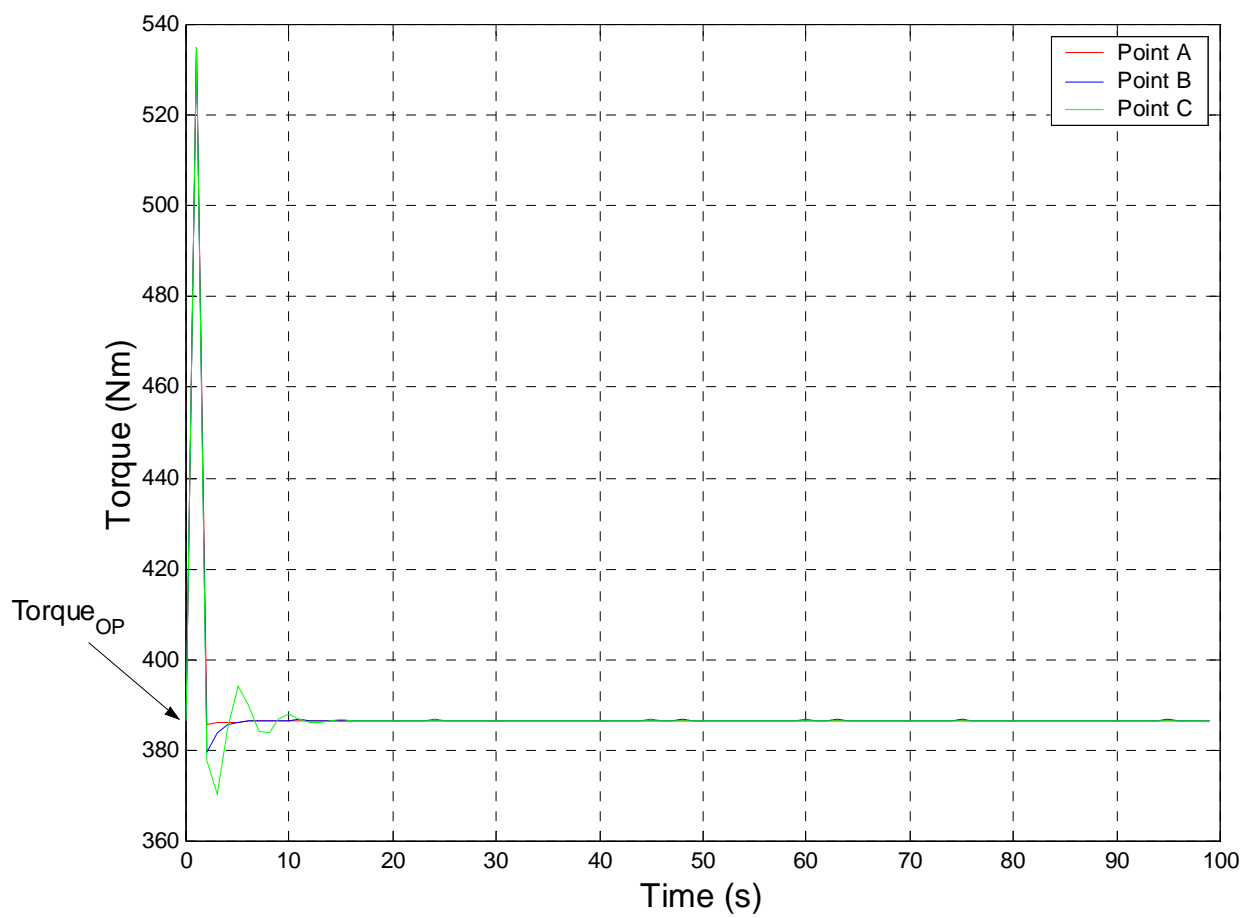

Figure 4.7b: Torque response to unit step in wind speed for controlled turbine

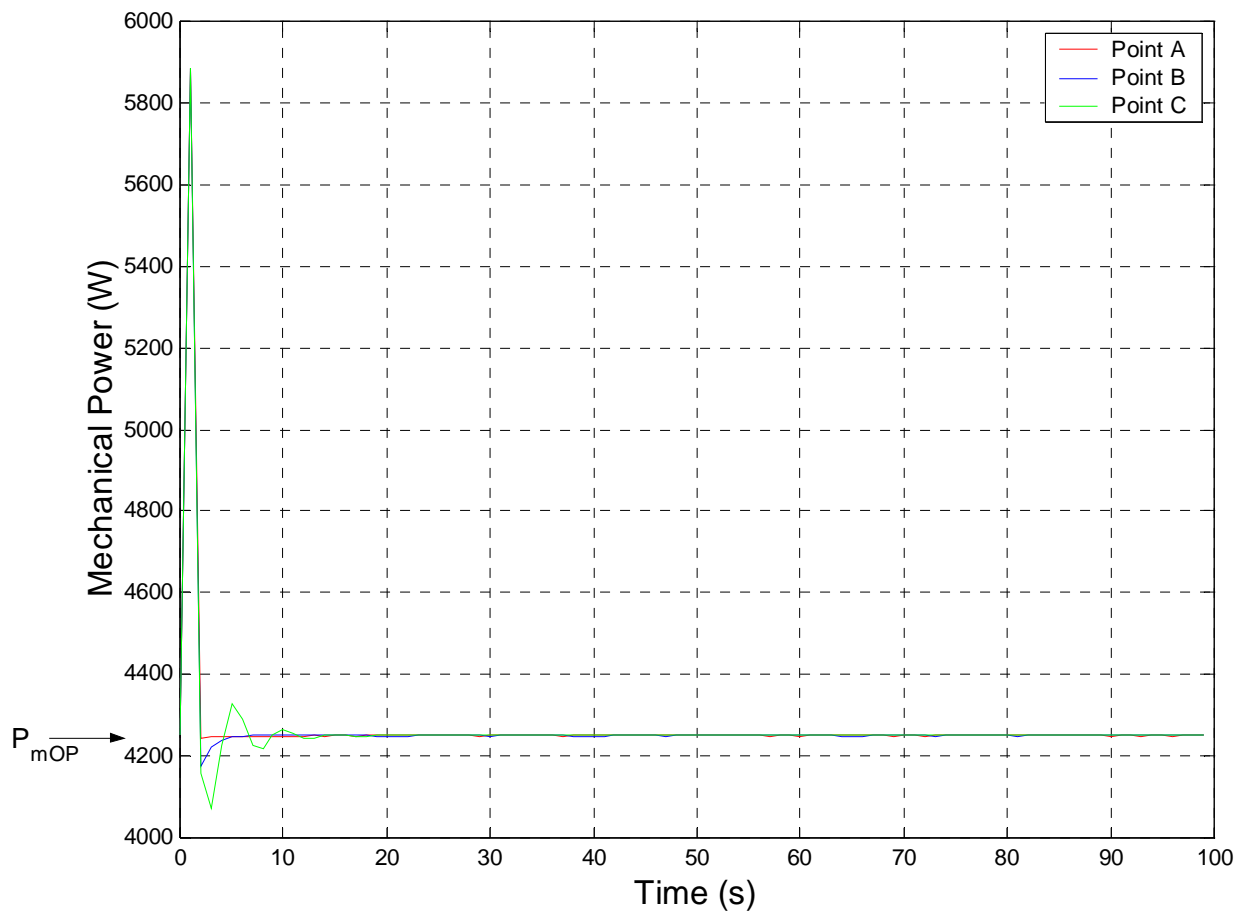

Figure 4.7c: Mechanical power response to unit step in wind speed for controlled turbine 


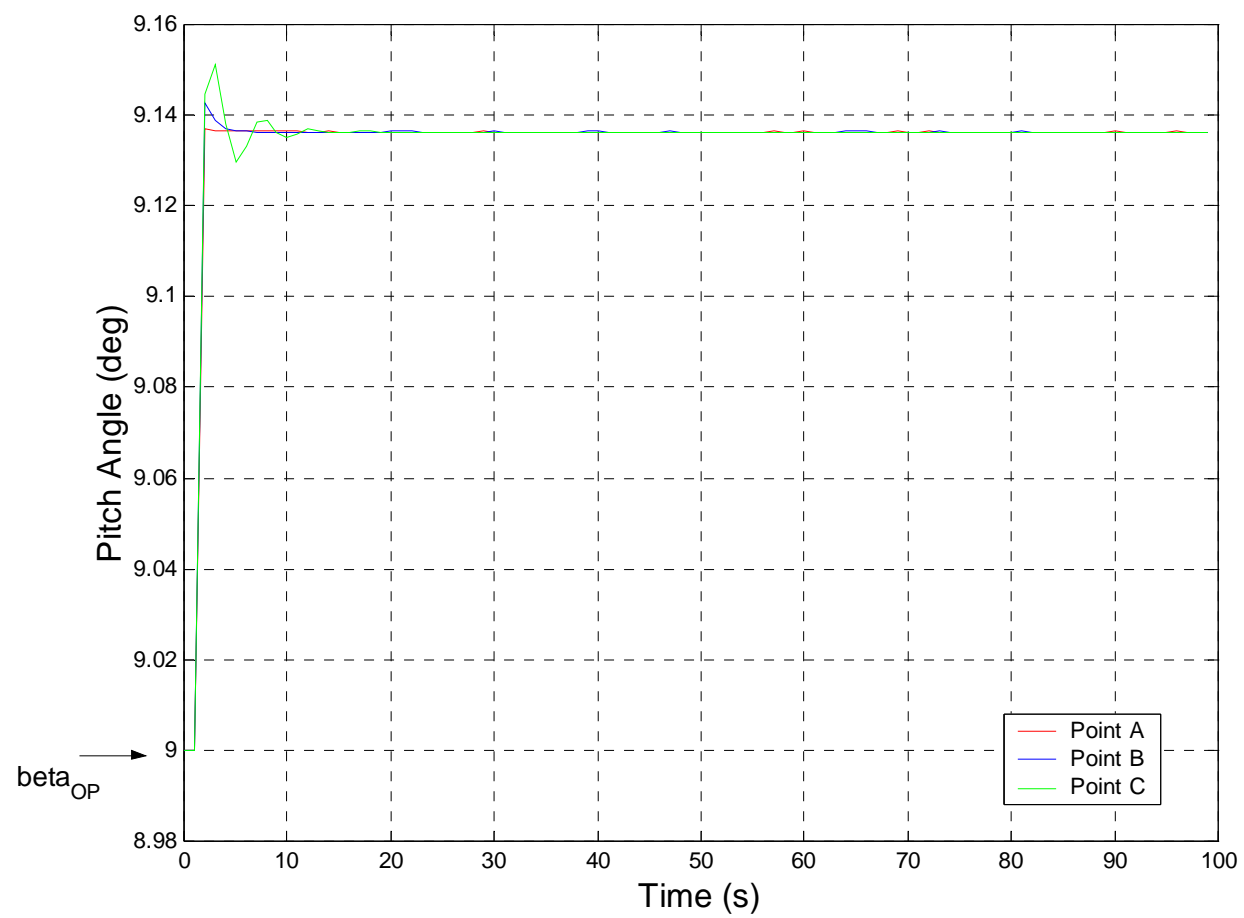

Figure 4.7d: Pitch angle response to unit step in wind speed for controlled turbine

The linear turbine model was subjected to wind gusts simulated with unit step inputs while the gain values reflected those of each of three points selected above. The rotor speed, torque, power and blade pitch angle responses are shown in Figure 4.7a, 4.7b, 4.7c and 4.7d. At Point $\mathrm{C}$, the lowest gain region, the rotor response is underdamped, dropping below the constant speed while the response is overdamped, as suspected, at Point B. The long settling time evident in the rotor speed response for very low gain values is unacceptable. The time required to return to a constant speed is about 5 seconds when the gains were in Point B and this was consistent with the desired value. For Point A, the overshoot is reduced considerably but the settling time is still unacceptable. However, because the wind actually behaves as a persistent disturbance, 
instead of a single step, the traditional view of PID controller performance might be slightly different from reality.

The systematic approach presented herein relies heavily on the two specific minimization parameters that were selected for this particular application. Servomechanical actuators could easily replace the hydraulic actuators that were simulated for this study. In this case, the actuator duty cycle metric would not apply. However, servomotors are also susceptible to over-heating. Constant acceleration of the motor draws current, which could lead to heat build-up if the blade-pitch angle is not regulated.

The reference angular rotation was made to vary throughout the simulation and the output angular speed was observed using the same controller. Figure 4.8 shows the response that was obtained.

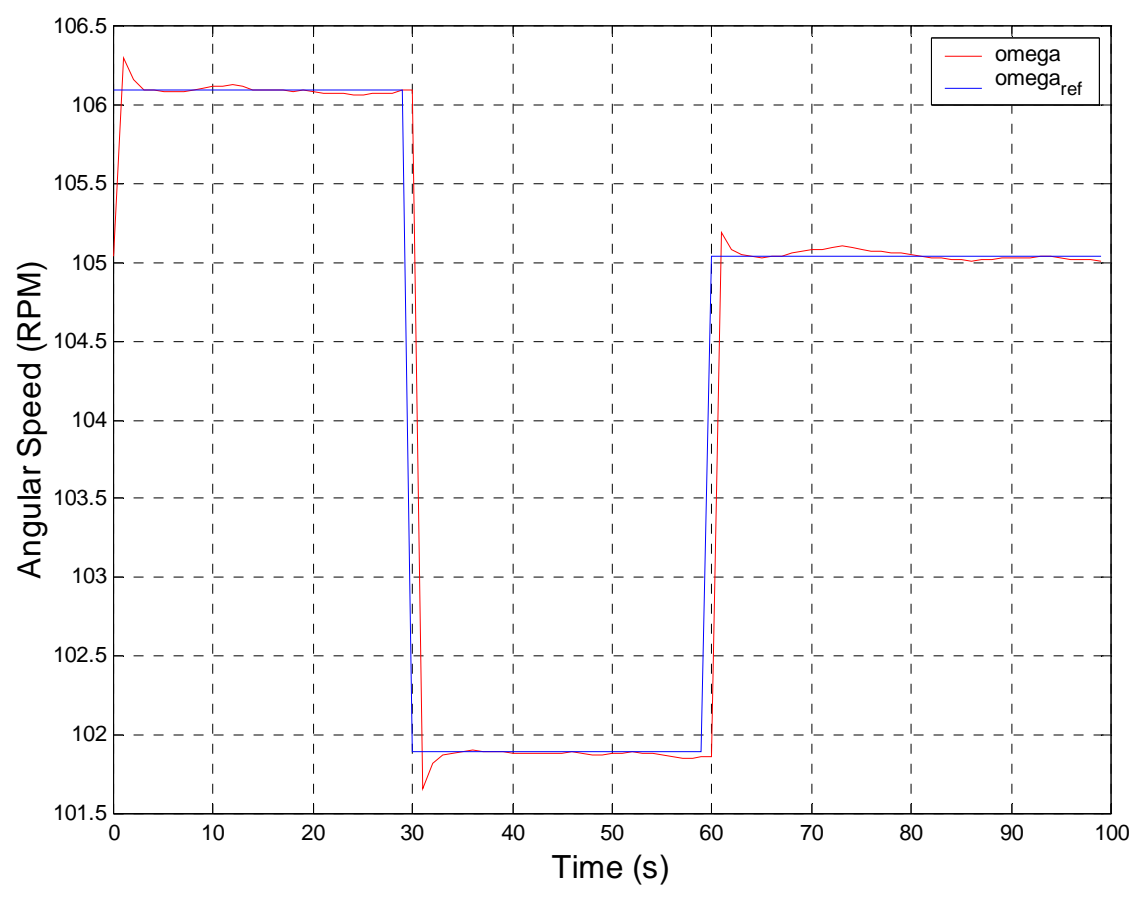

Figure 4.8: Angular speed profile for varying reference angular speed 
The output angular speed satisfactorily tracks the reference angular speed. This shows the robustness of the controller and the fact that wind turbine operation heavily depends on the control strategy.

\subsection{Synchronous Generator Control}

Synchronous generator control has been studied more than any other electricitygenerating unit $[2,3,4]$. Most of the recent research has been focused more on the control of the device producing the mechanical power than the electrical generator. In this thesis, as stated before, control has focused more on the mechanical wind turbine system in order to get a desirable angular speed and mechanical power profiles. When these variables are fed into the generator as controlled variables, most control strategies can be used on the generator to track the required electrical variables.

The wind turbine system in this thesis has already been controlled to track the desired angular speed and the mechanical power profile. Therefore, the voltage controls only depended on the exciter of the synchronous generator. The inbuilt excitation system was used for the control of the generator. This excitation system implements an IEEE type 1 synchronous generator voltage regulator combined to an exciter [33]. The basic elements that form the Excitation System block are the voltage regulator and the exciter. The voltage regulator consists of a main regulator with gain $\mathrm{K}_{\mathrm{a}}$ and time constant $\mathrm{T}_{\mathrm{a}}$ and a lead-lag compensator with time constants $T_{b}$ and $T_{c}$. A derivate feedback is also provided with gain $\mathrm{K}_{\mathrm{f}}$ and time constant $\mathrm{T}_{\mathrm{f}}$. The limits $\mathrm{E}_{\mathrm{fmin}}$ and $\mathrm{E}_{\mathrm{fmax}}$ are imposed to the output of the voltage regulator. The upper limit can be constant and equal to $\mathrm{E}_{\mathrm{fmax}}$ or variable and equal to the rectified stator terminal voltage $V_{t f}$ times a proportional gain $K_{p}$. 
If $\mathrm{K}_{\mathrm{p}}$ is set to zero, the former will apply. If $\mathrm{K}_{\mathrm{p}}$ is set to a positive value, the latter will apply. The stator terminal voltage transducer is represented by a first-order low-pass filter with time constant $\mathrm{T}_{\mathrm{r}}$. Figure 4.9 shows the block diagram of the excitation system.

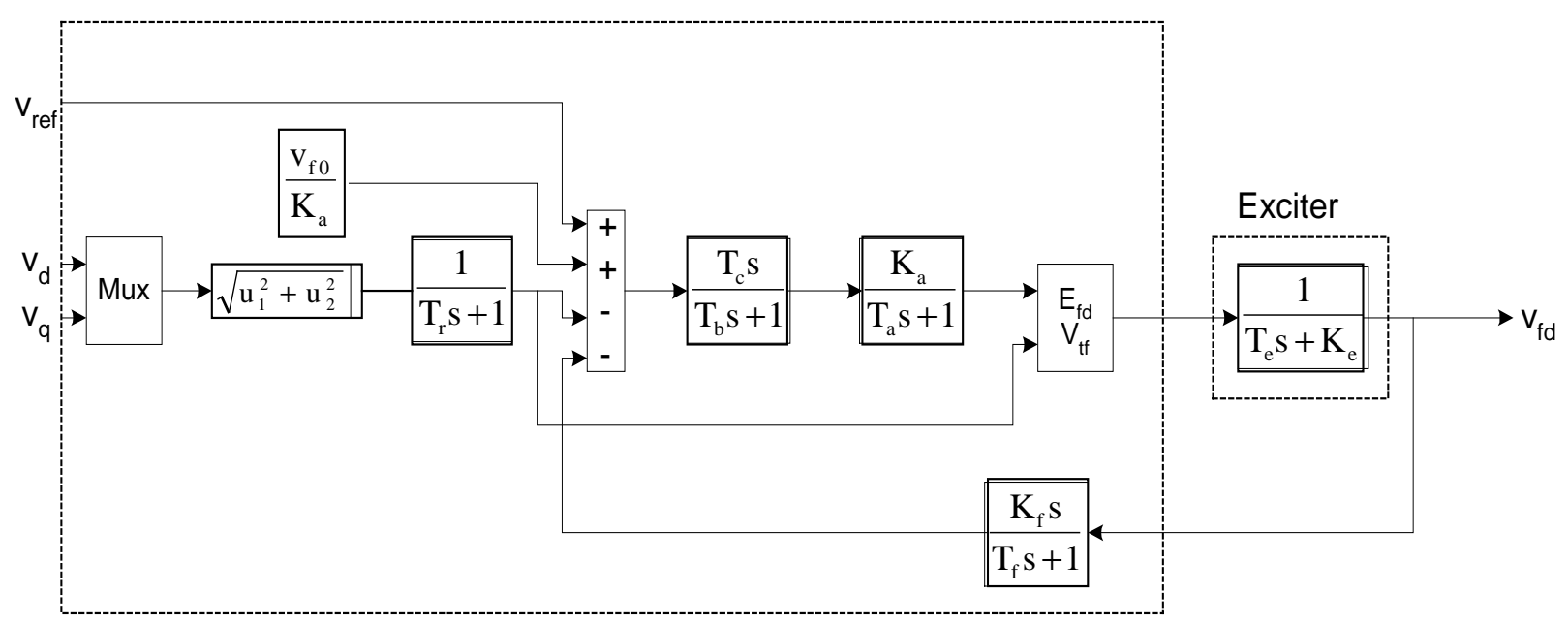

Voltage Regulator

Figure 4.9: Block diagram of the excitation system courtesy of Mathworks

There are some electrical-grid case studies provided in the Power System Blockset, which have controlled synchronous generators as their focus. The exciter in the study called "psbturbine" was used and its variables are listed below. The exciter gain, $\mathrm{K}_{\mathrm{e}}$ was varied slowly from one until it gave a satisfactory response time as will be seen from the graphs representing the electrical outputs from the synchronous generator.

$$
\begin{aligned}
& \mathrm{K}_{\mathrm{e}}=5 \\
& \mathrm{~K}_{\mathrm{a}}=300 \\
& \mathrm{~T}_{\mathrm{a}}=0.001 \\
& \mathrm{~T}_{\mathrm{b}}=0 \\
& \mathrm{~T}_{\mathrm{c}}=0
\end{aligned}
$$


$\mathrm{K}_{\mathrm{f}}=0.001$

$\mathrm{T}_{\mathrm{f} .}=0.1$

These values worked well in controlling the generator to produce the reference voltage specified as one of the controller inputs.

Figure 4.10 shows the mechanical power output profile, which was obtained from the wind turbine system using gains $\left(\mathrm{k}_{\mathrm{P}}=15, \mathrm{k}_{\mathrm{I}}=10, \mathrm{k}_{\mathrm{D}}=5\right)$ and the wind profile shown in Figure 4.1. This profile was input to the synchronous generator.

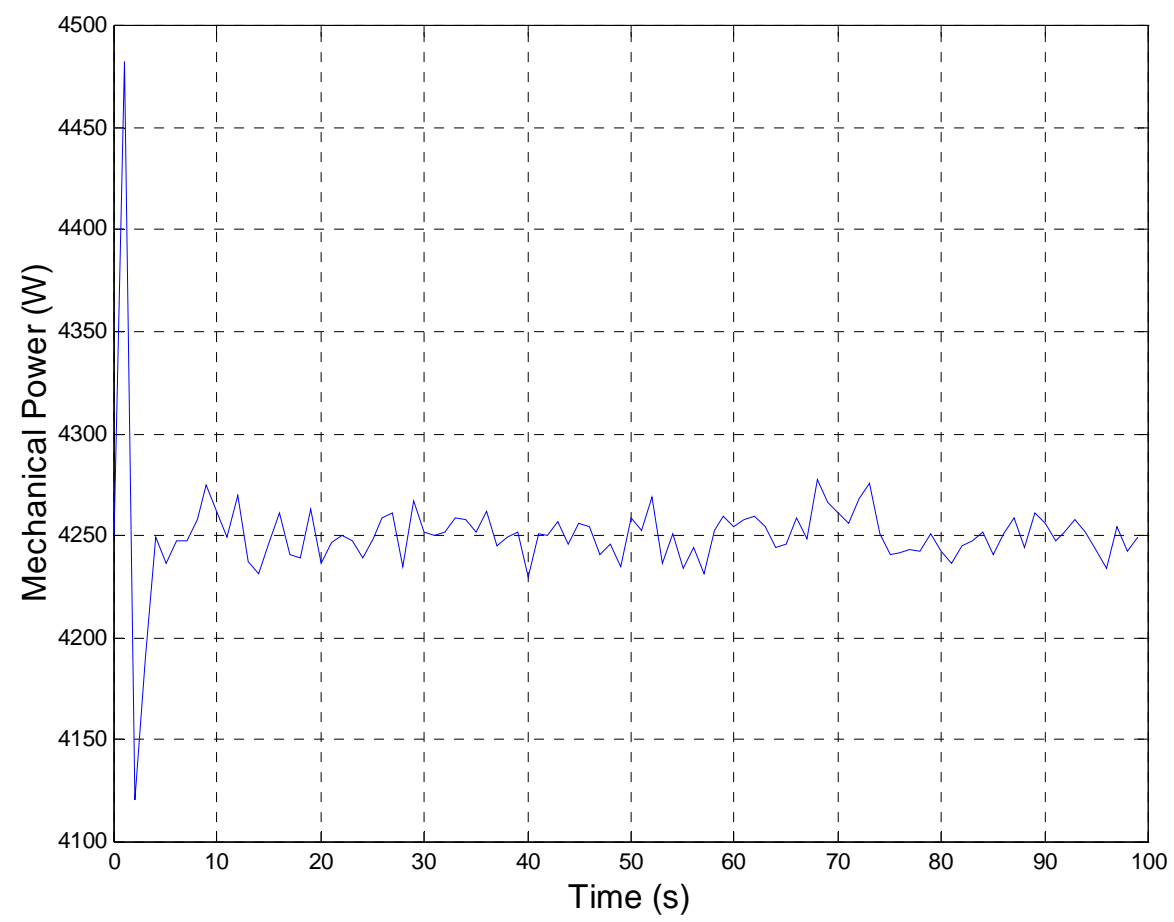

Figure 4.10: Wind Turbine Mechanical Power versus time

Figures 4.11 to 4.13 show the electrical outputs of the controlled synchronous generator, based on the reference voltage and the mechanical power profile shown in Figure 4.10. 


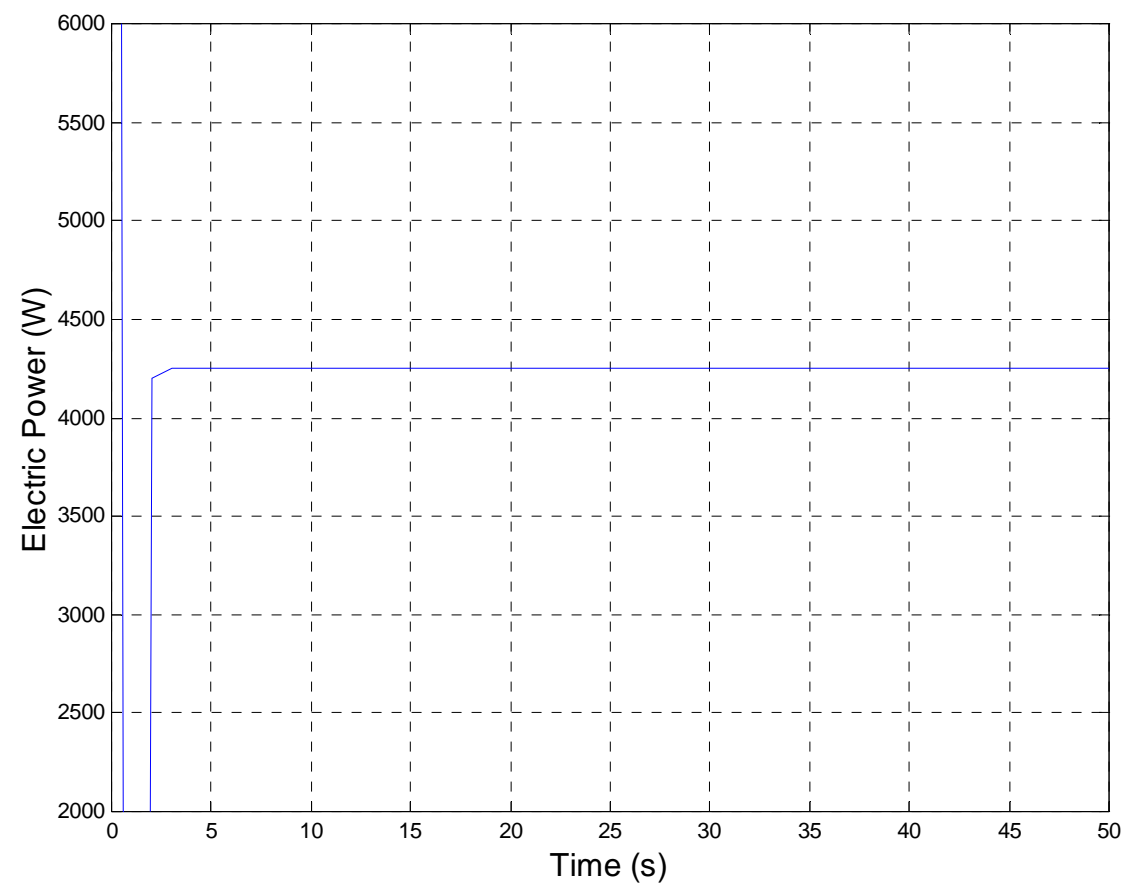

Figure 4.11: Electric Power versus time

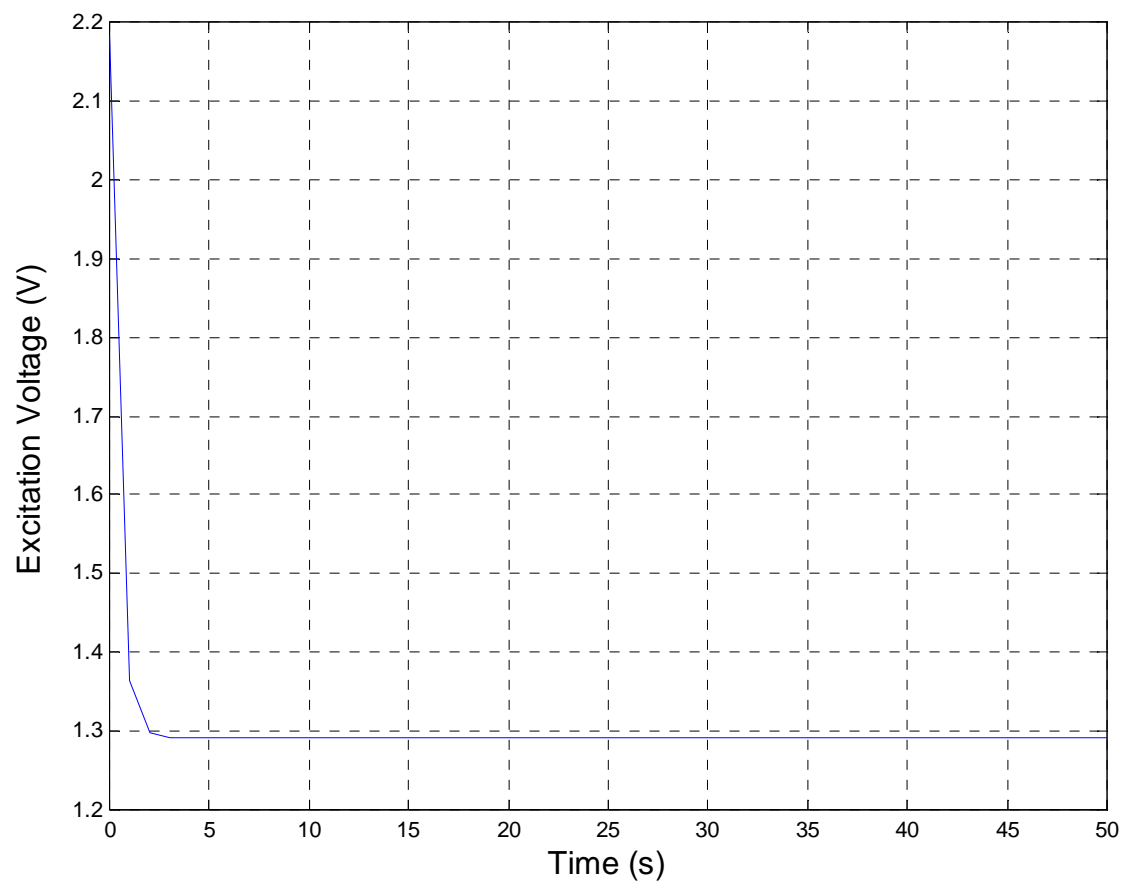

Figure 4.12: Excitation voltage versus time 


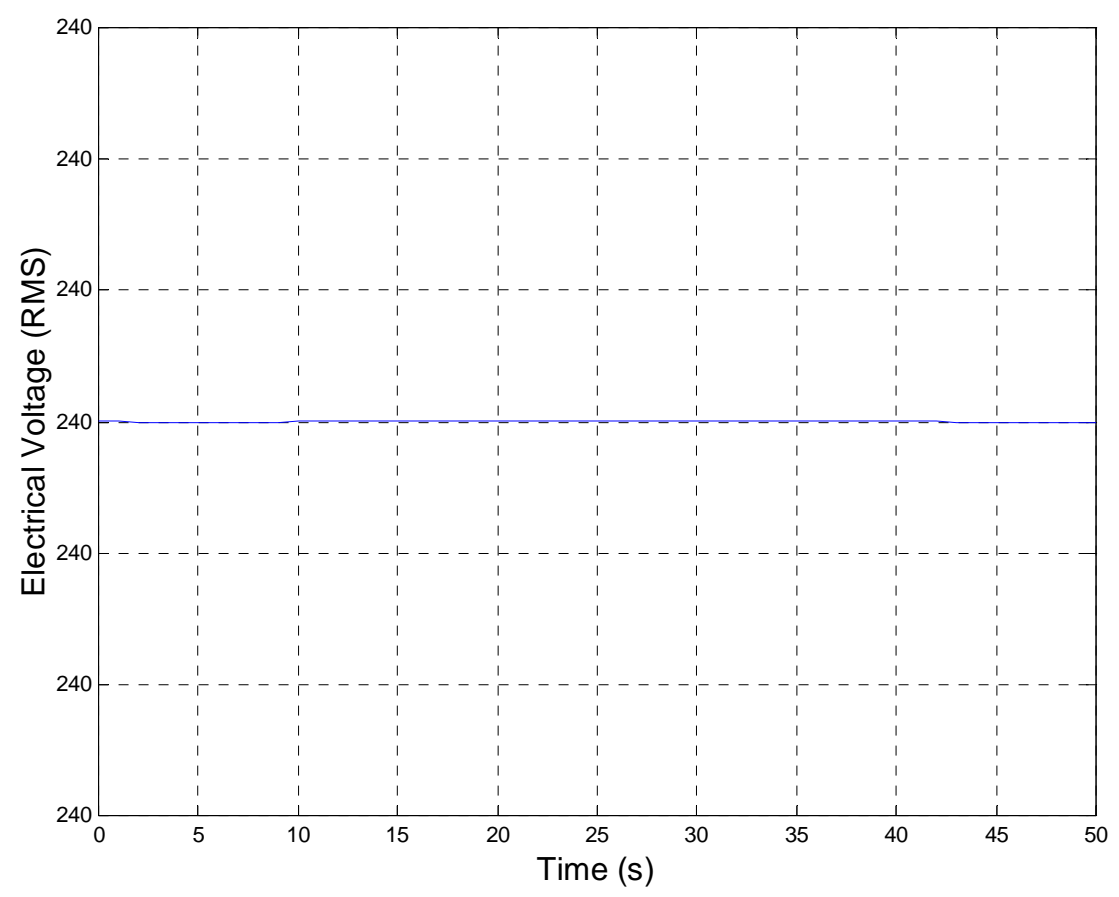

Figure 4.13: Output voltage versus time

In the electrical simulations, it is assumed that there are no losses and that is why the electrical power output of figure 4.11 is consistent with the mechanical power. Figure 4.12 shows that the excitation voltage stabilizes as soon as the reference voltage is achieved. The excitation parameters that were used controlled the system satisfactorily to prove that the generator was controllable with wind power as its input.

The reference root mean square of the operating voltage was set at $240 \mathrm{~V}$ during the simulation. Figure 4.13 shows that the voltage output goes to steady state almost immediately. For grid-connected generators, the terminal voltage is usually set by the bus at the generator connection point. 
The control strategy was easy for the generator because the mechanical power input and the angular rotation of the shaft were already controlled at the wind turbine. Synchronous generators are a common platform for most electricity production. The only difference between generation devices is the reliability and controllability of the mechanical power system. This thesis has shown that a wind turbine can replace a diesel engine and electric power production will continue satisfactorily, using the same generator. This also shows the extent of wind turbine applicability. Wind turbines have reached a stage where their operation and controls have matched that of traditional electric generators. 


\section{Chapter 5: Wind Turbine Economics}

\subsection{Introduction}

Representing wind power plants in utility production cost and reliability models poses a challenge to modelers because of the wide range of potential variability of the resource; that is the wind. As utilities evaluate wind turbine plants for possible future resource additions, it is important to accurately determine the energy value of the wind turbine plant. Renewable power plants, such as wind turbine power plants, may also contribute other benefits. Among these, other benefits are fuel diversity and lack of emissions. Although economic factors play a major role in determining the type of wind turbine to be modeled in this project, they should not compromise the technical objectives and the target performance of the wind turbine.

The economic study was done in three parts. Part one deals with the cost of the physical system and its installation. The objective of part two is to analyze the economic performance of wind turbine systems, which includes running costs and the total cost of wind energy. The third part will present an analysis and the benefits of grid-connected wind turbines. Overall, this economic study will focus more on general wind turbine economics than specific wind system economics.

Selection of a suitable site is key to the economics of wind energy systems. The mechanical power available from the wind is a function of the cube of the wind speed, which means that, all other things being equal, a turbine at a particular site will produce much more mechanical power than a turbine at a location where the wind speed averages are $1 \mathrm{~m} / \mathrm{s}$ less. In the electric power industry, where plant technology and complexity 
options often depend on very small economic differences, good wind resource assessment and siting is critical. The wind profile that was used in this thesis had an average wind speed of $9.37 \mathrm{~ms}^{-1}$, which represents a moderate wind resource.

\subsection{Wind Turbine System Hardware}

A wind turbine consists of three main parts; namely, the rotor, the gearbox and the generator, as outlined in Chapter 2. Other wind turbines also have inverters and rectifiers, which improve the quality of electricity but also increase the cost.

\subsubsection{Rotor}

The rotor is the part that extracts mechanical power from the wind and is often the part that is used to describe or classify wind turbines. The type of rotor to be implemented depends on that for which it will be used. The level of complexity of the rotor varies, and it directly affects the cost. For example, a variable pitch wind turbine is much more expensive to build and yet its features (capabilities) are desired for large-scale electricity production. On the other hand, for small-scale applications, the wind turbines should be as simple as possible. Therefore, there is a tradeoff between desired features and cost.

\subsubsection{Gearbox}

This is the component that transmits power from the low-speed rotor shaft to the high-speed generator shaft. The considerations for this component involve the allowable 
efficiency range, which will determine the type of gearbox to be used. The required properties for this component should justify the amount of money put into it.

\subsubsection{Generator}

Table 5.1 shows eight examples of systems that could be selected for generating synchronous power. There is a lot of flexibility in terms of the number of ways synchronous power can be generated, but it comes down to how much each one of the options will cost.

Table 5.1: Eight systems of generating synchronous electrical power

\begin{tabular}{|l|l|l|l|}
\hline System & Rotor & Transmission & Generator \\
\hline 1 & $\begin{array}{l}\text { Variable Pitch, Constant } \\
\text { Speed }\end{array}$ & Fixed-ratio gear & ac generator \\
\hline 2 & $\begin{array}{l}\text { Variable Pitch, Constant } \\
\text { Speed }\end{array}$ & $\begin{array}{l}\text { Two-speed-ratio } \\
\text { gear }\end{array}$ & ac generator \\
\hline 3 & Fixed Pitch, Constant Speed & Fixed-ratio gear & ac generator \\
\hline 4 & Fixed Pitch, Variable Speed & Fixed-ratio gear & $\begin{array}{l}\text { dc generator /dc motor /ac } \\
\text { generator }\end{array}$ \\
\hline 5 & Fixed Pitch, Variable Speed & Fixed-ratio gear & $\begin{array}{l}\text { ac generator / rectifier / dc } \\
\text { motor /ac generator }\end{array}$ \\
\hline 6 & Fixed Pitch, Variable Speed & Fixed-ratio gear & $\begin{array}{l}\text { ac generator / rectifier / } \\
\text { inverter }\end{array}$ \\
\hline 7 & Fixed Pitch, Variable Speed & Fixed-ratio gear & Field-modulated generator \\
\hline 8 & Fixed Pitch, Variable Speed & Variable-ratio gear & ac generator \\
\hline
\end{tabular}

Systems 1, 2 and 3 are all constant speed systems, which differ only in pitch controls and gearbox details. Variable-pitch wind turbines are more expensive than fixedpitch wind turbines, so a careful study needs to be made to determine if the cost per unit of energy is lower with the more expensive system. Systems 4 through 8 are all fixed- 
pitch, variable-speed systems and accomplish fixed frequency outputs by one of five methods. The disadvantage of System 4 over System 3 is the requirement of two electrical machines, which increases the cost. Efficiency and cost considerations make System 4 rather uncompetitive for turbine ratings below about $100 \mathrm{~kW}$. Above the 100 $\mathrm{kW}$ rating, however, the two dc machines have reasonably good efficiency (about $92 \%$ each) and may add only 10 to $15 \%$ of the overall cost of the wind turbine plant. A careful analysis may show System 4 to be competitive with the constant-speed systems in the larger sizes. System 5 is very similar to System 4 except that an ac generator and a threephase rectifier are used to produce direct current. The ac generator-rectifier combination may be less expensive than the dc generator and may also be more efficient. System 6 uses an inverter, which is very reliable and System 7 uses a special electric generator, whose electronics are rather expensive. Finally, System 8 produces $60-\mathrm{Hz}$ electricity from a standard ac generator by using a variable speed gearbox. Variable speed can be accomplished by a hydraulic pump driving a hydraulic motor or by other techniques. Both cost and efficiency tend to be the problems on variable ratio transmissions.

Therefore, in choosing a wind turbine system, both cost and desirable features have to be optimized. Overall, System 3 is the simplest and cheapest technique; however, it is very limited in the ways in which it can be controlled and that is a disadvantage. System 1 is the next best system because it is the simplest system that can be controlled to extract the same (or different) amounts of power at a wide range of wind speeds. The Grumman Windstrem-33 that was modeled and simulated in this research is System1. 


\subsection{Wind Turbine Economic Performance}

The economic goal is to maximize the wind turbine power output per dollar investment. The unit cost of electricity can be determined in a straightforward manner from knowledge of capital investment and operating costs. The three methods customarily used to measure the costs and economic performance of wind turbine systems are described below.

\subsubsection{Installed Capital Cost}

The simplest measure of the cost for a wind turbine system is the installed capital cost, ICC. This measure includes all planning, equipment purchases, construction and installation costs for a wind turbine system ready to operate. As such, this cost will include the purchase price for the tower site, permits, wind turbine and tower delivered and installed at the site together with all electrical, maintenance and other supporting infrastructure. This deals only with the installed capital cost and is measured in dollars per kilowatt $(\$ / \mathrm{kW})$ as expressed in Equation 5.1.

$$
\mathrm{ICC}_{\$ / \mathrm{kW}}=\frac{\mathrm{TIC}}{\mathrm{WTRP}}
$$

where TIC is the total installed costs and WTRP is the wind turbine rated power. Thus, for a typical wind turbine system, installed capital cost includes the following elements:

1. Wind resource assessment and analysis.

2. Permitting, surveying and financing.

3. Construction of service roads.

4. Construction of foundations for wind turbines.

5. Wind turbine and tower delivered to the site and installed. 
6. Construction and installation of wind speed and direction sensors together with communication capability to the associated wind turbines.

7. Construction of power collection system including the power wiring from each wind turbine to the substation.

8. Construction of operations and maintenance facilities.

9. Construction and installation of a wind turbine communication network supporting control commands and data flow from each wind turbine to a central operations facility.

10. Provision of power measurement and wind turbine computer control facilities.

11. Integration and checkout of the wind turbine system for correct operation.

12. Commissioning period.

13. Final turnover to owner or operating agency.

There was no specific data about the economics of installing the Grumman Windstream33 but according to the Danish Windpower Association [35], the average price for modern windfarms is about $\$ 1,000 / \mathrm{kW}$.

\subsubsection{Specific Capital Cost}

This measure of cost combines the installed cost, the strength of the wind resource and the matching of the wind turbine power curve to the wind speed distribution. This cost measure is called the specific capital cost, SCC, or the unit of energy capital cost. The specific capital cost is the installed cost to obtain a kilowatt-hour of energy per year. That is, the cost to install and make ready generating capacity that will generate a 
kilowatt-hour per year. This measure, denominated in dollars per kilowatt-hour per year ( $\$ / \mathrm{kWh} / \mathrm{year})$, is simply the total installed cost divided by the annual energy production, AEP, as shown in Equation 5.2.

$\mathrm{SCC}_{\$ /(\mathrm{kWh} / \mathrm{year})}=\frac{\mathrm{TIC}}{\mathrm{AEP}}$

This cost measure is still not all-inclusive. It does not include the costs of operation and maintenance over the lifetime of the facility, the costs of infrequent major overhauls.

\subsubsection{Operating and Maintenance Costs}

The Operating and Maintenance Costs (O\&MC) include all normally recurring costs associated with routine operation of the installed facility and unscheduled maintenance. The maintenance costs for modern wind turbines are $\$ 0.01 / \mathrm{kWh}$ or less [9].

\subsubsection{Other Operating Costs}

In addition to the Operating and Maintenance Costs, there are other annually recurring operating costs (ROC), which include:

1. Property and other taxes

2. Land-use payments

3. Insurance

4. Transmission access and wheeling fees

5. Management fees and general and administrative costs 
The values of these operating cost elements vary depending on the situation. Compared with the maintenance costs, these operating cost elements typically are small and in total contribute less than $\$ 0.005 / \mathrm{kWh}$ to the overall cost of energy.

\subsubsection{Cost of Energy}

The most comprehensive measure of wind energy cost is the life-cycle cost of energy, CoE. The life-cycle cost of energy (with units of $\$ / \mathrm{kWh}$ ) combines the installed capital cost, the quality of the wind and the costs of operations and maintenance throughout the 20 to 30 year life of the wind system. It is calculated using Equation 5.3.

$\mathrm{CoE}_{\$ / \mathrm{kWh}}=\frac{(\mathrm{TIC} * \mathrm{FCR})+(\mathrm{O} \& \mathrm{MC})+(\mathrm{ROC})}{\mathrm{AEP}}$

In Equation 5.3, FCR is the fixed cost rate, which is a very hard figure to predict and is a function of a lot of factors, O\&MC is the annual operating and maintenance costs, and $\mathrm{ROC}$ is the recurring operating costs.

The cost of electricity from utility-scale wind systems has dropped by more than $80 \%$ over the last 20 years, according to a publication [10] by the American Wind Energy Association. Now, state-of-the-art wind power plants are generating electricity at costs as low as $\$ 0.04 / \mathrm{kWh}$, a price that is competitive with many conventional energy technologies. Costs are continuing to decline as more and larger plants are built and advanced technology is introduced.

\subsection{Economics of Grid Connected Wind Turbines}

Grid connected systems primarily include turbines rated at more than $10 \mathrm{~kW}$. Although there are also turbines as small as $1 \mathrm{~kW}$ that can be grid-connected, they are not 
usually designed for that. All the configurations in Table 5.1 can be used for grid connected wind turbines. The economic analysis is done by evaluating the net profit as a function of the supplied power versus its market value. Also, it can be evaluated as a means of reducing fuel and related operating costs to the utility (fuel savings).

\subsubsection{Fuel-Savings Methodology}

The fuel-savings justification is widely accepted in the utility industry as a basis for evaluating investments into wind-electric technology. The capacity credit is considered somewhat controversial, as utilities, in general, are not willing to adjust their conventional expansion plan around a stochastic source technology. Nevertheless, the capacity-credit concept has a sound theoretical basis and may sometimes equal or exceed fuel savings in economic importance.

Fuel savings are obtained when the utility reduces the operating level of an oil, coal, or nuclear plant in response to a reduced load induced by the presence of wind energy on the grid. The value of the fuel saved depends on the particular generator that is backed down to a lower operating level and the unit value of the fuel at that time. Thus the value of the fuel displaced by the presence of wind depends on the hour of the day, the day of the week and the season of the year.

Also, since the equipment mix of a utility changes from year to year, the fuel savings depends on the year itself. The most accurate methodology for estimating the fuel savings, given these variations, is a simulation of the hour-by-hour equipment dispatch by the utility to meet the load, taking account of scheduled and forced outage events of all equipment controlled by the utility. By simulating the fuel used under a base-case 
simulation without wind and then resimulating in the presence of wind, the cumulative reduction in fuel costs can be obtained for any time period of interest. This kind of simulation is usually accomplished using a utility production-cost model [8].

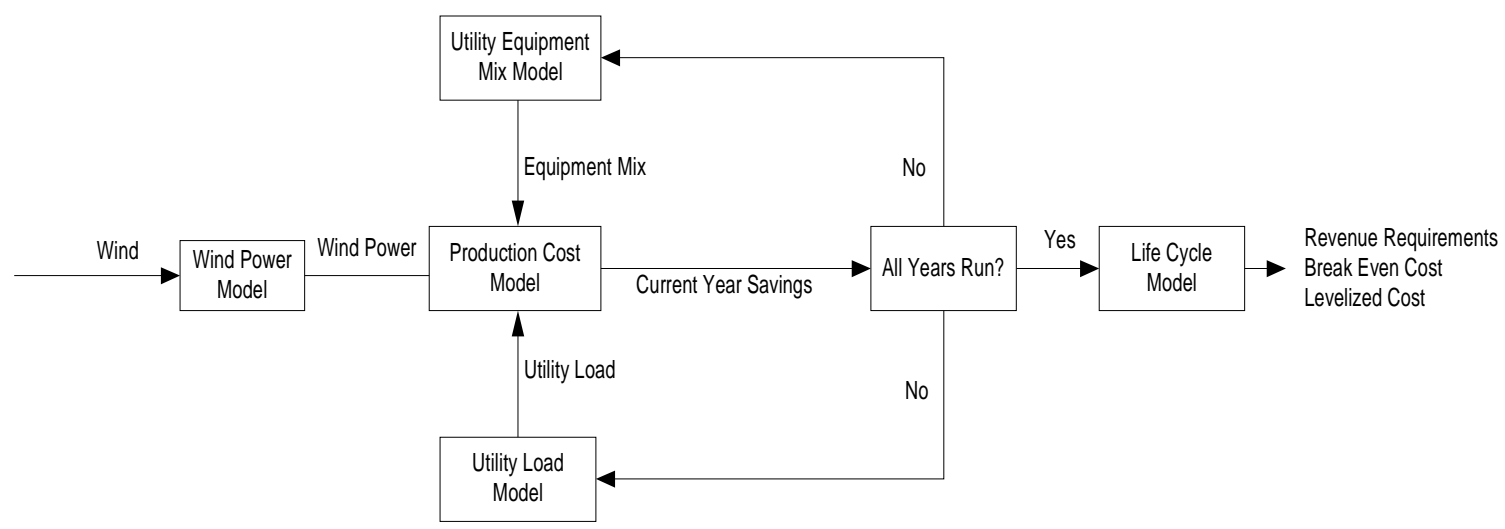

Figure 5.1: Typical Methodology for wind turbine electric value analysis

Figure 5.1 shows the production-cost model at the heart of a typical methodology for wind-electric value analysis. A wind-power model provides simulated or historical values of wind speed each hour. A utility-load model specifies the electric energy that the utility must generate each hour of the year. A utility equipment-mix model specifies for the current year the list of generating equipment that can be dispatched at a given hour. The production-cost model integrates all this information and selects the minimum-cost combination of available equipment to satisfy the load each hour. The difference in production cost, with and without wind, is the current year's savings. If the utility's load and/or equipment mix are expected to change over the years of interest, each subsequent year needs to be simulated. The series of annual savings, suitably escalated by an 
estimate of future fuel-price increases, becomes the input to a life-cycle model, which is used to compute the revenue requirements, the breakeven cost or the levelized cost.

\subsubsection{Availability of Wind Power}

The figures for annual energy output assume that wind turbines are operational and ready to run all the time. In practice, however, wind turbines need servicing and inspection once every six months to ensure that they remain safe. In addition, component failures and accidents (such as lightning strikes) may disable wind turbines. Very extensive statistics [9] show that the best wind turbine manufacturers consistently achieve availability factors above 98 per cent, i.e. the wind turbines are ready to run more than 98 per cent of the time. Total energy output is generally affected less than 2 per cent, since wind turbines are never serviced during high winds. Such a high degree of reliability is remarkable, compared to other types of machinery, including other electricity generating technologies. The availability factor is therefore usually ignored when doing economic calculations, since other uncertainties (e.g. wind variability) are far larger. Not all wind turbine manufacturers around the world have a good, long reliability record; however, so it is always a good idea to check the manufacturers' track record and servicing ability before one goes out and buys a new wind turbine.

\subsubsection{Reliability and Dispatchability of Wind Power}

As seen from Chapter 4 (Controller Design), with enough wind resource, wind turbines with a good control strategy are as reliable as any generation device. As long as the power requirement falls within the power production envelope of the wind turbine, 
dispatchability is not an issue. Therefore, the two main factors affecting the reliability and dispatchability of wind power are the wind resource and the controllability of the wind turbine.

In comparison to other technologies, wind power has about the same economic efficiency depending on the control scheme. The biggest advantage of wind power over other generation devices is that its energy source (wind is free), it has a long lifespan (about 25 years) it has very low operating costs and its overall cost of energy is relatively low [9]. With more research geared towards bigger, more efficient wind turbines and advanced control strategies, the cost of wind power is steadily falling [9]. 


\section{Chapter 6: Conclusions and Recommendations}

\subsection{Contributions}

This thesis contributed a method of wind turbine performance estimation, modeling, linearization and control. The specific contributions are:

1. The wind turbine model was derived using a linearization technique coupled with the approximation of the wind turbine dynamics. Given that there was no readily available data for a straightforward data reduction procedure, the method developed by Justus [30] was used and it proved to be successful based on the output profiles that were obtained for all the simulations. All of them were comparable to the profiles of other wind turbines that have been studied [5]. This was a different and useful approach to wind turbine modeling.

2. The systematic approach to PID-controller design that was used provides a means of visually observing the effect of gain changes on both RMS speed error and actuator duty cycle, which is also tied with the size of the gains and the cost. While these parameters were in opposition by nature, the surfaces permitted selection of gain values that produce favorable results for both of the parameters. This visualization of the effect of gain permits selection of the best possible combination of controller parameters without requiring a lengthy trial-and-error process.

3. It was shown that the operation of wind turbines depends heavily on the control strategy. This was evident when the reference angular speed was made to vary 
throughout the simulation. This means that the same wind turbine can be made to operate at different modes depending on the control strategy.

4. A valuable aspect of this controller design approach was the ability to observe the robust nature of the PID controller in this constant-speed wind turbine application. Generation of the surfaces over such varied gain values illustrated the controller sensitivity. The wide, flat surfaces indicated robust behavior for the PID controller. This is valuable information for comparison with other types of controllers.

5. The level of connectivity of wind turbines to the electric grids was reflected by the ease with which the mechanical wind turbine was connected to the synchronous generator without having to apply any special control scheme to the generator. It is the reliability and the controllability of the mechanical power output of the wind turbine that determines its connectivity to the grid.

6. It was shown that in a place with a moderate wind resource, wind turbines can provide mechanical power just like any other conventional machine and on top of that, they have the advantages of producing clean energy, with low operating costs and a long lifespan.

\subsection{Future Research and Recommendations:}

1. The non-linear dynamics simulated with this simple model are easily linearized, but several considerations must be made in order to design a PID controller using a linear model. The optimal region based on the balanced performance of the two minimization parameters shifts with the linearization point selection. Operating 
point selection for a linear model is critical to obtaining the best possible performance from this highly non-linear system. Therefore, other operating points can be selected and analyzed.

2. Although the surfaces are relatively flat, performance does vary when gain combinations from different areas of the surface are compared. These small variations may be magnified by more complicated dynamics and sensor noise when these gains are implemented in the field. Thus, it is assumed that the nonlinear model-based design will be superior to the designs that relied upon the linear model. Therefore a non-linear study of wind turbines will be appropriate.

3. Several opportunities for use of control exist within the wind turbine industry. In addition to speed regulation with actuator motion, control may be used to extend the fatigue life of blades and rotor shafts. Adding control objectives introduces the need for multiple-input-multiple-output controllers. Fuzzy logic and neural network controllers, as well as state-estimation based controllers, could be employed to incorporate the interaction between the various control objectives.

4. This research was done with the assumption that the synchronous machine is always in phase with the electric grid. There is need to investigate phase differences and how to accommodate them. Also, depending on the connection point of the wind turbine to the grid, there might be a need to study transformers and their interaction with wind turbines. 
5. A more accurate non-linear model might give more realistic results and as a way to test the PID controller that was used in this research, the controller can be tested on the non-linear model.

6. One of the most important requirements for distributed resources is the ability to follow the load fluctuations. In the case of wind turbines, this will require the electrical power demand to be fed back into the mechanical system for the wind turbine to extract the exact amount of power that is required. The load following control scheme will expand the use of wind turbines as distributed resources. 


\section{REFERENCES}

[1] Muljadi, E. and Butterfield, C.P.; "Pitch-Controlled Variable-Speed Wind Turbine Generation," Presented at the IEEE Industry Applications Society Annual Meeting, Phoenix, AZ, October. 3-7, 1999.

[2] Muljadi, E., Butterfield, C.P., Sallan, J. and Sanz M.; "Investigation of Self-Excited Induction Generators for Wind Turbine Applications," Presented at the IEEE Industry Applications Society Annual Meeting, Phoenix, AZ, October. 3-7, 1999.

[3] Hinrichsen, E.N.; "Controls for Variable-Pitch Wind Turbine Generators," IEEE Transactions on Power Apparatus and Systems, Vol. PAS-103, No. 4, April 1984, pp 886-892.

[4] Hand, M.M. and Balas M.J.; "Non-Linear and Linear Model Based Controller Design for Variable-Speed Wind Turbines," Presented at the $3^{\text {rd }}$ ASME/JSME Joint Fluids Engineering Conference, San Francisco, CA, July 18-23, 1999.

[5] Johnson, Gary L.; Wind Energy Systems, Englewood Cliffs, NJ: Prentice Hall, 1985.

[6] Le Gourieres, D.; Wind Power Plants: Theory and Design, Pergamon Press Inc, NY: 1982.

[7] Eggleston, D.M. and Stoddard F.S.; Wind Turbine Engineering Design, Van Nostrand Reinhold Company, NY: 1987.

[8] Forsyth, T., Tu, P. and Gilbert, J.; "Economics of Grid-Connected Small Wind Turbines in the Domestic Markert", Windpower'99, Burlington, VT, June 20-23, 1999.

[9] American Wind Energy Association (AWEA)

[10] March, F., Dlott, E.H., Korn, D.H., Madio, F.R., McArthur, R.C. and Vachon, W.A.; "Wind Power for the Electric-Utility Industry", Arthur D. Little Book, Lexington MA, 1982.

[11] Mullane, A., Lightbody, G., Yakamini, R. and Grimes, S.; "The Simulation and Control of a Grid-Connected Variable Speed Wind Turbine", Department of Electrical Engineering, National University of Ireland, Cork, Ireland.

[12] Jadric, I.; "Modeling and Control of a Synchronous Generator with Electric Load," Master's Degree Thesis, Virginia Polytechnic Institute and State University, Blacksburg, VA, 1998. 
[13] Machowsi, J., Bialek, J., Robak, J. and Bumby, J.; "Excitation Control System for Use with Synchronous Generators.", IEE Procedures in Generation Transmission and Distribution, Volume 145, No. 5, September 1988, pp537 - 546.

[14] Leithhead, W.E., Lieth, D.J., Hardan, F. and Markou, H.; "Direct Regulation of Large Excursions for Variable Speed Wind Turbines", Department of Electronic and Electrical Engineering, University of Strathclyde, Glasgow, UK.

[15] Hirayama, K.; "Practical Detailed Model for Generators.", IEEE Transactions on Energy Conversion, Volume 10, No. 1, March 1995, pp105 - 110.

[16] Muljadi, E., Pierce, K. and Migliore, P.; "A Conservative Control Strategy for Variable-Speed Stall-Regulated Wind Turbines", $19^{\text {th }}$ American Society of Mechanical Engineers (ASME) Wind Energy Symposium, Reno, NV, January 10 - 13, 2000.

[17] Pierce, K. and Fingersh, L.J.; "Wind Turbine Control Systems Modeling Capabilities", American Controls Conference, Philadelphia, PA, June 24 - 26, 1998.

[18] Gevorgian, V., Corbus, D.A., Drouilhet, S., Holz, R. and Thomas, K.E.; "Modeling, Testing and Economic Analysis of a Wind-Electric Battery Charging Station" Windpower '98, Bakersfield, CA, April 27 - May 1, 1998.

[19] Kelley, N.D., Wright, A.D. and Osgood, R.M.; "A Progress Report on the Characterization and Modeling of a Very Flexible Wind Turbine Design", ASME/AIAA Wind Energy Symposium Reno, NV, January 11-14, 1999.

[20] Bir, G.S. and Robinson, M.; "Code Development for Control Design Applications Phase I: Structural Modeling", ASME/AIAA Wind Energy Symposium Reno, NV, January 11-14, 1999.

[21] Muljadi, E., Pierce, K. and Migliore, P.; "Control Strategy for Variable-Speed StallRegulated Wind Turbines", American Controls Conference, Philadelphia, PA, June 24 26, 1998.

[22] Song, Y.D., Dhinakaran, B. and Bao, X.Y.; "Variable Speed Control of Wind Turbines Using Nonlinear and Adaptive Algorithms", Journal of Wind Engineering and Industrial Aerodynamics, Volume 85, 2000, pp293- 308.

[23] Das, D., Aditya, S.K. and Kothari, D.P.; "Dynamics of Diesel and Wind Turbine Generators on an Isolated Power System", Electrical Power and Energy Systems, Volume 21, 1999, pp183- 189.

[24] Magnusson, M. and Smedman, A.S.; "Air Flow Behind Wind Turbines", Journal of Wind Engineering and Industrial Aerodynamics, Volume 80, 1999, pp169 - 189. 
[25] Rosen, A. and Sheinman, Y.; "Power Fluctuations of a Wind Turbine", Journal of Wind Engineering and Industrial Aerodynamics, Volume 59, 1996, pp51 - 68.

[26] Welfonder, E., Neifer, R. and Spanner, M.; "Development and Experimental Identification of Dynamic Models for Wind Turbines", Control Engineering Practice, Volume 5, No. 1, 1997, pp63 - 73.

[27] Crespo, A., Hernandez, J. and Frandsen, S.; "Survey of Modeling Methods for Wind Turbine Wakes and Wind Farms", Wind Energy, Volume 2, 1999, pp1 - 24.

[28] Maalawi, K.Y. and Badawy, M.T.S.; "A Direct Method for Evaluation Performance of Horizontal Axis Wind Turbines", Renewable and Sustainable Energy reviews, Volume 5, 2001, pp175 - 190 .

[29] Pierce, K.; "Control Method for Improved Energy Capture Below Rated Power", $3^{\text {rd }}$ ASME/JSME Joint Fluids Engineering Conference, San Francisco, CA, July 18-23, 1999.

[30] Justus, C.G., Winds and Wind System Performance, The Franklin Institute Press, Philadelphia, PA, 1978.

[31] Wilson, E.R., Lissaman, P.B.S. and Walker, S.N.; "Aerodynamic Performance of Wind Turbines", National Science Foundation, Research Applied to National Needs (RANN) Under Grant No. AER 74-04014 A03, June 1976.

[32] Nise, Norman S.; Control Systems Engineering, $2^{\text {nd }}$ Edition, Addison-Wesley Publishing Company, 1995

[33] Mathworks: Matlab Notes and Help

[34] www.winddata.com 


\section{APPENDIX A: Wind Turbine Aerodynamics and Parameters}

Starting from the Wind Turbine dynamics equation:

$\mathrm{J}_{\mathrm{T}} \dot{\omega}=\mathrm{T}_{\mathrm{A}}-\mathrm{T}_{\mathrm{L}}$

where $T_{A}$ is the aerodynamic torque represented by:

$\mathrm{T}_{\mathrm{A}}=\frac{1}{2} \rho \mathrm{ARC}_{\mathrm{q}}(\lambda, \beta) \mathrm{u}^{2}$

assuming, $\left.\mathrm{T}_{\mathrm{A}}\right|_{\mathrm{OP}}=\left.\mathrm{T}_{\mathrm{L}}\right|_{\mathrm{OP}}$, linearization of the Equation 3.1 results in the following:

$\mathrm{J}_{\mathrm{T}} \dot{\omega}=\left.\mathrm{J}_{\mathrm{T}} \frac{\partial \dot{\omega}}{\partial \mathrm{u}}\right|_{\mathrm{OP}} \Delta \mathrm{u}+\left.\mathrm{J}_{\mathrm{T}} \frac{\partial \dot{\omega}}{\partial \omega}\right|_{\mathrm{OP}} \Delta \omega_{\mathrm{T}}+\left.\mathrm{J}_{\mathrm{T}} \frac{\partial \dot{\omega}}{\partial \beta}\right|_{\mathrm{OP}} \Delta \beta$

Simplifying the expression:

$\dot{\omega}=\alpha \Delta \mathrm{u}+\gamma \Delta \omega+\delta \Delta \beta$

Derivation of $\alpha$ :

$$
\begin{aligned}
\alpha=\left.\frac{\partial \dot{\omega}}{\partial \mathrm{u}}\right|_{\mathrm{OP}} & =\frac{1}{\mathrm{~J}_{\mathrm{T}}}\left[\frac{\partial \mathrm{T}_{\mathrm{A}}}{\partial \mathrm{u}}-\frac{\partial \mathrm{T}_{\mathrm{L}}}{\partial \mathrm{u}}\right]_{\mathrm{OP}} \\
& =\frac{1}{\mathrm{~J}_{\mathrm{T}}}\left[\frac{1}{2} \rho \mathrm{ARu}^{2} \frac{\partial \mathrm{C}_{\mathrm{q}}(\lambda, \beta)}{\partial \mathrm{u}}-0\right]_{\mathrm{OP}} \\
& =\frac{1}{2 \mathrm{~J}_{\mathrm{T}}} \rho \mathrm{AR}\left[\mathrm{u}^{2} \frac{\partial \mathrm{C}_{\mathrm{q}}(\lambda, \beta)}{\partial \mathrm{u}}\right]_{\mathrm{OP}} \\
& =\frac{1}{2 \mathrm{~J}_{\mathrm{T}}} \rho \mathrm{AR}\left[\mathrm{C}_{\mathrm{q}}(\lambda, \beta) \frac{\partial \mathrm{u}^{2}}{\partial \mathrm{u}}+\mathrm{u}^{2} \frac{\partial \mathrm{C}_{\mathrm{q}}(\lambda, \beta)}{\partial \mathrm{u}}\right]_{\mathrm{OP}}
\end{aligned}
$$

Substituting: $\lambda=\omega \mathrm{R} / \mathrm{u} \quad \Rightarrow(\mathrm{d} \lambda / \partial \mathrm{u})=-\left(\omega \mathrm{R} / \mathrm{u}^{2}\right)=-\lambda / \mathrm{u} \quad \Rightarrow \partial \mathrm{u}=-(\mathrm{u} / \lambda) \partial \lambda$ 
$\alpha$

$$
\begin{aligned}
& =\frac{1}{2 \mathrm{~J}_{\mathrm{T}}} \rho \mathrm{AR}\left[2 \mathrm{uC}_{\mathrm{q}}(\lambda, \beta)-\lambda \mathrm{u} \frac{\partial \mathrm{C}_{\mathrm{q}}(\lambda, \beta)}{\partial \lambda}\right]_{\mathrm{OP}} \\
& =\frac{1}{2 \mathrm{~J}_{\mathrm{T}}} \rho \mathrm{ARu}\left[2 \mathrm{C}_{\mathrm{q}}(\lambda, \beta)-\lambda \frac{\partial \mathrm{C}_{\mathrm{q}}(\lambda, \beta)}{\partial \lambda}\right]_{\mathrm{OP}} \\
& =\frac{1}{2 \mathrm{~J}_{\mathrm{T}}} \rho \mathrm{ARu}_{\mathrm{OP}}\left[\left.2 \mathrm{C}_{\mathrm{q}}\right|_{\mathrm{OP}}-\left.\left.\lambda\right|_{\mathrm{OP}} \frac{\partial \mathrm{C}_{\mathrm{q}}}{\partial \lambda}\right|_{\mathrm{OP}}\right]
\end{aligned}
$$

Derivation of $\gamma$ :

$$
\begin{aligned}
\gamma=\left.\frac{\partial \dot{\omega}}{\partial \omega}\right|_{\mathrm{OP}} & =\frac{1}{\mathrm{~J}_{\mathrm{T}}}\left[\frac{\partial \mathrm{T}_{\mathrm{A}}}{\partial \omega}-\frac{\partial \mathrm{T}_{\mathrm{L}}}{\partial \omega}\right]_{\mathrm{OP}} \\
& =\frac{1}{\mathrm{~J}_{\mathrm{T}}}\left[\frac{1}{2} \rho \mathrm{ARu}^{2} \frac{\partial \mathrm{C}_{\mathrm{q}}(\lambda, \beta)}{\partial \omega}-0\right]_{\mathrm{OP}} \\
& =\frac{1}{2 \mathrm{~J}_{\mathrm{T}}} \rho \mathrm{ARu}^{2}\left[\frac{\partial \mathrm{C}_{\mathrm{q}}(\lambda, \beta)}{\partial \omega}\right]_{\mathrm{OP}}
\end{aligned}
$$

Substituting: $\lambda=\omega \mathrm{R} / \mathrm{u} \quad \Rightarrow(\mathrm{d} \lambda / \partial \omega)=-(\mathrm{R} / \mathrm{u})=-\lambda / \mathrm{u} \quad \Rightarrow \partial \omega=-(\mathrm{u} / \mathrm{R}) \partial \lambda$

$$
\begin{aligned}
\gamma & =\frac{1}{2 \mathrm{~J}_{\mathrm{T}}} \rho \mathrm{ARu}^{2}\left(\frac{\mathrm{R}}{\mathrm{u}}\right)\left[\frac{\partial \mathrm{C}_{\mathrm{q}}(\lambda, \beta)}{\partial \lambda}\right]_{\mathrm{OP}} \\
& =\frac{1}{2 \mathrm{~J}_{\mathrm{T}}} \rho \mathrm{AR}^{2} \mathrm{u}\left[\frac{\partial \mathrm{C}_{\mathrm{q}}}{\partial \lambda}\right]_{\mathrm{OP}}
\end{aligned}
$$

Derivation of $\delta$ :

$$
\begin{aligned}
\delta=\left.\frac{\partial \dot{\omega}}{\partial \beta}\right|_{\mathrm{OP}} & =\frac{1}{\mathrm{~J}_{\mathrm{T}}}\left[\frac{\partial \mathrm{T}_{\mathrm{A}}}{\partial \beta}-\frac{\partial \mathrm{T}_{\mathrm{L}}}{\partial \beta}\right]_{\mathrm{OP}} \\
& =\frac{1}{\mathrm{~J}_{\mathrm{T}}}\left[\frac{1}{2} \rho \mathrm{ARu}^{2} \frac{\partial \mathrm{C}_{\mathrm{q}}(\lambda, \beta)}{\partial \beta}-0\right]_{\mathrm{OP}} \\
& =\frac{1}{2 \mathrm{~J}_{\mathrm{T}}} \rho \mathrm{ARu}^{2}\left[\frac{\partial \mathrm{C}_{\mathrm{q}}}{\partial \beta}\right]_{\mathrm{OP}}
\end{aligned}
$$




\section{APPENDIX B: Synchronous Generator Equations}

The Synchronous Machine block operates in generating or motoring modes. The operating mode is dictated by the sign of the mechanical power (positive for generating, negative for motoring). The electrical part of the machine is represented by a fifth-order state-space model. The model takes into account the dynamics of the stator, field, and damper windings. The equivalent circuit of the model is represented in the rotor reference frame (qd frame). All rotor parameters and electrical quantities are viewed from the stator. They are identified by primed variables. The subscripts used are defined as follows:

$d, q: \mathrm{d}$ and $\mathrm{q}$ axis quantity

$R, s:$ Rotor and stator quantity

$l, m$ : Leakage and mutual inductance

$f, k$ : Field and damper winding quantity

The electrical model of the machine is shown in Figure B.2:
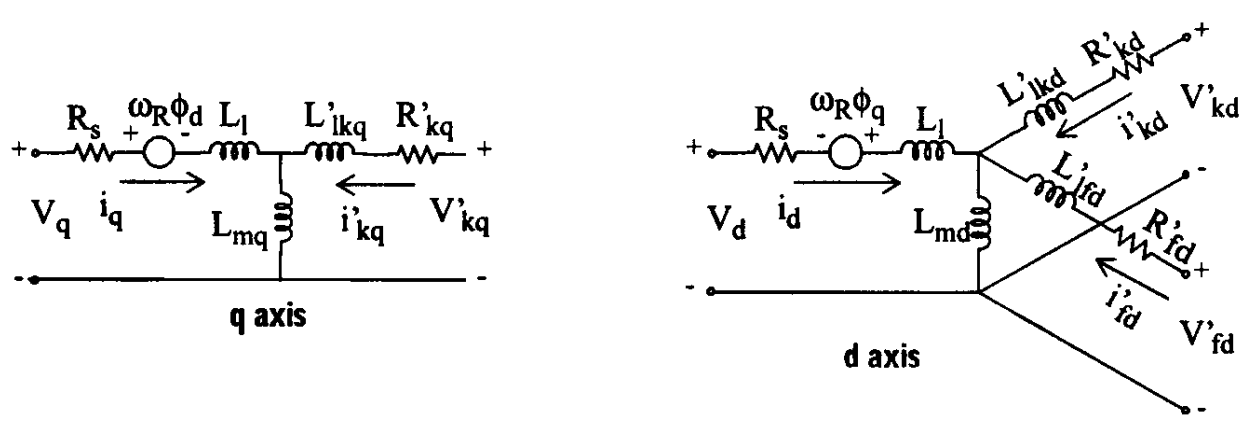

Figure B.2 : Electrical model of the synchronous machine

The equations that describe the system dynamics in the qd frame are: 


$$
\begin{aligned}
& \mathrm{V}_{\mathrm{d}}=\mathrm{R}_{\mathrm{s}} \mathrm{i}_{\mathrm{d}}+\frac{\mathrm{d}}{\mathrm{dt}} \varphi_{\mathrm{d}}-\omega_{\mathrm{R}} \varphi_{\mathrm{q}} \\
& \mathrm{V}_{\mathrm{q}}=\mathrm{R}_{\mathrm{s}} \mathrm{i}_{\mathrm{q}}+\frac{\mathrm{d}}{\mathrm{dt}} \varphi_{\mathrm{q}}-\omega_{\mathrm{R}} \varphi_{\mathrm{d}} \\
& \mathrm{V}_{\mathrm{fd}}^{\prime}=\mathrm{R}_{\mathrm{fd}}^{\prime} \mathrm{i}_{\mathrm{fd}}^{\prime}+\frac{\mathrm{d}}{\mathrm{dt}} \varphi_{\mathrm{fd}}^{\prime} \\
& \mathrm{V}_{\mathrm{kd}}^{\prime}=\mathrm{R}_{\mathrm{kd}}^{\prime} \mathrm{i}_{\mathrm{kd}}^{\prime}+\frac{\mathrm{d}}{\mathrm{dt}} \varphi_{\mathrm{kd}}^{\prime} \\
& \mathrm{V}_{\mathrm{kq}}^{\prime}=\mathrm{R}_{\mathrm{kq}}^{\prime} \mathrm{i}_{\mathrm{kq}}^{\prime}+\frac{\mathrm{d}}{\mathrm{dt}} \varphi_{\mathrm{kq}}^{\prime}
\end{aligned}
$$

where:

$$
\begin{aligned}
& \varphi_{\mathrm{d}}=\mathrm{L}_{\mathrm{d}} \mathrm{i}_{\mathrm{d}}+\mathrm{L}_{\mathrm{md}}\left(\mathrm{i}_{\mathrm{fd}}^{\prime}+\mathrm{i}_{\mathrm{fd}}^{\prime}\right) \\
& \varphi_{\mathrm{q}}=\mathrm{L}_{\mathrm{q}} \mathrm{i}_{\mathrm{q}}+\mathrm{L}_{\mathrm{mq}} \mathrm{i}_{\mathrm{kq}}^{\prime} \\
& \varphi_{\mathrm{fd}}^{\prime}=\mathrm{L}_{\mathrm{fd}}^{\prime} \mathrm{i}_{\mathrm{fd}}^{\prime}+\mathrm{L}_{\mathrm{md}}\left(\mathrm{i}_{\mathrm{d}}+\mathrm{i}_{\mathrm{kd}}^{\prime}\right) \\
& \varphi_{\mathrm{kd}}^{\prime}=\mathrm{L}_{\mathrm{kd}}^{\prime} \mathrm{i}_{\mathrm{kd}}^{\prime}+\mathrm{L}_{\mathrm{md}}\left(\mathrm{i}_{\mathrm{d}}+\mathrm{i}_{\mathrm{fd}}^{\prime}\right) \\
& \varphi_{\mathrm{kq}}=\mathrm{L}_{\mathrm{kq}}^{\prime} \mathrm{i}_{\mathrm{kq}}^{\prime}+\mathrm{L}_{\mathrm{mq}} \mathrm{i}_{\mathrm{q}}
\end{aligned}
$$

\section{Synchronous Generator Parameter Description}

$\omega: \quad$ rotor speed;

$\mathrm{v}_{\mathrm{d}}$ : armature $\mathrm{d}$ axis terminal voltage;

$\mathrm{v}_{\mathrm{q}}: \quad$ armature $\mathrm{q}$ axis terminal voltage;

$\mathrm{i}_{\mathrm{d}}: \quad$ armature $\mathrm{d}$ axis terminal current;

$\mathrm{i}_{\mathrm{q}}: \quad$ armature $\mathrm{q}$ axis terminal current;

$\mathrm{V}_{\mathrm{fd}}$ : field winding terminal voltage (reflected to the stator); 
$\mathrm{i}_{\mathrm{fd}}$ : field winding terminal current (reflected to the stator);

$\mathrm{i}_{\mathrm{kd}}$ : $\quad \mathrm{d}$ axis damper winding current (reflected to the stator);

$\mathrm{i}_{\mathrm{kq}}$ : $\quad \mathrm{q}$ axis damper winding current (reflected to the stator);

$1_{\mathrm{d}}: \quad$ total armature flux in $\mathrm{d}$ axis;

$1_{\mathrm{q}}: \quad$ total armature flux in $\mathrm{q}$ axis;

$\mathrm{R}_{\mathrm{s}}: \quad$ armature phase resistance;

$\mathrm{L}_{\mathrm{ls}}: \quad$ armature phase leakage inductance;

$\mathrm{L}_{\mathrm{md}}: \quad \mathrm{d}$ axis coupling inductance;

$\mathrm{R}_{\mathrm{fd}}$ : field winding resistance (reflected to the stator);

$\mathrm{L}_{\mathrm{lfd}}$ : field winding leakage inductance (reflected to the stator);

$\mathrm{R}_{\mathrm{kd}}$ : $\quad \mathrm{d}$ axis damper wining resistance (reflected to the stator);

$\mathrm{L}_{\mathrm{kd}}: \quad \mathrm{d}$ axis damper winding leakage inductance (reflected to the stator);

$\mathrm{L}_{\mathrm{mq}}: \quad \mathrm{q}$ axis coupling inductance;

$\mathrm{R}_{\mathrm{kq}}$ : $\quad \mathrm{q}$ axis damper winding resistance (reflected to the stator);

$\mathrm{L}_{\mathrm{kk}}$ : $\quad \mathrm{q}$ axis damper winding leakage inductance (reflected to the stator). 


\section{APPENDIX C: Matlab Code for Variation of $C_{p}$ with $u$ and $\lambda$}

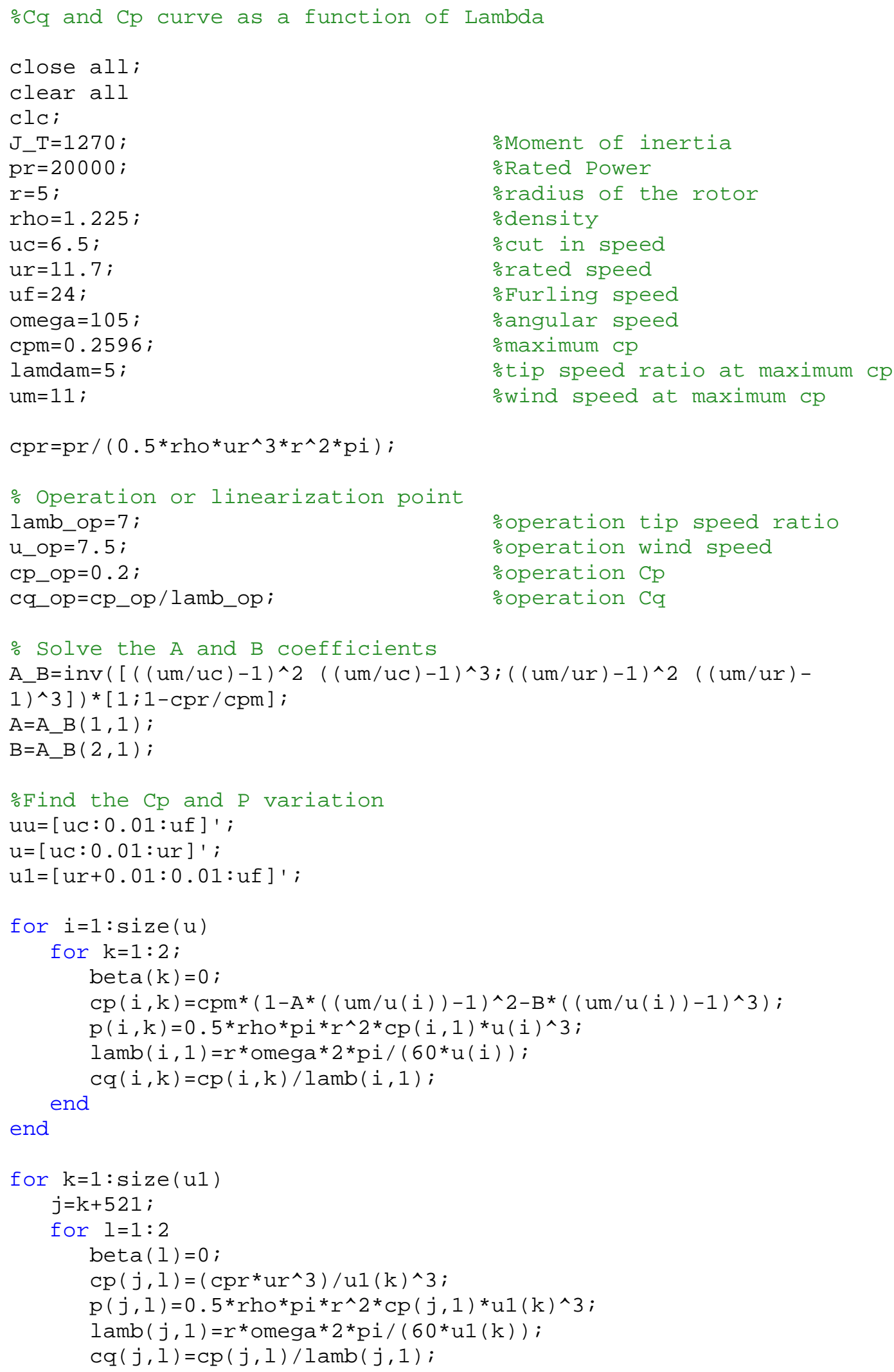




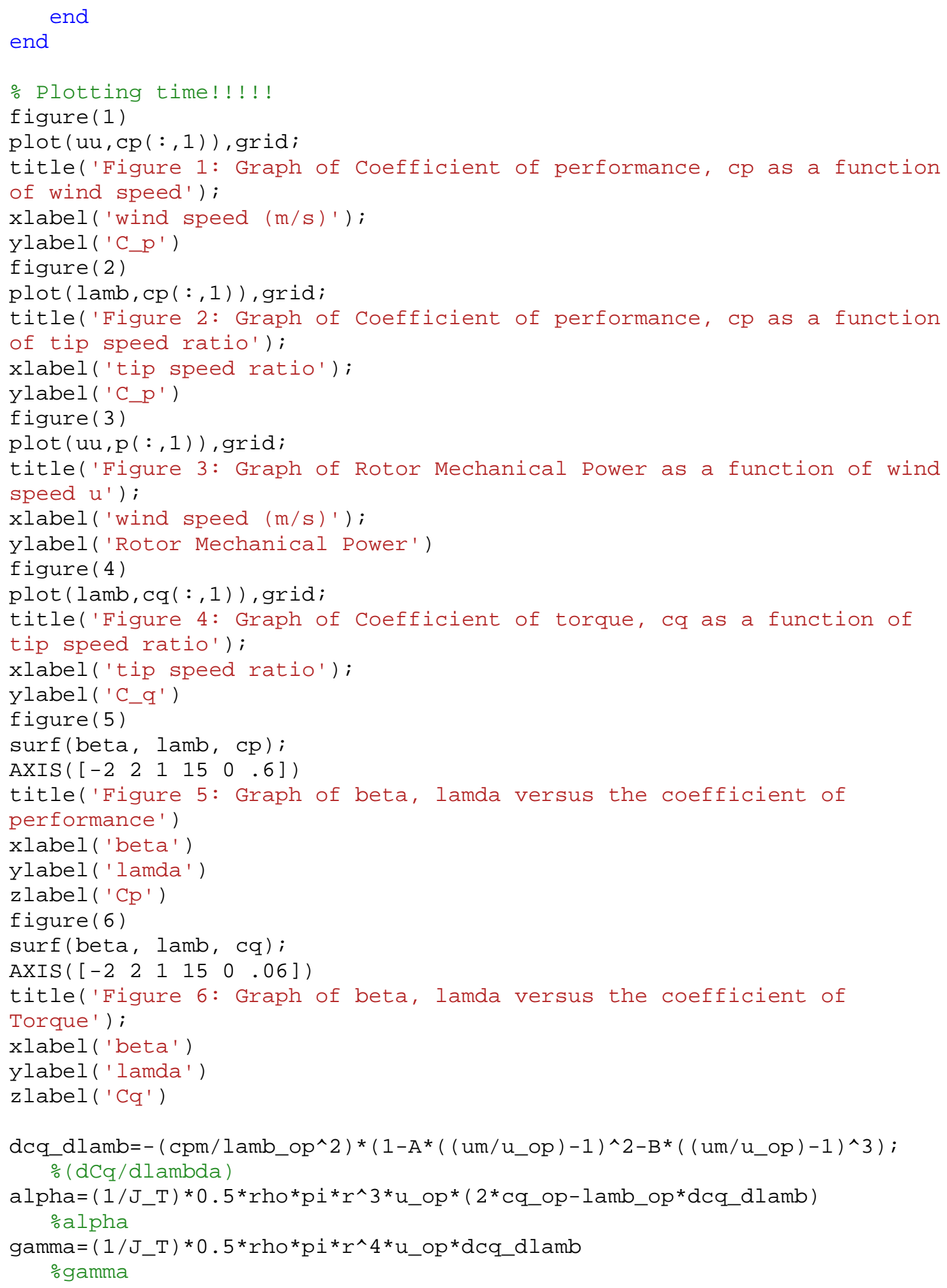




\section{APPENDIX D: Matlab Code for Controller Gain Selection}

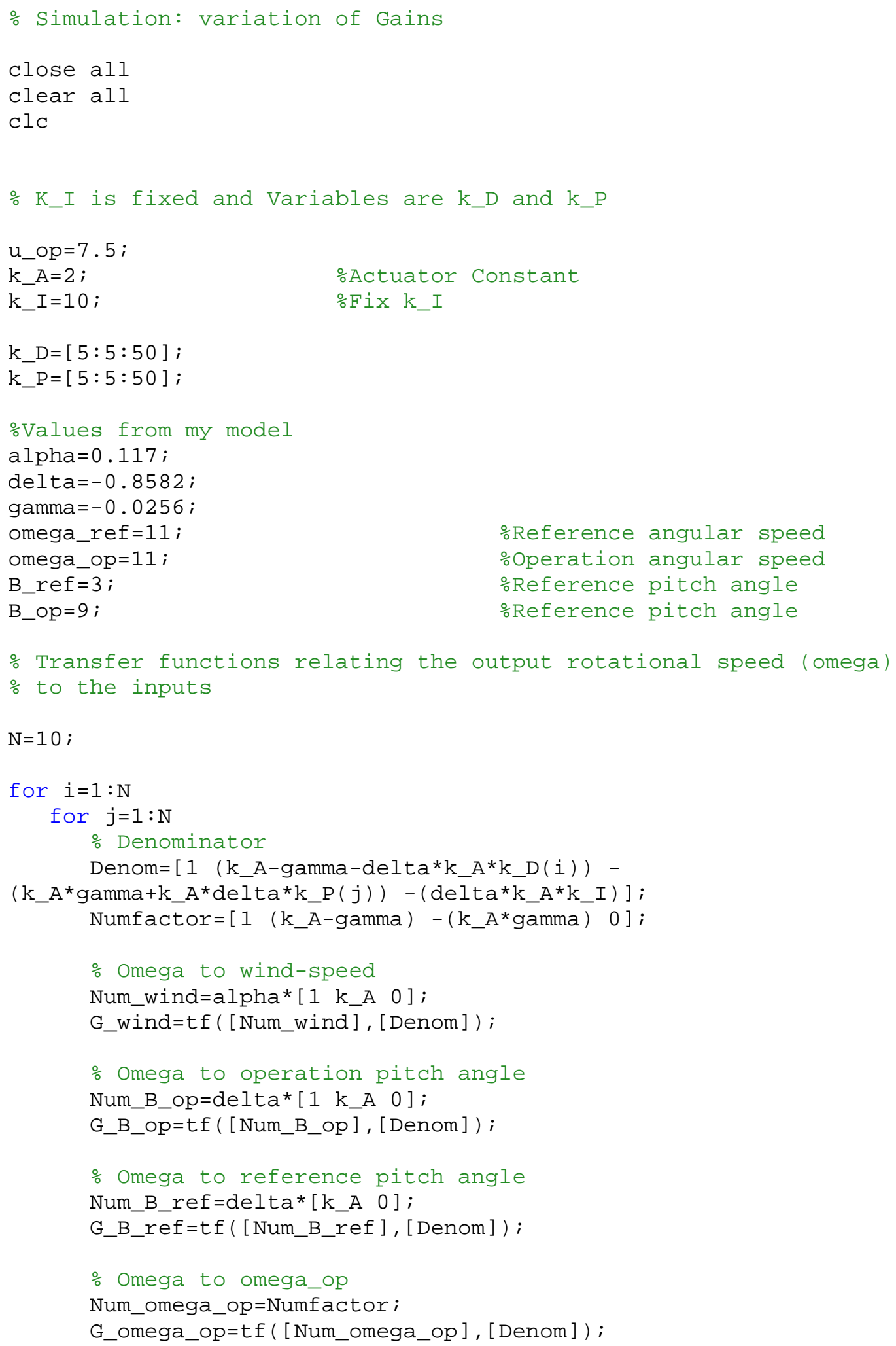




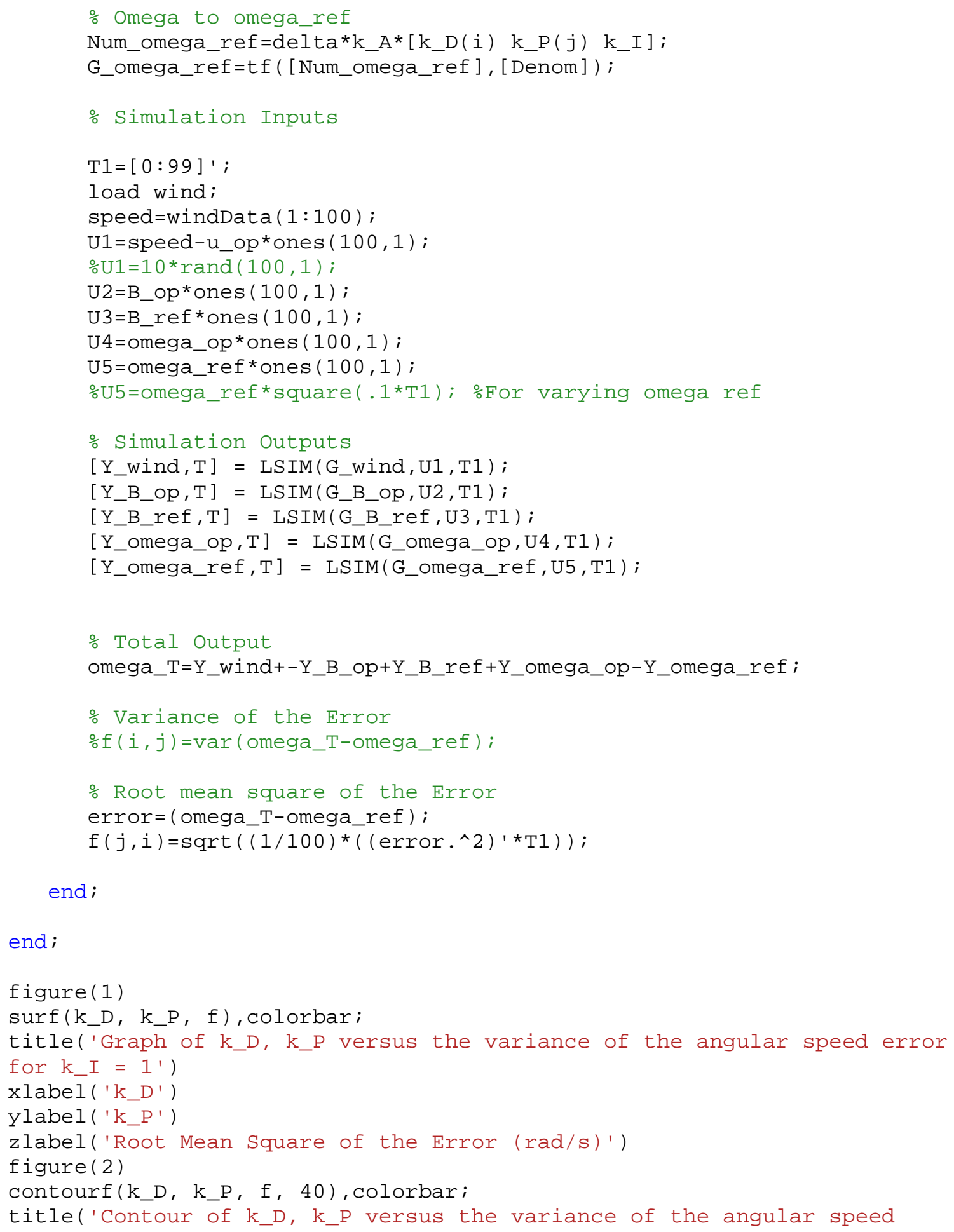




\section{APPENDIX E: Matlab Code for Wind Turbine Response Simulation}

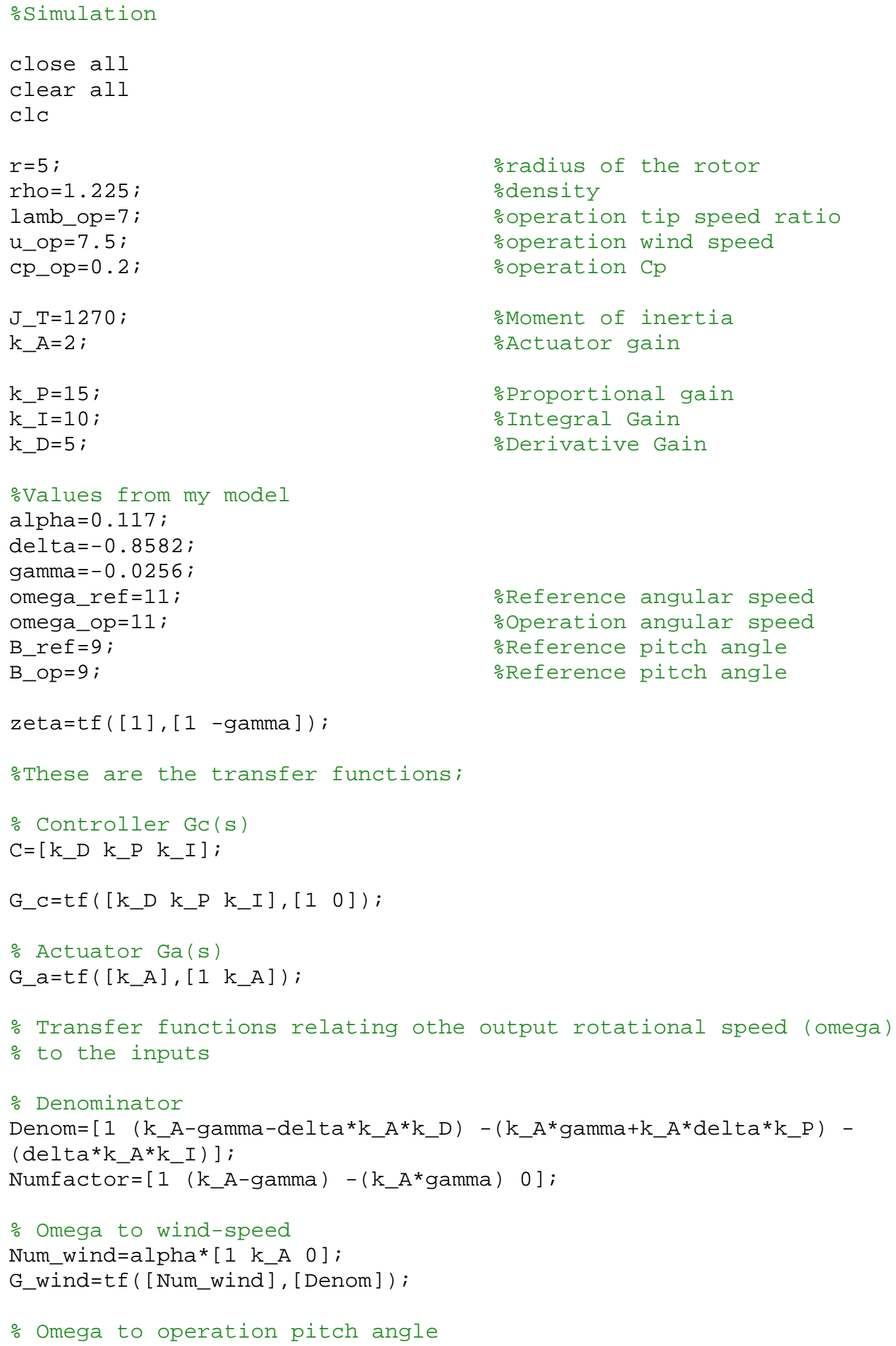




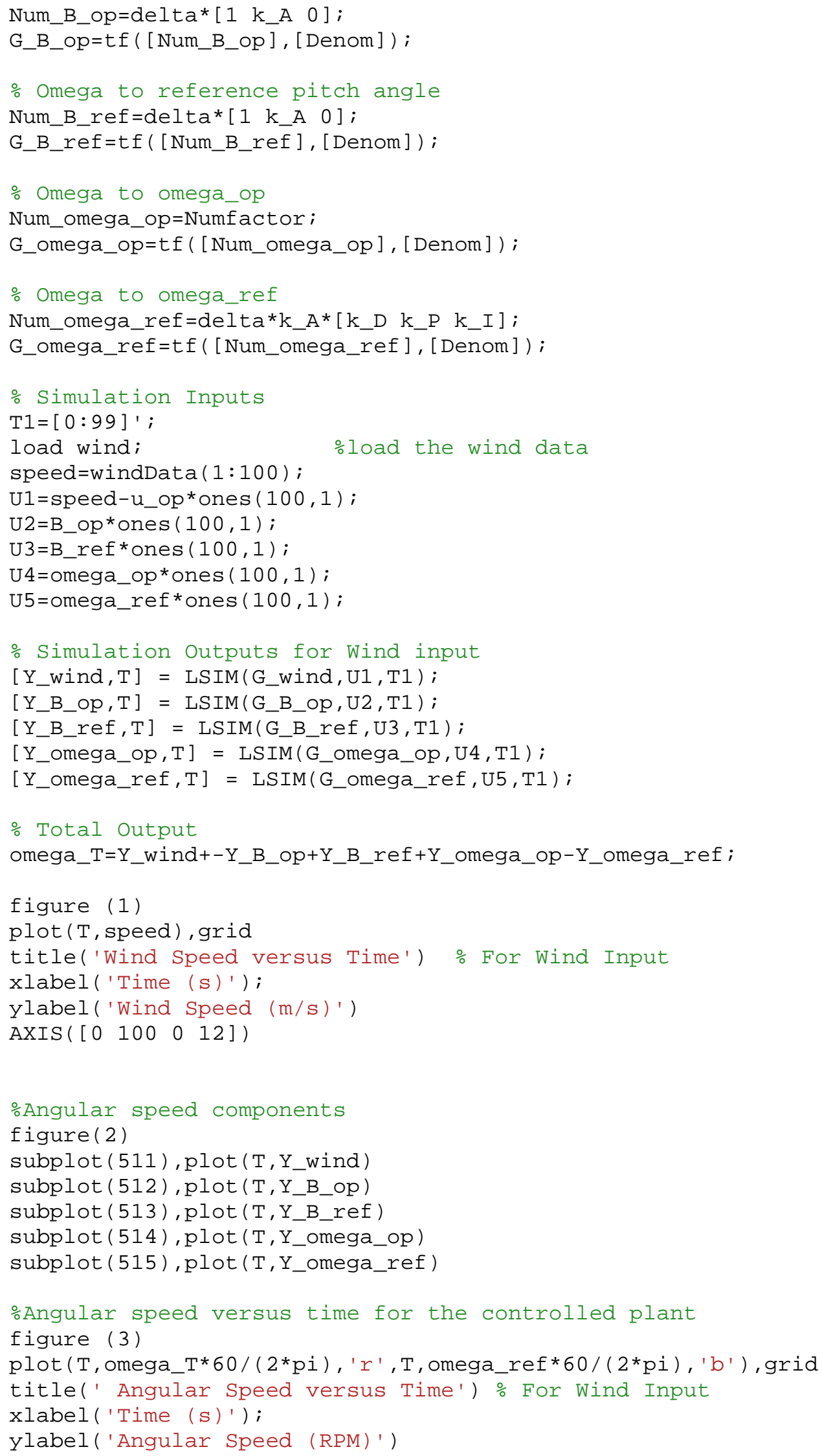




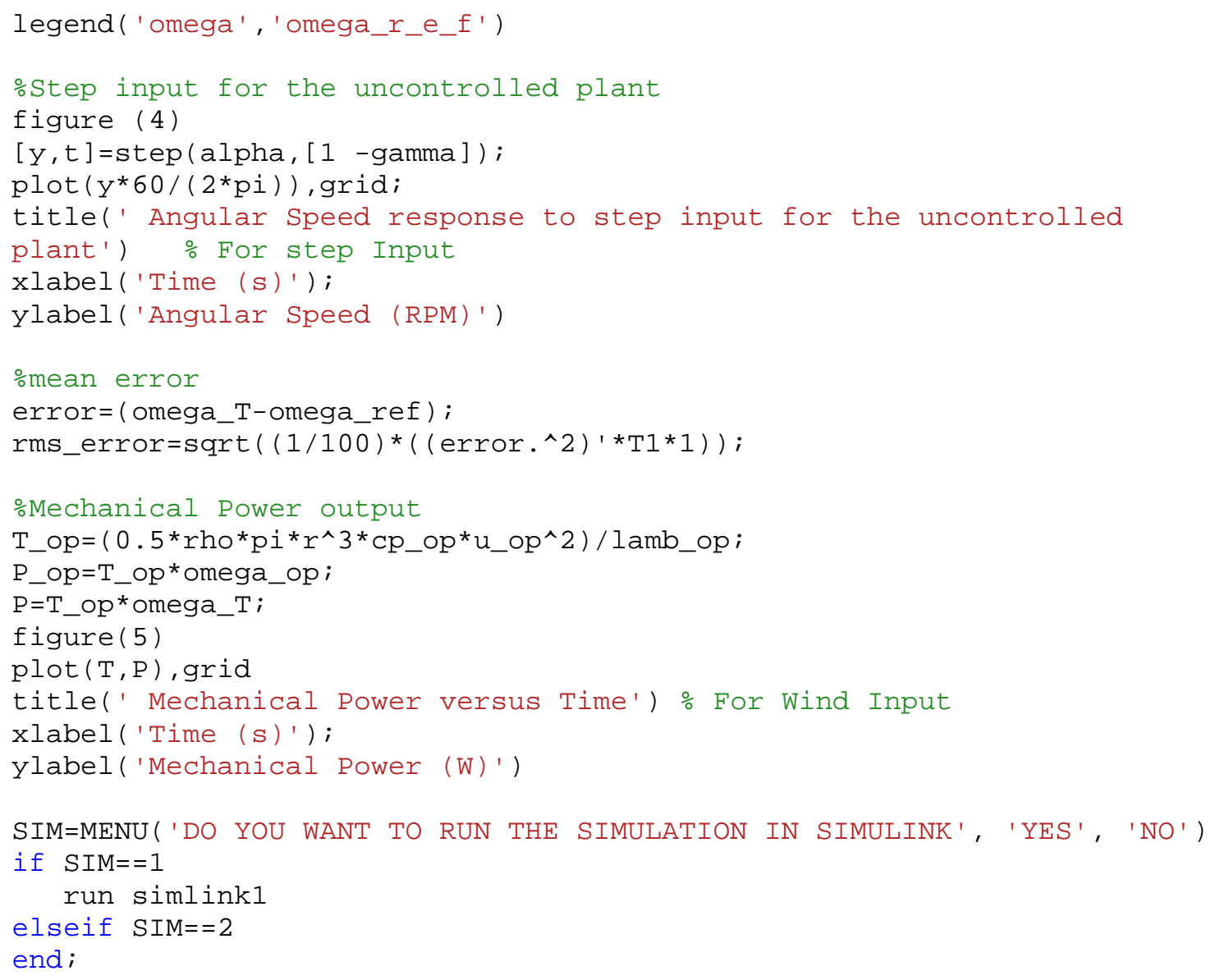




\section{APPENDIX F: Simulink Block Diagram for Wind Turbine Simulation}

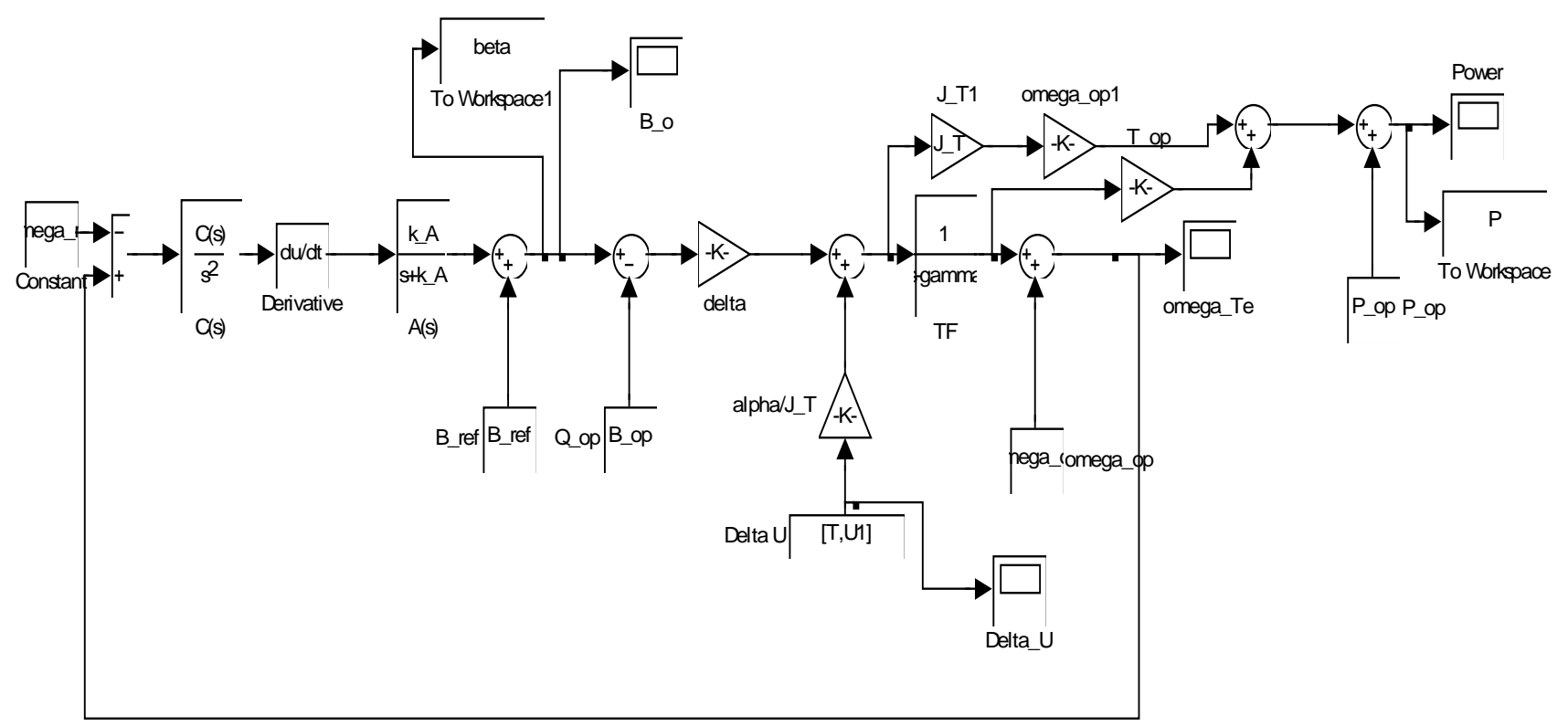

Figure F.1: Simulink Block Diagram for Wind Turbine Simulation 


\section{APPENDIX G: Simulink Block Diagram for Electric Generator Simulation}

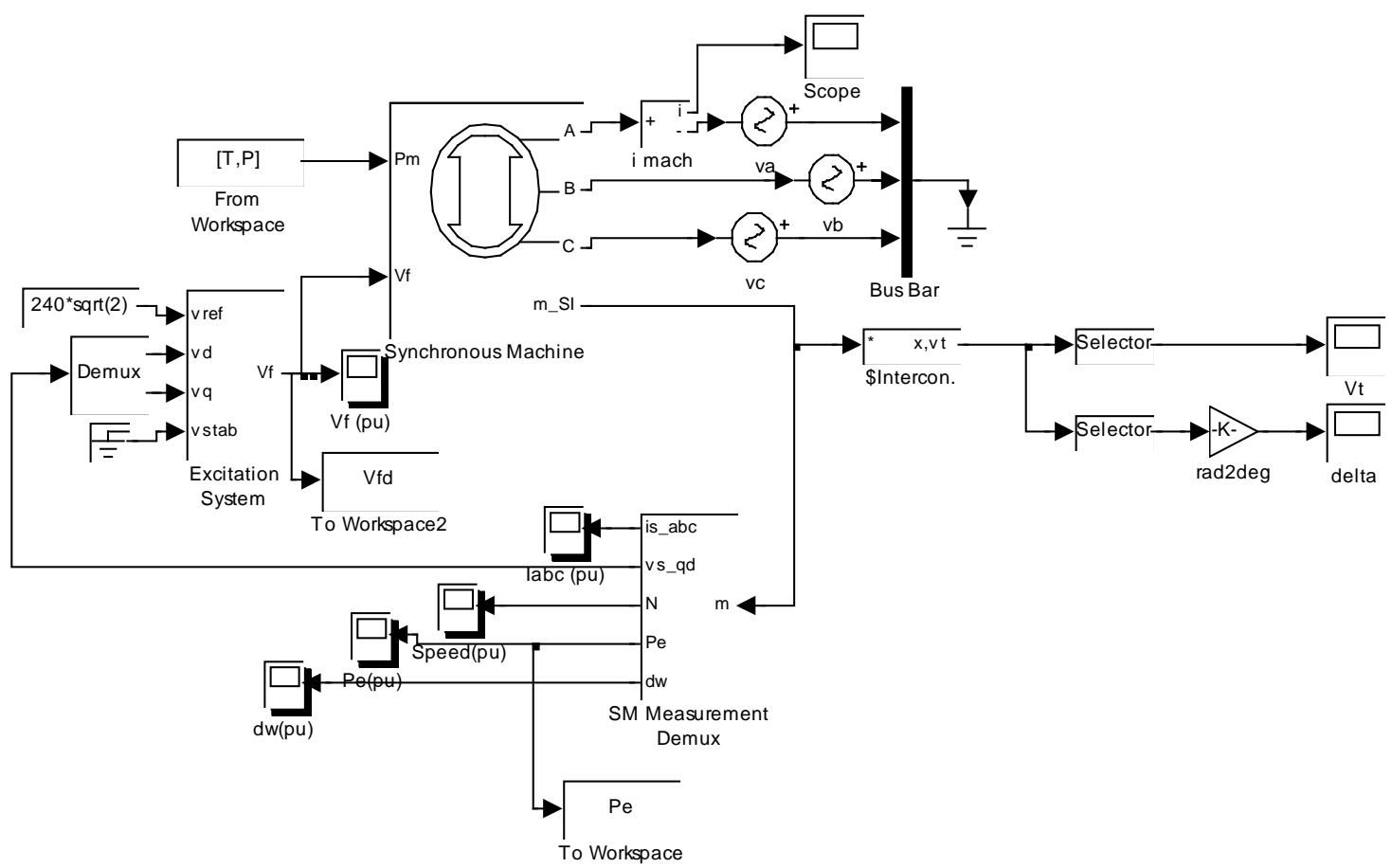

Figure G.1: Simulink Block Diagram for Electric Generator Simulation 